Florida International University FIU Digital Commons

8-31-2016

\title{
Investigating Sub-tropical Community Resistance and Resilience to Climate Disturbance
}

Ross E. Boucek

rbouc003@fiu.edu

DOI: $10.25148 /$ etd.FIDC001229

Follow this and additional works at: https:// digitalcommons.fiu.edu/etd

Part of the Integrative Biology Commons, Other Ecology and Evolutionary Biology Commons, Population Biology Commons, and the Terrestrial and Aquatic Ecology Commons

\section{Recommended Citation}

Boucek, Ross E., "Investigating Sub-tropical Community Resistance and Resilience to Climate Disturbance" (2016). FIU Electronic Theses and Dissertations. 2993.

https://digitalcommons.fiu.edu/etd/2993

This work is brought to you for free and open access by the University Graduate School at FIU Digital Commons. It has been accepted for inclusion in FIU Electronic Theses and Dissertations by an authorized administrator of FIU Digital Commons. For more information, please contact dcc@fiu.edu. 
FLORIDA INTERNATIONAL UNIVERSITY

Miami, Florida

INVESTIGATING SUB-TROPICAL COMMUNITY RESISTANCE AND RESILIENCE TO CLIMATE DISTURBANCE

A dissertation submitted in partial fulfillment of the

requirements for the degree of

DOCTOR OF PHILOSOPHY

in

BIOLOGY

by

Ross Boucek

2016 
To: Dean Michael R. Heithaus

College of Arts and Sciences

This dissertation, written by Ross Boucek, and entitled Investigating Sub-tropical Community Resistance and Resilience to Climate Disturbance, having been approved in respect to style and intellectual content, is referred to you for judgment.

We have read this dissertation and recommend that it be approved.

Michael Heithaus

Michael Ross

Evelyn Gaiser

Philip Stoddard

Philip Stevens

Jennifer Rehage, Major Professor

Date of Defense: 31 August 2016

The dissertation of Ross Boucek is approved.

Dean Michael R. Heithaus

College of Arts, Sciences, and Education

Andrés G. Gil

Vice President for Research and Economic Development and Dean of University Graduate School

Florida International University, 2016 
(C) Copyright 2016 by Ross Boucek

All rights reserved. 


\section{DEDICATION}

I dedicate this dissertation to Dr. Mark Boucek (1950-2009). Mark was a brilliant researcher, with a passion for Snook and Everglades ecology. My dissertation research would have been something he would have enjoyed seeing develop, and his input both as a scientist and an Everglades naturalist was sadly missed. 


\section{ACKNOWLEDGMENTS}

I thank my major professor, Dr. Jennifer Rehage, for teaching me how to be a researcher, and for being a supporting mentor and a good friend. I also thank her for teaching me how to be a good collaborator, how to foster professional collaborations, and to develop professional networks. I also acknowledge my committee: Dr. Michael Heithaus, Dr. Michael Ross, Dr. Evelyn Gaiser, Dr. Philip Stoddard, and Dr. Philip Stevens for their intellectual input, editing of this dissertation, and overall support and guidance. All of my committee members are natural leaders, and through their mentorship and by their example, I have learned and developed many leadership qualities that have undoubtedly made me a better scientist.

Second, I would like to acknowledge the Florida Coastal Everglades Long Term Ecological Research Network (FCE LTER), and the LTER national network. These institutions have provided not only equipment and funding resources, but provided an infrastructure for me to learn how to conduct global-scale synthetic research. The LTER networks have also introduced me to many collaborators and friends, professional relationships I hope to maintain throughout my career.

Last and most importantly, I thank my friends, family, and lab mates for all of their support throughout my graduate studies. Both my mom and dad have been a great source of support at every possible level, and without a doubt, I would not be where I am today without their past and ongoing guidance.

I also would like to acknowledge my funding sources that provided the means for me to produce my dissertation: the Guy Harvey Ocean Foundation, The Everglades Foundation, 
National Science Foundation Water Sustainability and Climate Grant, South Eastern

Environmental Research Center, and the Florida Coastal Everglades Long Term

Ecological Research network. 


\title{
ABSTRACT OF THE DISSERTATION \\ INVESTIGATING SUB-TROPICAL COMMUNITY RESISTANCE AND RESILIENCE TO CLIMATE DISTURBANCE
}

\author{
By \\ Ross Boucek \\ Florida International University, 2016 \\ Miami, Florida \\ Professor Jennifer Rehage, Major Professor
}

Changes in global climate will likely increase climate variability. In turn, changes in climate variability have begun to alter the frequency, intensity, and timing of climate disturbances. Continued changes in the climate disturbance regime experienced by natural systems will undoubtedly affect ecological processes at every hierarchical scale. Thus, in order to predict the dynamics of ecological systems in the future, we must develop a more mechanistic understanding of how and in what ways climate disturbance affects natural systems. In South Florida, two climate disturbances recently affected the region, a severe cold spell in 2010, and a drought in 2011. Importantly, these disturbances affected an ecosystem of long-term, comprehensive, and persistent ecological study in the Shark River estuary in the Everglades National Park. The aims of my dissertation were to (1) assess the relative severity of these two climate disturbances, (2) identify effects of these disturbances on community structuring, (3) compare community change from the 2010 cold spell with community change from another extreme cold spell that affected sub-tropical China in 2008, (4) assess the effects of the drought on predator prey 
interactions in the Shark River and (5) apply a spatial approach to predicting population resistance to these events. My results show that the 2010 cold spell was the most severe cold event to affect the Shark River in the last 80 years, while the drought was the worst drought to occur in the last 10 years. The cold spell drove community change that was predictable based on the traits of component species, whereas community change was less predictable using trait-based approaches. When comparing community change from the extreme 2010 event in Florida with the event in China, I identified three consistencies related to community change from extreme cold events that occurred across both events that will help build generalized understanding of community resistance to increasingly extreme climate events in the future. From the trophic study, I found that the drought reduced prey for estuarine piscivores. Not only was prey biomass reduced, the drought drove a compositional shift in prey communities from fish to invertebrates, which are lower in calories. Last, I found that animal movement may create temporally dynamic resistance scenarios that should be accounted for when developing predictive models. 
TABLE OF CONTENTS

CHAPTER

PAGE

INTRODUCTION 1

I. CLIMATE EXTREMES DRIVE CHANGS IN FUNCTIONAL COMMUNITY STRUCTURE .................................................................

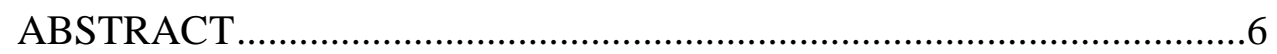

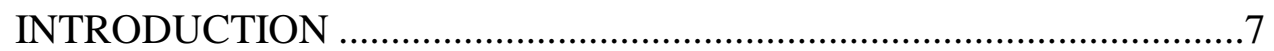

MATERIALS AND METHODS .....................................................11

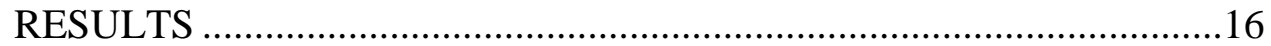

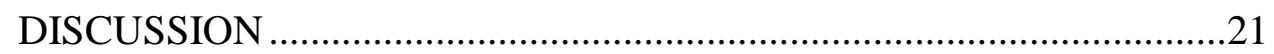

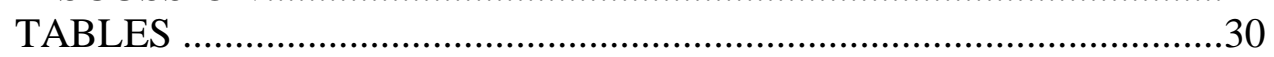

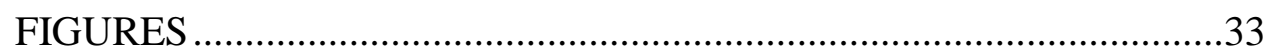

II. A REVIEW OF SUB-TROPICAL COMMUNITY RESISTANCE AND RESILIENCE TO EXTREME COLD SPELLS .............................................37

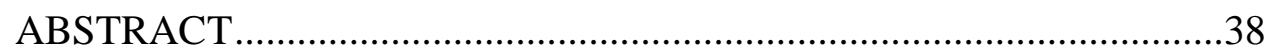

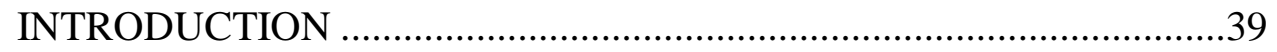

CLIMATE FACTORS THAT DRIVE EXTREME COLD SPELLS .......41

SUB-TROPICAL EXTREME COLD SPELLS RELATIVE TO OTHER

EXTREME CLIMATE EVENTS .......................................................44

CHANGES IN COMMUNITY STRUCTURE FOLLOWING

EXTREME COLD SPELLS IN THE SUBTROPICS ............................47

EFFECTS OF LANDSCAPE FEATURES ON SUBTROPICAL

COMMUNITY RESISTANCE AND RESILIENCE .............................48

DIFFERENCES IN RESISTANCE AND RESILIENCE AMONG

TROPICAL NATIVE AND NON-NATIVE TAXA .............................51

CONCLUSIONS: SUB-TROPICAL CONSERVATION IN A

WARMING WORLD WITH EXTREME COLD SPELLS...

III. A ONCE IN TEN YEAR DROUGHT ALTERS THE COMPOSITION AND MAGNITUDE OF A FLOODPLAIN PREY SUBSIDY TO

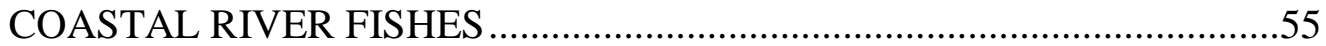

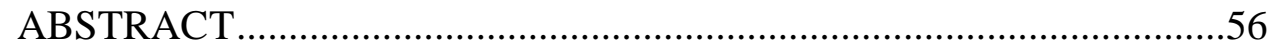

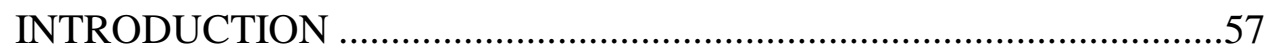

MATERIALS AND METHODS ........................................................60

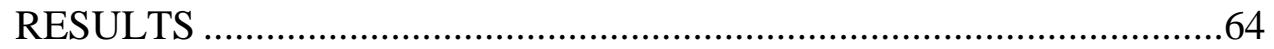

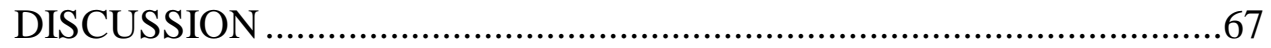

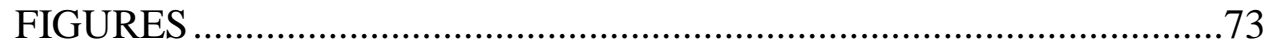

IV. CAN ANIMAL HABITAT USE PATTERNS INFLUENCE THEIR VULNERABILITY TO EXTREME CLIMATE EVENTS? AN ESTUARINE SPORTFISH CASE STUDTY .78 


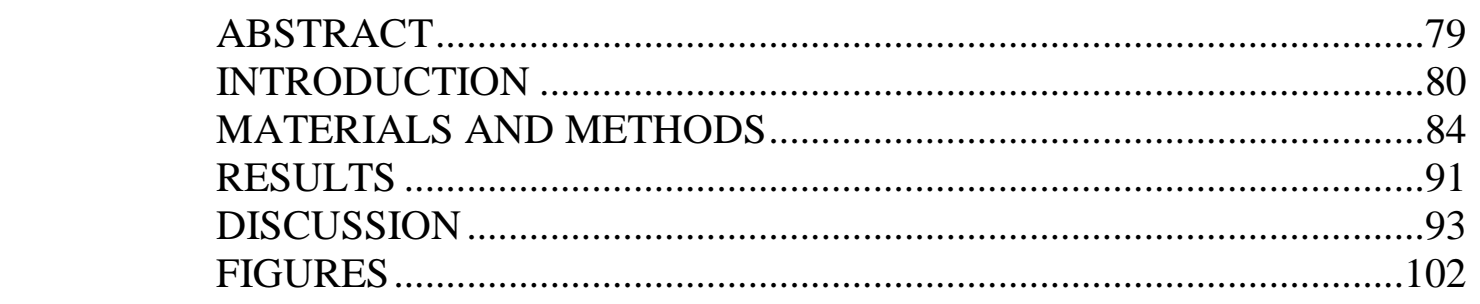

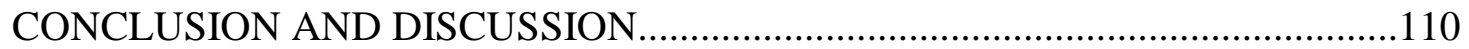

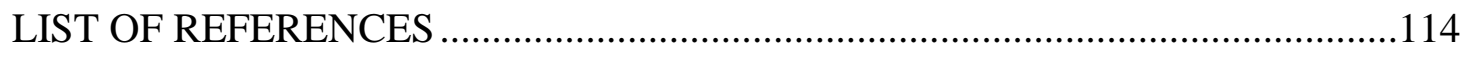

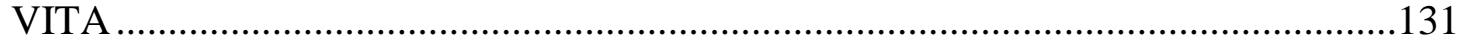




\section{LIST OF FIGURES}

FIGURES

PAGE

\section{CHAPTER I}

1.1 Map depicting location of our study sites in the southwest region of ENP. Circles represent 6 fixed sampling sites, while squares represent USGS and NPS hydrostations

1.2 a) Area under the severity index curves (AUC) for all 319 cold fronts identified between 1927 and 2012. b) Minimum air temperature (black line), minimum water temperature (dashed line), and duration (in \# of days, vertical bars) for each cold front during the study, 2004-2012, blue lines in panels (a) and (b) highlight the 2010 cold front. c) The number of days per year with no freshwater flow into the estuary for the longest period of record in ENP, 1955 2012. d) The number of days the estuary experienced no freshwater flow during the study, 2004-2012 (bars, red highlights the 2011 drought), and the accompanying maximum daily salinity values (solid

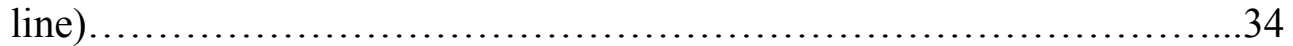

1.3 a) Yearly variation in total fish abundance (sum of the 15 dominant species, \# of fish per $100 \mathrm{~m}$ of mangrove shoreline) between 2006 to 2012. b) Variation in functional trait identities across years for our Everglades fish community. The solid line and black symbols represent the salinity functional identity, whereas the dashed line and white symbols reflects the temperature functional identity. The blue line shows the timing of cold front, while the red line shows the drought...........................................35

1.4 Figure 1.4 Changes in structure of our Everglades fish communities across functional trait space defined by maximum salinity and minimum temperature limits (Table S1). The size of the circles corresponds to each species relative abundance (natural log transformed). Panels show changes in abundance across the four time periods of interest: a) pre-disturbance (20062009, green), b) pre-disturbance (green) vs. 2010 cold front (blue), c) predisturbance (green) vs. 2011 drought (orange), and d) pre-disturbance (green) vs. post-disturbances (red). Two letter codes identify individual species: plain co des are euryhaline species, italicized codes are freshwater species and bolded codes are nonnatives (see Table 1 for species common names \& Table S2 for scientific names). The dashed circles on figure 4d highlight which species that fully recovered from the cold front. 


\section{CHAPTER III}

3.1 Map showing the location of the five study sites in the upper Shark River Estuary in southwestern region of Everglades National Park. Study sites are shown in black circles, while black squares denote hydrological stations used to examine drought severity. Insert shows the three fixed bout locations sampled via electrofishing at each site. Shaded area denotes Shark River Slough, located upstream of study sites and the main freshwater drainage in the southern Everglades...........................................73

3.2 Daily floodplain stage at station SH1 (see map above) from November 2010 to September 2014 (black line), and the number of days floodplains remained dry per year (grey bars). The red line represents the water depths that floodplain habitats are no effectively dry for centrarchid fishes $(10 \mathrm{~cm}$, Trexler et al 2005)

3.3 Mean kilograms per 100 meters of sunfishes (upper panel, $\pm 1 \mathrm{SE}$ ), and the mean abundance of snook per 100 meters (lower panel, $\pm 1 \mathrm{SE}$ ) from 2010-

2014.

3.4 Mean biomass consumed by snook per 100 meters of all prey (upper panel), macroinvertebrates (middle panel) and fishes $( \pm 1 \mathrm{SE})$. Note that scaling in the middle panel differs from the other panels.............................76

3.5 Figure 3.5 Mean caloric content of common fish (grey) and macroinvertebrates (white) species in the study region. Bars represent 1 standard error from the mean.

\section{CHAPTER IV}

4.1 Conceptualization of the interaction between animal habitat use and spatially explicit nature of ECEs. Consider a population that moves freely between habitat patches (shaded shapes) that differ in their capacity to mitigate stressors from ECEs, represented by the color of the shape. In the high vulnerability scenario, animal density is high in habitats that cannot modulate stressors from the disturbance (blue circle), and population losses are high. In the low vulnerability scenario, population densities are higher in a habitat that mitigates stressors of climate disturbance (green symbol), and population losses are lessened.

4.2 Flow diagram of our research approach.

4.3 Map of study system, polygons represent habitat zones, consisting of the downstream coastal zone (black dashed line), meso-haline bay habitat (grey 
dashed line), and the upstream habitat (solid black line). Black dots represent passive acoustic monitoring stations used to track snook movements. Red dots and red halos on acoustic monitoring stations represents temperature loggers that were active for a least a portion of the study, and grey squares represent USGS temperature loggers......................................... 104

4.4 Average paired difference in $\mathrm{T}_{\text {ave }}$ (open circles) and $\mathrm{T}_{\min }$ (black circles) during the 22 cold events that occurred from 2003-2012. The error bars represent $95 \%$ confidence intervals.

4.5 Left: Average daily temperatures across the three USGS stations during the January 2008 (A), the January 2010 (B), and the December 2010 (C) event, grey shaded areas mark the lethal limit for snook. Center: Spatial variation in $\mathrm{T}_{\text {ave }}$ across the January 2008 (D), January 2010 (E), and December 2010 (F) events, each bubble represents a temperature logger active during the event, the size and color of the bubble represents the difference in $T_{\text {ave }}$ at that station relative to the mean $\mathrm{T}_{\text {ave }}$ across all stations active during the event. For visual aid, those bubbles that recorded $\mathrm{T}_{\text {ave, }}$ similar to the mean are outlined in red. Bubbles with the dashed border are the USGS hydrostations used in for the long term analysis. Polygons correspond to the zones used in analyses. Mean $T_{\text {ave }}$ per zone for the January 2008 (G), January 2010 ( H), December 2010(I) disturbances. Error bars represent $95 \%$ confidence intervals................106

4.6 Frequency distribution of the calendar day of the year that each of the 312 cold events occurring in Everglades National Park. The Black dashed lines represent +-1 standard deviation around the mean (January $20^{\text {th }}$ ). The blue lines indicate when each of the three extreme events occurred over the last 90 years. The height of the lines represents their relative severity from Boucek and Rehage (2014) ............................................. 107

4.7 The daily standardized proportion of snook occurring within the upstream zone (upper panel), bay zone (mid panel) and the coastal zone (lower panel). Error bars represent $+-1 \mathrm{SE}$ from the mean. The grey dashed line represents the average proportion of snook occurring within each zone for the entire time series. The grey shading indicates the windows in time when cold spells are most frequently occurring (Dec 23-Feb 27) ..........................108

4.8 The average proportion of snook occurring within the a) upstream zone), bay zone (b) and the coastal zone (c) during the $23^{\text {rd }}-\mathrm{Feb} 17^{\text {th }}$ window in time when cold spells are most frequent. The error bars represent $95 \%$ confidence intervals. 


\section{ABBREVIATIONS AND ACRONYMS}

$\begin{array}{ll}\text { AMO } & \text { Atlantic Multi-decadal Oscillation } \\ \text { AUC } & \text { Area Under the Curve } \\ \text { CE } & \text { Climate Extreme } \\ \text { CPUE } & \text { Catch Per Unit Effort } \\ \text { ENP } & \text { Everglades National Park } \\ \text { ENSO } & \text { El Niño Southern Oscillation } \\ \text { FCE } & \text { Florida Coastal Everglades } \\ \text { FL } & \text { Florida } \\ \text { ISO } & \text { Intraseasonal Oscillation } \\ \text { LTER } & \text { Long Term Ecological Research } \\ \text { NAO } & \text { North Atlantic Oscillation } \\ \text { PNA } & \text { Pacific North American } \\ \text { SH } & \text { Siberian High } \\ \text { U.S. } & \text { United States } \\ \end{array}$




\section{INTRODUCTION}

Forecasted changes in global climate predict not only shifts in climate averages, but a general increase in climate variance (Easterling et al., 2000; Karl et al., 2008). Future changes in climate variability will in turn alter the frequency, intensity, and timing of climate disturbances, and importantly those disturbances that are considered extreme climate events (Smith 2011). Climate disturbance can be defined as events with a clear beginning and end that affect temperature, precipitation, or wind speed, in ways that result in biomass loss or mortalities of species within the affected region (Sousa 1986; White and Jentsch 2001; Smith 2011). These disturbances are having pronounced effects at every socio-ecological scale, altering not only on the functioning of ecological systems, but also the provisioning on natural resources, economies, anthropogenic infrastructure, human health, and federal and international legislation (Adger et al. 2005; Jentsch et al. 2007; Smith 2011). Not only are these disturbances already driving meaningful social-ecological change, but as gradual climate shifts and growing anthropogenic pressures continue to add stress to many ecosystems, the probability for climate disturbance to elicit non-linear or hysteretic social-ecological change will only increase (Smith 2011). Thus, as future climate disturbance regimes change, we as researchers must develop a more mechanistic and predictive understanding of how socioecological systems can resist or be resilient to these disturbances, in order to develop the most proactive, effective, and sustainable management strategies for the future.

Two climate disturbances that expected to change in their frequencies, timing, and intensities in the future are cold spells and droughts. Both disturbances are capable of 
driving extreme ecosystem change, natural resource losses, damage to anthropogenic infrastructure, alter economies, legislation actions, and result in the loss of life (Zhou et al. 2011; Pinho et al. 2014). Cold spells are generally defined consecutive days of temperatures that fall well below normal temperature averages, that cause stress for species occurring in the affected area. These events are abrupt, with temperatures decreasing to stressful levels almost overnight, are short in duration, lasting only days to weeks, and usually incur few dimensions of stress related to extreme low temperatures and physical damage due to ice formations (Wang et al. 2010; Zhou et al. 2011). In contrast, droughts are characterized by precipitation deficits that result in water shortage for some ecological process or anthropogenic activities (Wilhite and Glantz 1985). Unlike cold spells, which are abrupt, stressors associated with droughts increase in strength more gradually. Likewise, droughts are long in duration, with some events lasting years (Peters et al. 2012). Last, droughts often co-occur with other events such as heat waves that can interact to drive complex ecological responses that are difficult to predict. Thus, these climate disturbances provide good contrasts to develop generalities about how different drivers associated with climate disturbance may alter ecological processes.

In South Florida, both cold spells and droughts drive substantial ecological change, ranging from almost complete population losses of tropical species from extreme cold spells, to drought-induced fires that can completely re-arrange landscapes (Beckage et al. 2003; Stevens et al. 2016). In 2010, an extreme cold spell affected South Florida, and one year later, a once-in-10-year drought desiccated the region. The passage of 
these events provides a unique opportunity to improve our understandings of how these disturbances effect ecosystems in South Florida and thus improve predictions of ecosystem change following the passage of future events. Of particular interest, are the ecological effects of these to climate disturbances in the Shark River Estuary within the Everglades National Park. This region is a focal site of the Florida Coastal Everglades Long Term Ecological Research (FCE LTER), and is a region of persistent and comprehensive long-term study (Childers 2006). Using data from the FCE LTER and other long-term data sources, we aim to answer the following questions related to these two recent climate disturbances

1) What is the relative severity of these two climate disturbances in the Shark River estuary?

2) How do these disturbances differ in their effects on communities within the Shark River estuary?

3) How does population and community change from extreme cold spells differ in sub-tropical Florida from other Sub-tropical regions?

4) How does drought affect the trophic dynamics of consumers occurring within the shark river estuary?

5) Can spatially explicit approaches improve our understandings of population level vulnerability of mobile species to extreme climate events?

In Chapter 1, I use long-term climate and hydrologic records to assess the relative severity of the two climate disturbances. Along with our assessment of severity, we applied novel functional community-based metrics to test whether change in an estuarine 
fish community following the two disturbances was predictable based on component species' lethal upper salinity tolerance limits and lethal lower temperature limits (Mouillot et al. 2014).

The geographic scope of Chapter II expands beyond the Everglades. The overarching goal of Chapter II is to contrast community level effects of the 2010 extreme cold spell that affected South Florida with another extreme cold event that occurred in Southern China in 2008. In this chapter, I also review the meteorological drivers that influence the dynamics of extreme cold spells. I end this chapter by proposing three potential generalities of community change following extreme cold spells in the subtropics. In chapter III, I conducted a multiple year diet study to examine the effects of the 2011 drought on trophic interactions between an estuarine piscivore and a freshwater fish prey community. I complemented this diet study with an energetic analysis of prey to determine energetic differences between pre- and post-drought prey communities. Last in Chapter IV, I conducted a multiple-year habitat-use study during the coldest wintertime windows, or when cold spells are most frequent. I coupled this tracking work with a study on landscape level differences in temperatures during cold events. My hypothesis was that higher densities of snook occur in habitats that generally are colder during cold events, thus increasing vulnerability to these disturbances. 


\section{CHAPTER I}

CLIMATE EXTREMES DRIVE CHANGES IN FUNCTIONAL COMMUNITY

STRUCTURE 


\begin{abstract}
The response of communities to climate extremes can vary between no effects to complete and permanent community change. Much of this variation has been attributed to differences in community-specific functional trait diversity, as well as community composition. Yet, few if any studies have explicitly tested the response of the functional trait structure of communities following climate extremes (CEs). Recently in South Florida, two independent, but sequential CEs took place, a 2010 cold front, followed by a 2011 drought, both of which had profound impacts on a subtropical estuarine fish community. These CEs provided an opportunity to test whether the structure of south Florida fish communities following each extreme was a result of species-specific differences in functional traits. From historical temperature (1927-2012) and freshwater inflows records into the estuary (19552012), I determined that the cold front was a statistically extreme disturbance, while the drought was not, but rather a decadal rare disturbance. The two disturbances predictably affected different parts of functional community structure and thus different component species. The cold front virtually eliminated tropical species, including large-bodied snook, mojarra species, nonnative cichlids, and striped mullet, while having little effect on temperate fishes. Likewise, the drought severely affected freshwater fishes including Florida gar, bowfin, and two centrarchids, with little effect on euryhaline species. My findings illustrate the ability of this approach to predict and detect both the filtering effects of different types of disturbances and the implications of the resulting changes in community structure. Further, I highlight the value of this approach to developing predictive frameworks for better understanding community responses to global change.
\end{abstract}




\section{INTRODUCTION}

Forecasted changes in global climate predict not only shifts in average conditions, but also increases in the frequency and intensity of climatic extremes (CE; Karl et al. 2008; Easterling et al. 2000). CEs can be defined as statistically rare events that result in conditions that abruptly and substantially exceed the acclimation capacity of organisms (Gutschick \& BassiriRad 2003). CEs often trigger 'punctuated killing events' for vulnerable species that can alter community structure, selection regimes, and push ecosystems into novel trajectories outside their normal dynamic equilibrium (Kreyling et al. 2011; Jentsch et al. 2007; Sousa 1986). Thus, predicted future changes in the magnitude, timing, duration and frequency of CEs may result in profound ecological and evolutionary effects, driving long-term, hysteretic alterations to ecosystem structure and functioning (Bender et al. 2010; Jentsch et al. 2007; Haddad et al. 2002). Despite the gravity of these events, far fewer studies address the effects of CEs than gradual climate change (reviewed by Jentsch et al. 2007).

Community-level responses to climate extremes (i.e., changes in species dominance, richness and/or composition) have shown to be highly variable, spanning from events that had no effect on community composition nor species abundance patterns (Marchand et al. 2006) to those that completely re-organized dominance structure (Thibault and Brown 2008). This variability in community responses to CEs has made developing a predictive framework a difficult task, leading to an emphasis on context specificity at the expense of generality (Suding et al. 2008; McGill et al. 2006). Previous work suggests that community responses to CEs may be at least in part driven by interspecific variation in the functional traits of member species within each community, 
and variation in trait composition across communities (Kreyling et al. 2011; Smith 2011; Thibault and Brown 2008). A community of species with traits resistant to the abiotic stress caused by the CE will not change in composition (Marchand et al. 2006), whereas a community made up of species with traits vulnerable to the abiotic stressor may show species declines or losses, potentially restructuring biotic interactions, and resulting in major changes to the community. Yet, despite the likely importance of community functional trait structure in dictating responses to CEs ( Mouillot et al. 2013; Suding et al. 2008), few studies, if any, have explicitly evaluated the role that variation in functional trait structure plays in shaping community responses to CEs (but see Milbau et al. 2005).

Functional trait-based approaches are better suited than traditional taxonomicbased community metrics (e.g., diversity indices) for examining community-wide responses to disturbance (Mouillot et al. 2013; Webb et al. 2010), including CEs. Approaches that use functional traits (i.e., quantifiable traits that strongly influence fitness) are taxon- and system-independent, directly link traits to environmental drivers, and allow for a more mechanistic prediction of changes in species composition and abundance (Elliott et al. 2007; McGill et al. 2006). Trait-based approaches may be especially informative in predicting community shifts following CEs relative to other more gradual climate stressors. Due to the rapid rate of environmental change, the high intensity of CEs, and the suite of accompanying effects (e.g., aquatic habitat contraction associate with a drought), CEs may become dominant structuring drivers in effected communities. Thus, by identifying traits that make species resistant to these extremes, we can gain predictability of community structure responses following these events that is 
not system-specific nor specific to the identity and diversity of component species (Webb et al. 2010).

Two climatic extremes recently affected South Florida (U.S.A.), a cold spell in 2010 and a drought in 2011. Effects of the 2010 cold spell were severe on fishes and other taxonomic groups (e.g., corals, primary producers and top predators; Barr et al. 2013; Adams et al. 2012; Matich \& Heithaus 2012; Mazzotti et al. 2011; Kemp et al. 2011). Estuarine fish communities in this region may be particularly vulnerable to these CEs. These communities are largely composed of tropical euryhaline species originating from the Caribbean, and temperate freshwater species that colonized south Florida from more northern regions of the continental U.S. The tropical euryhaline species can suffer hypothermal stress in the sub-tropics during episodic cold spells (Adams et al. 2012). Whereas, temperate freshwater species are resistant to sudden temperature drops, but are vulnerable to osmoregulatory stress from high salinities brought on by reduced freshwater flows to estuaries in times of drought (Blewett et al. 2013). The 2010 cold spell and 2011 drought provide a unique opportunity to test the response of the functional trait structure of this estuarine community to two unrelated but sequential CEs.

Using a functional structure approach developed by Mouillot et al. (2014), we quantified the effects of both CEs on the structure of this estuarine subtropical fish community. Their functional structure approach provides ways to measures changes in the abundance-weighted trait distributions of communities before and after disturbance, and provides a way to visualize both the distribution and abundance of component species in multidimensional functional trait space. The combination of abundance and species functional traits may serve as a more sensitive and accurate representation of 
community changes to CEs, since CEs may be more likely to affect abundance patterns rather than altering the species assemblage itself (Mouillot et al. 2013; Kreyling et al. 2011; Thibault and Brown 2008; Mueller et al. 2005).

I used species' temperature and salinity lethal limits to characterize the functional trait structure of an estuarine fish community, and used these trait values to predict community structure following the two CEs. I first examined the severity of each CE, and then quantified changes (1) in total fish abundance, and (2) on complimentary indices that describe functional structure. The index I used, functional identity, calculates a mean abundance-weighted trait value for the community (Mouillot et al. 2014). I used this approach to calculate the functional temperature identity and the functional salinity identity of this fish community or, in other words, the abundance-weighted average minimum temperature and maximum salinity lethal limits of dominant members of the focal subtropical estuarine community.

I predicted that interspecific variation in temperature and salinity lethal limits would shape community structure following each CE. More specifically, I predicted that the cold spell would affect tropical species with relatively high minimum temperature lethal limits, increasing the dominance of temperate species with low temperature lethal limits, thus decreasing the community functional temperature identity. In contrast, I predicted that the drought would affect species with low salinity lethal limits, increasing the dominance of species with higher salinity lethal limits, and increasing the overall salinity identity of the community. If these focal traits are not important in shaping community responses to CEs, I expected to see changes in total fish abundance, but no changes to community functional identities. I also expected that the effects of the CEs 
would overwhelm other important structuring forces in the system (e.g., predation; Boucek and Rehage 2013), at least in the short-term, resulting in a strong signal of trait selection following the disturbance.

\section{MATERIALS AND METHODS}

\section{Cold spell severity}

To assess the severity of the 2010 cold spell relative to previous cold events, I used fall, winter, and spring (September-March) minimum daily air temperatures from the longest and closest air temperature record (Everglades City, FL; 1927-2012, approximately $66 \mathrm{~km}$ from study sites; http://www.ncdc.noaa.gov/cdo-web/). To ensure that these records were representative of temperature conditions at our study sites, I first used simple linear regression to relate minimum daily air temperatures at the Everglades City station to minimum daily water temperatures at the closest hydrostation to study sites (Bottle Creek, $<1 \mathrm{~km}$, Fig. 1, http://sofia.usgs.gov/eden ) for the period of study (2004-2012). Regression fit was adequate $\left(\mathrm{r}^{2}=0.83, \mathrm{p}<0.001, \mathrm{~N}=2873\right.$ days $)$, indicating that minimum air temperatures at this station correspond to minimum water temperatures experienced by our focal ecotonal fish community.

I then identified individual cold spells in the 85-year time series. I defined a cold front as single or consecutive days when the minimum daily air temperature dropped to or below two standard deviations from the mean minimum daily temperature of the entire time series. Because the ecological severity of cold fronts depends both on the amplitude (degree of coldness) and duration (length of cold front), I used methods to account for 
both of these parameters. First, I developed an index to describe the amplitude of the event. The ecological severity of extreme temperature events increases non-linearly as temperature changes (Smith 2011). I accounted for this non-linearity by converting daily minimum temperatures during the cold front to severity index values with the equation below:

$$
\text { Severity Index } i j=\frac{1}{\left(M T_{i j i}+\left(M T_{a v e}-M T_{\text {min }}\right)\right)}
$$

Where $\mathrm{MT}_{i j}$ is the minimum temperature of day $i$ of cold front $j, \mathrm{MT}_{\text {ave }}$ is the average minimum temperature of the time series, and $\mathrm{MT}_{\min }$ the coldest temperature of the time series. The inverse power function was used to increase the weight of lower temperature days. Also, by calculating the difference of the average and minimum temperatures of the time series in the denominator, I ensured that all severity index values were positive.

To account for the duration of each cold front, I used these daily severity index values to develop severity index curves and then calculated the area under the curve (AUC) following each cold front. Cold fronts with greater AUC were considered more severe. The AUC approach is a common method to relate the effects of temperature to biological processes (Baskerville and Emin 1969; Chezik et al. 2014). Cold fronts that were considered a CE were those with AUCs that fell in the upper one percent median probability distribution of all the cold front AUCs of the entire time series (Smith 2011).

\section{Drought severity}


I determined drought severity by calculating the number of days per year marshes upstream of study creeks were dry (i.e., no freshwater flow and higher salinity regimes in the estuary (Boucek and Rehage 2015). I extracted stage data from hydrostation SH1 (Fig. 1, http://sofia.usgs.gov/eden/). Since stage data at SH1 dates back to only 1996, I complemented stage data for 1955 to 1995 with data from Everglades National Park (ENP) hydrostation P33 (approximately $21.1 \mathrm{~km}$ upstream of SH1, http://sofia.usgs.gov/eden/). For these years, I regressed stage between the SH1 and P33 stations $\left(\mathrm{r}^{2}=0.801, \mathrm{p}<0.01\right)$, and used this relationship to predict SH1 stages for the earlier part of the time series. To ensure that duration of marsh drying had an effect on salinity conditions experienced by estuarine fishes in focal mangrove creeks, I regressed the number of days per year that marshes were dry against peak annual salinities at the nearby Bottle Creek hydrostation (Figure 1.1, $\mathrm{r}^{2}=0.78, \mathrm{p}<0.001, \mathrm{~N}=9$ years).

\section{Sampling effort}

I sampled fish communities three times per year at six fixed ecotonal mangrove creek sites in ENP (Figure 1.1): once in the wet season (November-December), and twice in the dry season (early dry: February-March, and late dry: April-May) from February 2006 to December 2012. The ecotone I sampled serves as s a transitional habitat and physical connection between inland freshwater Everglades marshes and the mangrovedominated estuary downstream (Basset et al., 2013). At these sites, fish communities are relatively dynamic across seasons, following patterns similar to those of many tropical floodplain rivers (Boucek and Rehage 2015; Jardine et al. 2012; Rehage and Loftus 2007). However, despite strong seasonal structuring, community composition and dominance do not vary across multiple years sampled prior to these CEs. 
Sampling was conducted using a boat-mounted, generator-powered electrofisher (two-anode, one cathode Smith-Root 9.0 unit). These sites are generally oligohaline with the average salinity of $1.3 \mathrm{ppt}(\mathrm{SE} 0.12)$, therefore electrofishing is an adequate sampling method (Burkhardt and Gutreuter 1995). I conducted three replicate electrofishing transects at fixed points in each site, each $200 \mathrm{~m}$ apart (6 sites x 3 transects x 3 seasons $\mathrm{x}$ 7 years $=378$ electrofishing samples; Figure 1.1). I report fish abundance, as the number of fish caught per 100 meters of mangrove creek shoreline (see Boucek \& Rehage 2013; for additional details). Because of our interest in examining the effect of the 2010 and 2011 CEs and because there is little inter-annual variation in community structure (Table 1.1), I aggregated CPUE from 2006-2009 as pre-disturbance years for all analyses. I also averaged the two dry season samples, prior to all analyses ( 3 bouts $\mathrm{x} 6$ sites $\mathrm{x} 2$ samples per year $\mathrm{x} 7$ years $=252$ samples used in analyses). I chose to aggregate these dry season samples a priori to avoid increasing the weight of dry season community samples relative to wet season community samples in our statistical analyses. Within this focal community, the majority of dominant species are adults (Boucek and Rehage, unpubl. data), thus within species ontogenetic differences in lethal limits is expected to be minimal.

\section{Abundance and functional trait-based analyses}

I first examined fish community responses to the two CEs by comparing total abundance patterns (number of fish/100 m) for the 15 dominant species ( $>1 \%$ of total catches; Table 1.2), which accounted for $84 \%$ of total fish abundance, and the abundances of each of the 15 species across four time periods of interest: pre-disturbance 
(2006-09), 2010 cold front, 2011 drought, and post-disturbances (2012). Since lethal drought conditions occurred in June and July 2011, after our last dry season sample, I expected drought affects to be observable in the 2012 samples. Comparisons of total abundance, and the abundances of individual species across these time periods of interest were done using Friedman's test (a non-parametric test analogous to repeated measures ANOVA; Verbitsky 2012; Bonnington et al. 2013; Castillo et al. 2013). Subjects were defined as sampling bouts nested within season. Post hoc comparisons were done with Mann Whitney U tests in $\mathrm{SAS}{ }^{\circledR} 9.2$.

Following Mouillot et al. (2014), I plotted both the distribution of the 15 species and changes in their abundances in two-dimensional Euclidian trait space (analogous to Bary diagrams for multiple taxa; Whitfield et al. 2012; Taylor 1993) across the four time periods of interest. I defined this two-dimensional trait space using each species minimum lethal temperature limit and maximum lethal salinity limit. I chose these traits because they most likely reflect each species' susceptibility to either the cold front or drought conditions. Trait values were extracted from the literature, and if none were reported, temperature and salinity limits were inferred based on the species' geographic ranges or survival from documented extreme temperature or salinity disturbances (see Table 1.1). These biplots provide not only a clear visualization of the trait values of component species, but more importantly of the changes in the functional structure of the entire community in response to both CEs.

I then examined changes in the community trait composition across years by calculating abundance-weighted average values for both the temperature and salinity traits (i.e. functional identity; Mouillot et al. 2014). Using the minimum temperature and 
maximum salinity traits of all species, I calculated the community's salinity and temperature functional identity, or the abundance weighted average trait value of the community:

Functional identity $\left._{j}=\right\rangle$. (standardized trait value $\left.{ }_{i} * \sqrt{s p_{i}}\right)$

With functional identity $y_{j}$ being either the salinity or temperature identity of the community; the standardized trait value representing the maximum salinity or minimum temperature lethal limit of species $i$, and $s p_{i}$ representing the proportion of fish abundance accounted by species $i$ per electrofishing sample. I square root transformed proportional species abundances to reduce the influence of very abundant species, as commonly done in community-based studies (Anderson et al. 2006). Functional identities were compared across the four same time periods using Friedman's tests. I considered sampling bout nested within season as the subjects in tests, and post hoc comparisons were done with Mann Whitney $\mathrm{U}$ tests in $\mathrm{SAS} \AA 9.2$ as done with abundance analyses.

\section{0 cold spell severity}

\section{RESULTS}

From 1927 to 2012, I identified 319 cold front events (i.e., single or consecutive days events with air temperatures two standard deviations below the average temperature-days $<5.37^{\circ} \mathrm{C}$ ). The 2010 cold front dropped minimum daily air temperatures to a low of $-3.3{ }^{\circ} \mathrm{C}$. This minimum temperature is tied for the fourth lowest of all of the cold spells in the time series. The five cold spells with the lowest minimum temperature in rank order were the Feb 1996 (minimum temperature of $-5.0^{\circ} \mathrm{C}$ ), followed by Dec 1989 and January $1940\left(-4.4^{\circ} \mathrm{C}\right)$, Jan 2010 and Jan 1981 (-3.3 ${ }^{\circ}$, Fig. $\left.1.2 b\right)$. The 
duration of the 2010 cold spell (or number of days with air temperatures $<5.37^{\circ} \mathrm{C}$ ) lasted for 12 days, 5 days longer than any cold spell of the entire time series. The next four longest cold fronts were the Jan 1940 (7 days), January 1977 (6 days), Jan 1981 (6 days), and the Jan 1970 (4 days).

Based on the severity index curves I created, which incorporate both the amplitude and the duration of cold spells, I identified three extreme cold spells that fell outside the 99\% median probability distribution: Jan 2010, Jan 1940, and January 1981 cold spells. The 2010 cold spell was the most severe of the entire time series (Fig. 1.2a). The relative magnitude of 2010 cold spell (based on AUCs) was approximately $36 \%$ greater than second most severe (Jan 1940), and 44\% greater than the third most severe

event (Jan 1981). At study sites, Jan 2010 water temperatures reached a minimum of 6.2 ${ }^{\circ} \mathrm{C}$, at or below the minimum lethal temperature limit for tropical fishes (Fig. 1.2b, Table $1.1)$.

2011 drought severity

Between 1955 and 2012, the average number of days that marshes were dry and the estuary experienced no freshwater inflow was 47.0 days ( $\pm 8.4 \mathrm{SE}$, Fig. 1.2c). The number of days with no freshwater flow to the estuary in 2011 doubled the mean for this period (95 days), but unlike the cold front, the 2011 drought did not fall outside the $99 \%$ median probability distribution, and thus does not constitute a true CE (only 1963 fell in this range; Smith, 2011). Although the 2011 drought is not a statistically extreme event (i.e., a 100-year drought), a drought of this magnitude has not been experienced in the system since 2001 (99 days with no freshwater flow to the estuary), thus is a rare event. 
Daily salinities during the 2011 drought reached a maximum 13.9 PSU at the Bottle Creek hydrostation, within the range that would cause mortalities to some species (Fig. 1.2d; Table 1.1).

\section{CE effects on total fish abundance}

Total fish abundance varied as a function of disturbance periods (Table 1.3, Fig. 1.3a). Surprisingly, total CPUE following the 2010 cold front did not differ from predisturbance total fish abundance $(\mathrm{p}=0.129)$. However, total fish abundance in 2011 (prior to the drought) decreased by $28 \%$ relative to pre-disturbance values $(\mathrm{p}<0.001)$. Total fish abundance further decreased in 2012 to 10.8 fish $/ 100 \mathrm{~m}, 45 \%$ lower than total fish abundance in 2011, and 61\% lower than pre-disturbance conditions $(\mathrm{p}<0.001)$.

\section{Changes in community salinity and temperature identity}

Both the cold spell and the drought had effects on the temperature and salinity functional identities of the mangrove creek fish community (Fig. 1.3b; Table 1.3). The cold spell caused the temperature and salinity identity of this fish community to decrease by $42 \%$ and $48 \%$ respectively ( $p<0.001$ ), leaving a community dominated by temperate freshwater species. In 2011, the temperature and salinity identity remained $21 \%$ and $18 \%$ lower than pre-disturbance conditions ( $\mathrm{p}<0.001$ ), however they were $35 \%$ and $62 \%$ higher compared to trait identities in 2010. In 2012 (post-drought), both temperature and salinity functional identity increased by $26 \%$ and $30 \%$ relative to $2011(\mathrm{p}<0.001)$, returning to pre-disturbance conditions $(\mathrm{p}>0.45)$.

Functional structure in salinity and temperature trait space

The biplots of species trait values in salinity and temperature lethal limits show that native taxa fall along an axis of low salinity and low temperature lethal limits 
occupied by the freshwater fishes, to high salinity and high temperature lethal limits occupied by the euryhaline fishes (italicized vs. plain text species codes in Fig. 1.4a). These trait patterns are likely due to the different colonization histories by these freshwater and estuarine species (Lodge 2005). Of interest is that the three nonnative taxa (blue tilapia, peacock eels, and Mayan cichlids) appear to fall off this axis, perhaps occupying novel trait space, characterized by middle salinity tolerances and greater cold tolerance (bold species codes in Fig. 1.4a).

\section{CE effects on individual species abundances}

Of the 15 dominant species ( 6 euryhaline, 6 freshwater and 3 nonnative taxa), the abundances of 12 species abundances changed following both CEs (Fig. 1.4, Table 1.2, Table 1.3). Following the 2010 cold front, 7 species abundances decreased by at least an $80 \%$ relative to pre-disturbance conditions, all with a minimum temperature tolerance above $6{ }^{\circ} \mathrm{C}(\mathrm{p}<0.02$; Fig. 1.4b). Affected species included four of the six euryhaline species and all three dominant nonnatives (Table 1.3). Of these affected species, the abundance of the dominant estuarine predator, snook, decreased by $86 \%$. Nonnative Mayan cichlids and tidewater mojarras dropped completely from our catches after the cold front in 2010 (Fig. 1.4b). In contrast, only one species with a minimum temperature lethal limit below $6^{\circ} \mathrm{C}$ decreased in abundance (by 59\%) relative to pre-disturbance conditions (bowfin, $\mathrm{p}=0.032$; Fig. 1.4b). Yet, decreases in bowfin abundance were likely caused by unrelated factors since no bowfin were observed dead during statewide fish and wildlife mortality surveys (Blewett \& Stevens 2013) nor at our own at study sites (Boucek \& Rehage unpublished data). Interestingly, two of the dominant freshwater prey 
species, dollar and spotted sunfish increased in abundance by $490 \%$ and $420 \%$ respectively in 2010 , relative to the pre-disturbance period ( $\mathrm{p}<0.02$; Fig. 1.4b).

Post-cold spell and pre-drought in 2011, of the seven species potentially negatively-affected by the first CE, striped mullet was the only species whose abundance returned to pre-disturbance conditions $(\mathrm{p}=0.55$; Fig. 1.4c). In contrast, for the six other negatively-affected species, their numbers remained at least $47 \%$ below their pre-cold front abundance, indicating little recovery $(\mathrm{p}<0.033$; Fig. 1.4c). The two sunfish species that increased in abundance in 2010, decreased in abundance in 2011, returning to predisturbance numbers $(p>0.061)$. Likewise, bowfin abundance returned to levels indistinguishable from before the disturbance $(\mathrm{p}=0.345)$.

Following the drought, four of the six temperate dominant freshwater species decreased in abundance relative to pre-disturbance conditions (Table 1.3, Fig. 1.4d). Of these four affected species, three had salinity lethal limits below the maximum salinity measured during this study. Two of the three large-bodied freshwater predators, Florida gar and bowfin, decreased in abundance by $69 \%$ and $88 \%$ relative to pre-disturbance conditions, and by $54 \%$ and $87 \%$ relative to their post-cold front abundances $(\mathrm{p}<0.001$, Fig. 1.4d). Also, the abundance of the two small-bodied freshwater prey species that had responded positively to the cold front (dollar and spotted sunfish) now decreased by $66 \%$ and $79 \%$ relative to pre-disturbance conditions, and by $81 \%$ and $76 \%$ when compared to abundances in $2011(\mathrm{p}<0.014)$. Along with these declines in the freshwater fishes, snook, a euryhaline species, still remained at an abundance $60 \%$ lower in 2012 relative to pre-disturbance $(\mathrm{p}<0.001)$, but trended toward levels higher than its 2010 abundance ( $p$ $=0.072$ ), possibly indicating some recovery from the cold front. 
Out of the other seven species negatively affected by the cold front, two fully recovered to pre-disturbance conditions by 2012 , striped mullet, which recovered in 2011, and tidewater mojarra ( $p>0.16$, Fig. 1.4d). The native euryhaline hogchoker, which was unaffected by the cold front, showed an $80 \%$ increase in abundance relative to pre-disturbance conditions following the drought and a $61 \%$ increase compared to 2011 $(\mathrm{p}<0.001)$. In contrast, the three dominant nonnative taxa remained at least at $93 \%$ lower abundances compared to pre-disturbance $(\mathrm{p}<0.001)$, suggesting no population recovery.

\section{DISCUSSION}

With forecasted increases in CEs (Smith 2011), community assembly mechanisms may be altered, including selection for novel functional traits, and perhaps a greater role of exogenous (e.g., environmental) relative to endogenous (e.g., species interactions) structuring mechanisms (Webb et al. 2010). Thus, developing unifying frameworks that will help predict these new or altered trait structures and species assemblages is paramount. Our results show that interspecific differences in abiotic limits to temperature and salinity drove changes in functional trait and thus the community structure of estuarine fish community following a 70-year cold front and a 10-year drought in a predictable fashion. The cold spell negatively affected half of the fish community, reducing the abundance of tropical euryhaline and nonnative species, and re-organizing community dominance to favor temperate freshwater species. These temperate freshwater species were then affected by the 2011 drought, which restored the dominance of the recently affected and recovering tropical euryhaline native taxa. The second disturbance, the drought, pushed both the salinity and temperature functional identities of this community back to pre-disturbance conditions. However, changes in abundance were 
not due to the recovery of affected species, since total fish abundance was reduced by $61 \%$ post both CEs and many tropical euryhaline species still had yet to recover. But, instead the post community observed in our community surveys represents the combined restructuring effects of the sequence of both CEs, and their differential effects on community components.

I view the sequence of these two disturbances as an opportunity since studies that document multiple and varied CEs are rare. At the same time, CEs are projected to increase with future climate change. Because CEs are increasing in frequency, a pressing need exists to better understand the potential effects of multiple CEs (Smith 2011). But, I acknowledge that due to the sequence of CEs, the effects of the drought cannot be easily separated from the recovery of impacted species from the preceding cold front in shaping functional structure in 2012. The observed drought effects are thus, to some extent, conditional on the prior cold front effects. For instance, the upward shift in functional identities I observed post both CEs in 2012 likely resulted from a combination of factors, including (1) the recovery of tropical euryhaline species post cold-spell, (2) the loss of temperate freshwater species presumably from the drought, (3) the effects of the CEs on species vulnerable to both (i.e., nonnatives), and (4) the subsequent effects of these altered abundances on species interactions.

I speculate that mortality caused by the drought may have been a more important driver than these other mechanisms potentially shaping trait structure post both CEs in 2012. The drought caused $66-90 \%$ decreases in the abundance of the dominant freshwater species (i.e., bowfin, Florida gar, and dollar and spotted sunfishes), which accounted for $55 \%$ of the total fish abundance pre-disturbance. Upon recovery from the cold front, only 
two tropical euryhaline species, accounting for $7 \%$ of the total abundance, showed increases in 2012. Thus, their recovery probably had little effect on functional community trait structure following the two CEs (Fig 4d). The loss of nonnative fishes prior to the drought also likely dampened the magnitude of change in functional trait identities in 2012. I expect that if the drought had occurred in isolation, nonnatives would have been negatively affected, the same as native freshwater species, and thus the magnitude of change in functional identify due to the drought would have been greater than that seen here. Lastly, I hypothesize that the loss of individuals and species from the cold spell likely reduced interspecific competition and predation between tropical euryhaline species and temperate freshwater species (Sponseller et al. 2010), making temperate freshwater species less vulnerable to the drought than predicted by mortality due to physiological stress alone. These factors highlight the need for both manipulative and long-term observational studies to not only capture community responses to single CEs, but to the combination of multiple and varied CEs.

Two differences in the behaviors of these CEs exist that merit consideration when comparing their effects on community structure: (1) their abruptness and duration (Jentsch et al. 2007) and (2) the number of complementary stressors associated with each CE. The cold spell was a more abrupt disturbance, decreasing water temperatures to lethal conditions within days, but was short in duration, lasting less than two weeks. In contrast, the drought increased salinities gradually and lasted for over 3 months. The second key difference between these two CEs is that the cold front only influenced temperature regimes, whereas the drought likely incurred other complementary effects. Droughts in estuarine systems not only increase salinities, but also reduce flushing, which 
results in an accumulation of organic matter, increased respiration and decreased oxygen levels (Koehn et al. 2011). Reduced freshwater inflows associated with droughts can also reduce the extent of littoral and floodplain habitat, increasing concentration of fish in less structurally-complex and deeper estuarine habitats, and subsequently increasing inter and intra-specific competitive interactions, as well as predation risk (Welcomme and Halls 2003).

These differences in the nature of the two CEs likely explain some of variation in the species responses observed. Following the cold front, every species with a temperature lethal limit warmer than the lowest water temperature of the cold front decreased in abundance by at least $70 \%$. On the other hand, species with maximum salinity lethal limits below the maximum measured during the drought, showed no change in abundance (e.g., red-ear sunfish), and species with salinity lethal limits well above the maximum salinity values I observed, showed up to $80 \%$ decreases in abundances (e.g., Florida gar). One explanation for the more direct effects of the cold front on abundances may be the abruptness of the event. The rapid chilling of the water following the cold front may have prevented vulnerable species from moving to suitable temperature refugia microhabitats (Kearney et al. 2009). Alternatively, the temperature may have dropped faster than normally cold-tolerant species can acclimate (Matich and Heithaus 2012). These two factors likely increased the importance of purely physiological tolerances in surviving this climate extreme. In contrast, with the drought, potentially vulnerable species may have been able to acclimate to these conditions or seek out more freshwater refuge habitats, shielding species from large mortality effects. 
Complementary stressors associated with the drought may have also played some role in the overall functional community response. I speculate on their relative importance for certain species based on their traits. For instance, bowfin showed a high degree of change following the drought. This species has a vascular swim bladder (Peterson and Meador 1994), and can tolerate anoxic conditions. However, bowfin have low salinity lethal limits, making salinity, and not anoxia, the likely cause of their decline. Similarly, the dollar and spotted sunfishes affected by the drought have salinity lethal limits close to the maximum salinity observed (Table 1.1) and can tolerate hypoxia (Schofield et al., 2007), but they are a major prey class for larger predators (Boucek and Rehage 2013). A reduction in littoral habitat area by the drought should have increased their vulnerability to predation, likely driving their reduction in numbers. These differences between the two disturbances may indicate that simple trait-based (two traits) approaches like ours may be appropriate for CEs that are pulsed and affect species via a single or few mechanisms. In cases where CEs are more gradual and result in multiple stressor effects, a more complex multivariate trait-based approach involving more and different types of traits may be needed.

CEs may alter the functional trait structure of affected communities in two fundamental ways, both of which have the potential to be detected with trait-based approaches. First, the $\mathrm{CE}$ causes mortality in species with vulnerable traits, acting as a performance filter, and thus increasing the representational dominance of species with resistant trait values without changing their population sizes (i.e., changes in trait structure and decreased total abundance, Webb et al., 2010). Second, the loss of 
vulnerable species may alter biotic controls (predation and competition) causing less competitive species, that may be resistant to the extreme, to increase in abundance, further shifting functional structure and identity in favor of resistant species (i.e., higher than expected changes in trait structure with less than expected decreases in abundance). For instance, Thibault and Brown (2008) found that an extreme flood, affecting rodent communities in arid grasslands of the southwestern US, severely affected dominant, larger bi-pedal kangaroo rats that are relatively poor swimmers and climbers, but had no effect on smaller, invasive pocket mice that have more plastic locomotion. The loss of the competitively-dominant kangaroo rat subsequently released pocket mice from food competition causing their populations to increase. Thus, through direct mortality of the dominant species, competitive release, and the positive numerical response of the less competitive species, the community's functional traits (i.e., size and locomotion) shifted to favor smaller rodents with more plastic locomotion following the CE. In this example, biotic regulation of the rodent community was lessened by the climate extreme, resulting in a change in trait dominance, but accompanied by relatively small changes in total abundance.

Like this rodent example, the cold front altered an important biotic interaction in the focal system. Despite the extreme nature of the 2010 cold front, and the substantial mortality across about half of the 15 dominant species, I detected no change in total fish abundance post cold front. I suspect that the role of predation, a dominant structuring mechanism in this fish community, was lessened following the cold front. Previous diet work showed that tropical euryhaline snook heavily exploit freshwater sunfishes when the sunfish move off drying marsh floodplains into the estuary (Boucek and Rehage 
2013). Sunfish abundance quadrupled in the year following the cold spell and the loss of snook, likely the result of a release from snook predation. Thus, the major tropical taxa declines were compensated by increased survival of small-bodied temperate freshwater species, explaining why total fish abundance did not change. Restructuring of biotic interactions, in this instance predation, likely drove functional identities further toward temperate freshwater species than what would be predicted with the loss of the tropical species alone. This result highlights the need to incorporate species interactions and trophic linkages into trait-based approaches to fully understand the mechanisms of community response to CEs (Wootton and Emmerson 2005; Suding et al. 2008).

Whether increases in the frequency of CEs will facilitate species invasions is uncertain (Diez et al. 2012). For instance, CEs can increase the vulnerability to invasion of ecosystems by directly increasing resource availability or by causing mass mortality in native species, freeing resources (e.g., nutrients, prey, light, space), and allowing for the establishment and propagation of more opportunistic nonnative species with novel and/or resistant functional traits (Jiménez et al. 2011; Shea and Chesson 2002; Davis et al. 2001). Likewise, CEs can create conditions that are unsuitable for the invader, reducing their abundance (Kreyling et al. 2008). Whether invadibility of an ecosystem will change following CEs will likely depend on the traits of the invader, the $\mathrm{CE}$, and the affected community structure. Functional structure approaches should improve our understanding of whether CEs act to shield or promote invasions. For instance, in the coastal Everglades, the three dominant nonnatives (Mayan cichlids, blue tilapias, peacock eels) are likely vulnerable to both droughts and cold fronts, failing to recover after the 2010 cold front. If either of these CEs increase in frequency (Berry et al. 2011, Kodra et al. 
2011), I may expect population regulation and thus reduced abundances for nonnative species. However, if a new nonnative species is appears with traits resistant to both of these filtering mechanisms, then CEs may instead act to increase the invasibility of estuarine reaches.

Our results suggest that with increases in the frequency of CEs, biotic structuring mechanisms may be replaced by abiotic structuring mechanisms. These changes may result in the increased dominance of species with traits resistant or resilient to CEs and possibly of generalist species able to survive in extreme abiotic environments (Elliot and Whitfield 2011). The capability to survive under extreme abiotic environments may be of importance in already altered ecosystems such as the Florida Everglades (Sklar et al. 2005 ) and others, where the structure of communities is already influenced and responsive to anthropogenic-driven abiotic regimes (e.g., changes in water management; Trexler et al. 2005). Functional structural approaches allow researchers to identify the relative vulnerabilities of member species, and more important the vulnerabilities of their traits, to specific stressors associated with CEs. Identifying a quantifiable link between environmental stressors and community responses greatly improves our predictive understanding of how CEs may similarly affect different communities affect by climate change, and potentially providing a powerful tool in biodiversity conservation. Researchers may also use this information to guide manipulative experiments testing how community structure, species interactions, and ecosystem functioning may be altered with vulnerable species at reduced abundances or perhaps absent. The challenge continues to be the development of conceptual frameworks that combine trait-based approaches with the indirect effects of biotic interactions to better predict community responses to CEs 
(Smith 2011). However, functional structure approaches may provide a good first step to identify at least the loss of species to communities and the resulting changes in trait space associated with CEs. 


\section{TABLES}

Table 1.1 Trait values used in all analyses for the 15 dominant members of the community. Trait values used came from published physiological studies, or inferred from extreme ranges and/or published mortality experienced during extreme temperature and salinity disturbances

\begin{tabular}{|c|c|c|c|c|}
\hline Species & Scientific name & $\begin{array}{l}\text { Salinity } \\
\text { lethal } \\
\text { limit } \\
\text { (PSU) }\end{array}$ & $\begin{array}{l}\text { Temperature } \\
\text { lethal limit } \\
\quad\left({ }^{\circ} \mathrm{C}\right)\end{array}$ & Sources \\
\hline \multicolumn{5}{|l|}{ Euryhaline } \\
\hline Tidewater mojarra & Eucinostomus harengulus & 90 & 8 & 15 \\
\hline Striped mullet & Mugil cephalus & 75 & 12.3 & 16 \\
\hline Snook & Centropomus undecimalis & 50 & 6 & 7 \\
\hline American eel & Anguilla rostrate & 36 & 3 & 10 \\
\hline Striped mojarra & Eugerres plumieri & 36 & 7.2 & 14 \\
\hline Hogchoker & Trinectes maculatus & 30 & 5 & 4,5 \\
\hline \multicolumn{5}{|l|}{ Nonnative } \\
\hline Blue tilapia & Oreochromis aureus & 27 & 6.5 & 4,11 \\
\hline Peacock eel & Macrognathus siamensis & 15 & 9 & 13 \\
\hline Mayan cichlid & Cichlasoma urophthalmus & 37 & 9.9 & 12 \\
\hline \multicolumn{5}{|l|}{ Freshwater } \\
\hline Florida gar & Lepisosteus platyrhincus & 18 & 3 & 1,2 \\
\hline Largemouth bass & Micropterus salmoides & 16 & 1.5 & 1,3 \\
\hline Red ear sunfish & Lepomis microlophus & 12 & 3 & 1,6 \\
\hline Dollar sunfish & Lepomis marginatus & 12 & 3 & 1,6 \\
\hline Spotted sunfish & Lepomis punctatus & 12 & 1.5 & 1,6 \\
\hline Bowfin & Amia calva & 8 & 0 & 8,9 \\
\hline
\end{tabular}


Table 1.2 Percent abundances across years of the 15 dominant species in the focal subtropical estuary community

\begin{tabular}{cccccccc} 
Year & $\begin{array}{c}\text { Florida } \\
\text { gar }\end{array}$ & $\begin{array}{c}\text { Largemouth } \\
\text { bass }\end{array}$ & Hogchoker & $\begin{array}{c}\text { Red } \\
\text { sunfish }\end{array}$ & $\begin{array}{c}\text { Spotted } \\
\text { sunfish }\end{array}$ & $\begin{array}{c}\text { Dollar } \\
\text { sunfish }\end{array}$ & Snook \\
\hline 2006 & 26.2 & 8.0 & 3.3 & 2.8 & 6.2 & 14.2 & 12.9 \\
2007 & 31.7 & 9.0 & 2.2 & 1.0 & 1.9 & 0.8 & 11.6 \\
2008 & 24.1 & 15.2 & 1.8 & 0.8 & 1.3 & 2.0 & 13.5 \\
2009 & 19.2 & 8.4 & 3.1 & 1.2 & 8.8 & 5.7 & 10.9 \\
$2010^{*}$ & 22.7 & 6.9 & 4.0 & 2.1 & 17.0 & 20.3 & 6.5 \\
2011 & 24.5 & 12.4 & 3.9 & 2.4 & 11.6 & 10.9 & 6.3 \\
$2012^{* *}$ & 15.8 & 9.5 & 9.2 & 6.0 & 3.3 & 2.7 & 11.5 \\
\hline
\end{tabular}

\begin{tabular}{ccccccccc} 
Year & American eel & Bowfin & $\begin{array}{c}\text { Blue } \\
\text { tilipia }^{1}\end{array}$ & $\begin{array}{c}\text { Mayan } \\
\text { cichlid }^{1}\end{array}$ & $\begin{array}{c}\text { Peacock } \\
\text { eel }^{\mathbf{1}}\end{array}$ & $\begin{array}{c}\text { Striped } \\
\text { mojarra }^{2}\end{array}$ & $\begin{array}{c}\text { Tidewater } \\
\text { mojarra }\end{array}$ & $\begin{array}{c}\text { Striped } \\
\text { mullet }\end{array}$ \\
\hline 2006 & 1.4 & 1.4 & 0.9 & 6.4 & 0.0 & 4.1 & 5.0 & 7.1 \\
2007 & 2.1 & 6.2 & 5.8 & 5.9 & 0.0 & 4.4 & 10.7 & 6.5 \\
2008 & 3.2 & 7.5 & 10.7 & 0.5 & 1.3 & 4.0 & 5.8 & 8.2 \\
2009 & 2.0 & 3.9 & 4.5 & 2.2 & 14.9 & 3.5 & 6.0 & 5.5 \\
$2010^{*}$ & 1.4 & 1.8 & 1.7 & 0.1 & 0.3 & 5.9 & 2.4 & 7.0 \\
2011 & 0.9 & 6.4 & 0.8 & 0.2 & 0.1 & 3.7 & 7.6 & 8.3 \\
$2012^{* *}$ & 3.0 & 1.1 & 0.4 & 0.3 & 1.0 & 9.8 & 12.7 & 13.8 \\
\hline
\end{tabular}


Table 1.3: Summary statistics testing the impacts of the CEs on the abundance of the 15 dominant species and the community trait identities. Bold font indicates significant disturbance period effects.

\begin{tabular}{|c|c|c|}
\hline Response variable & $\chi_{(d f, N)}^{2}$ & $\mathrm{P}$ \\
\hline Total fish abundance & 32.1 $1_{(3,252)}$ & $<0.01$ \\
\hline \multicolumn{3}{|l|}{ Community trait identity } \\
\hline Temperature identity & $57.67_{(3,250)}$ & $<0.01$ \\
\hline Salinity identity & $\mathbf{5 6 . 3 4}(3,250)$ & $<0.01$ \\
\hline \multicolumn{3}{|l|}{ Freshwater species } \\
\hline Florida $\operatorname{gar}_{(F G)}$ & $42.68_{(3,252)}$ & $<0.01$ \\
\hline $\operatorname{Bowfin}_{(B F)}$ & $\mathbf{3 0 . 3 3}_{(3,252)}$ & $<0.01$ \\
\hline Spotted sunfish $_{(S F)}$ & $\mathbf{3 2 . 0 6}_{(3,252)}$ & $<0.01$ \\
\hline Dollar sunfish $_{(D F)}$ & $15.32_{(3,252)}$ & 0.02 \\
\hline Red ear sunfish $_{(R S)}$ & $1.30_{(3,252)}$ & 0.73 \\
\hline Largemouth bass $(L B)$ & $4.70_{(3,252)}$ & 0.2 \\
\hline \multicolumn{3}{|l|}{ Euryhaline species } \\
\hline Snook $_{(S K)}$ & $\mathbf{3 7 . 6 3}_{(3,252)}$ & $<0.01$ \\
\hline Striped mojarra $_{(S M)}$ & $18.51_{(3,252)}$ & $<0.01$ \\
\hline Tidewater mojarra $_{(T M)}$ & $\mathbf{3 4 . 8 5}_{(3,252)}$ & $<0.01$ \\
\hline Striped mullet $_{(M U)}$ & $10.72_{(3,252)}$ & 0.01 \\
\hline Hogchoker $_{(H C)}$ & $9.26_{(3,252)}$ & 0.03 \\
\hline American eel ${ }_{(A E)}$ & $5.17_{(3,252)}$ & 0.16 \\
\hline \multicolumn{3}{|l|}{ Nonnative species } \\
\hline Blue tilapia $_{(B T)}$ & $29.92_{(3,252)}$ & $<0.01$ \\
\hline Mayan cichlid $_{(M C)}$ & $37.31_{(3,252)}$ & $<0.01$ \\
\hline Peacock eel ${ }_{(P E)}$ & $10.17_{(3,252)}$ & $\mathbf{0 . 0 2}$ \\
\hline
\end{tabular}

Subscripts are used to identify these species in Fig.1.4. 


\section{FIGURES}

Figure 1.1 Map depicting location of our study sites in the southwest region of ENP. Circles represent 6 fixed sampling sites, while squares represent USGS and NPS hydrostations.

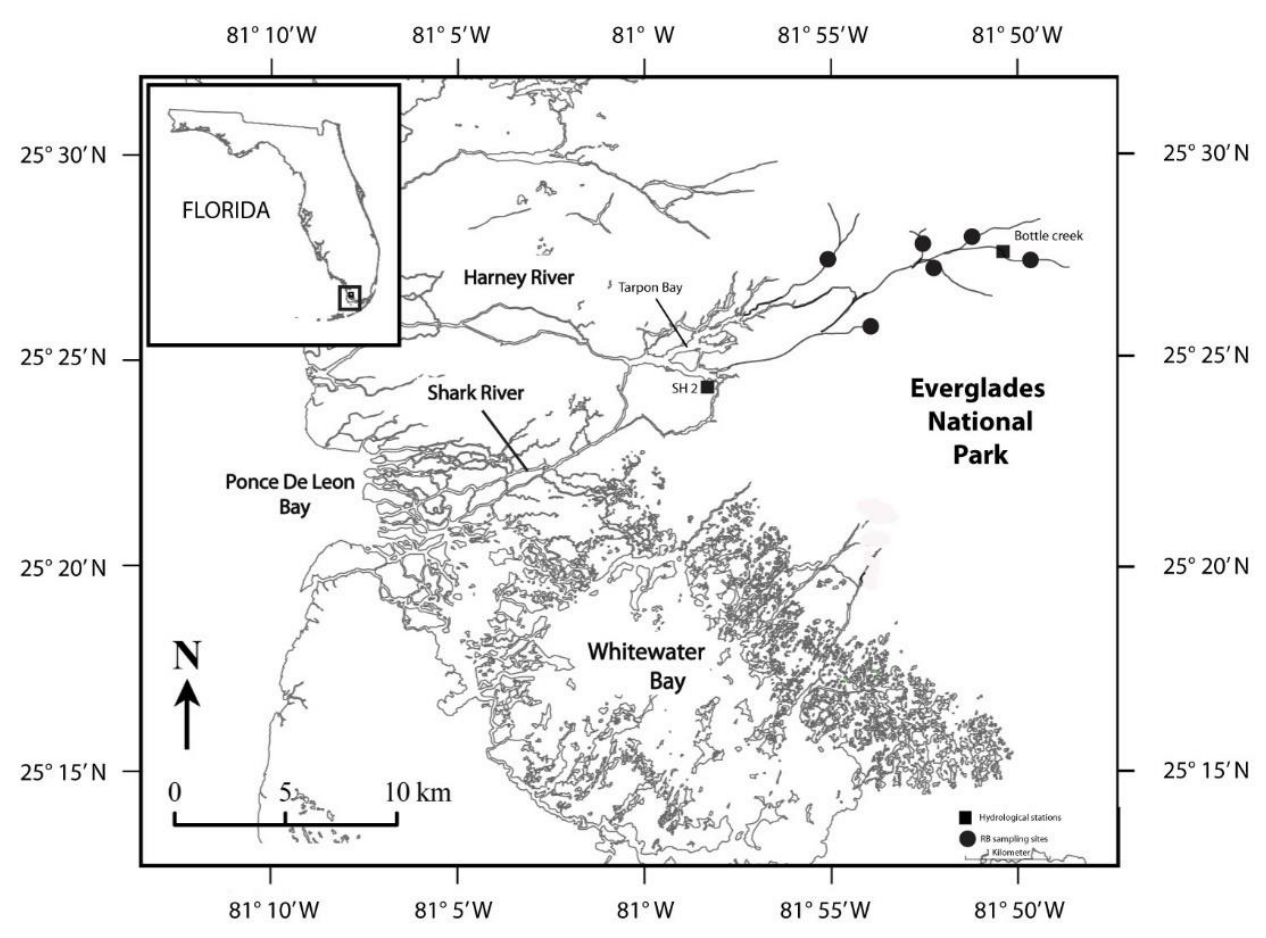


Figure 1.2 a) Area under the severity index curves (AUC) for all 319 cold fronts identified between 1927 and 2012. Dashed line represents the 99\% confidence interval. Blue line denotes the 2010 cold front. b) Minimum air temperature (black line), minimum water temperature (dashed line), and duration (in \# of days, vertical bars) for each cold front during the study, 2004-2012. Blue line denotes the 2010 cold front. c) The number of days per year with no freshwater flow into the estuary for the longest period of record in ENP, 1955 2012. d) The number of days the estuary experienced no freshwater flow during the study, 2004-2012 (bars), and the accompanying maximum daily salinity values (solid line). Red bar highlights the 2011 drought.
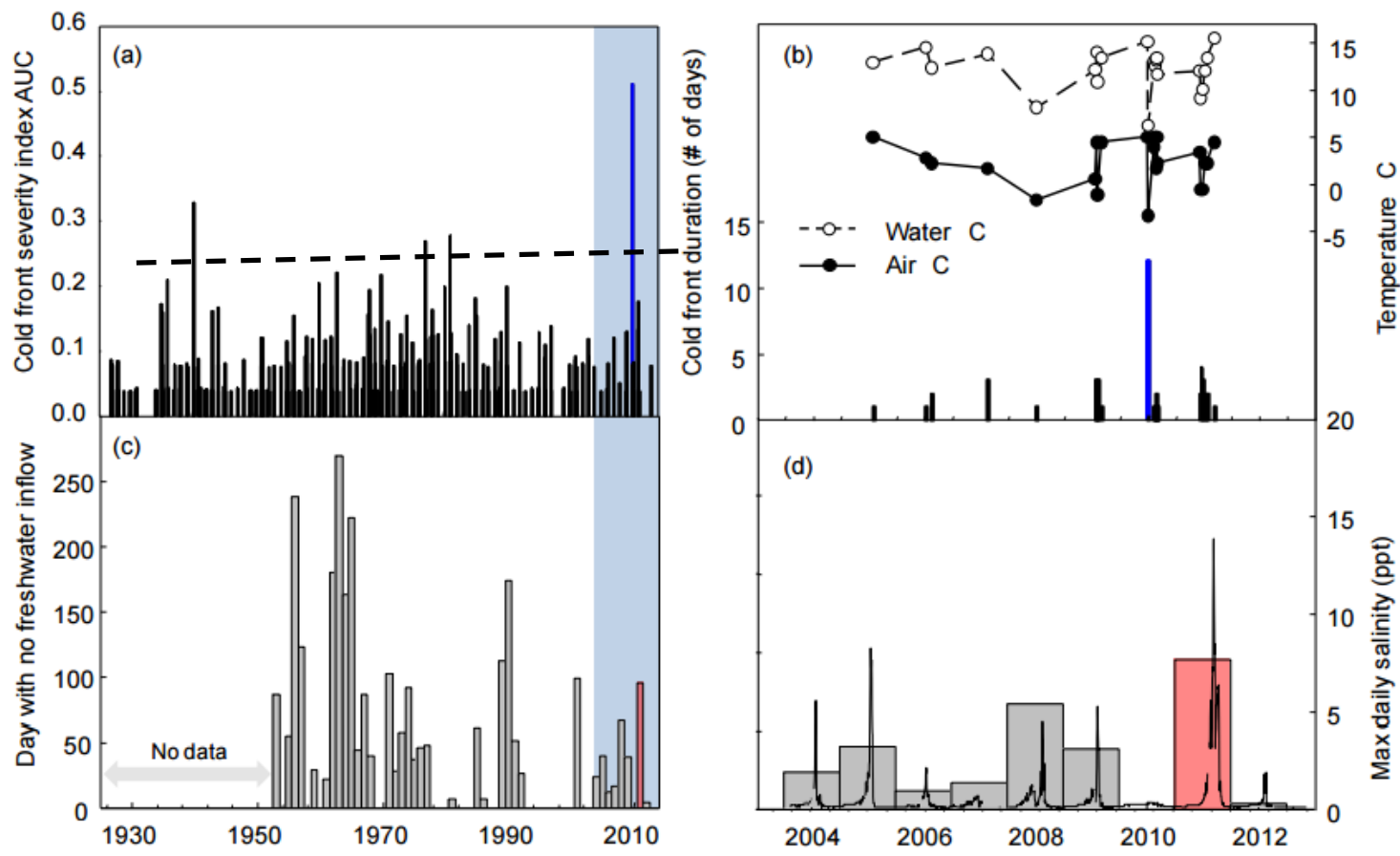
Figure 1.3 a) Yearly variation in total fish abundance (sum of the 15 dominant species, \# of fish per $100 \mathrm{~m}$ of mangrove shoreline) between 2006 to 2012 .

b) Variation in functional trait identities across years for our Everglades fish community. The solid line and black symbols represent the salinity functional identity, whereas the dashed line and white symbols reflects the temperature functional identity.

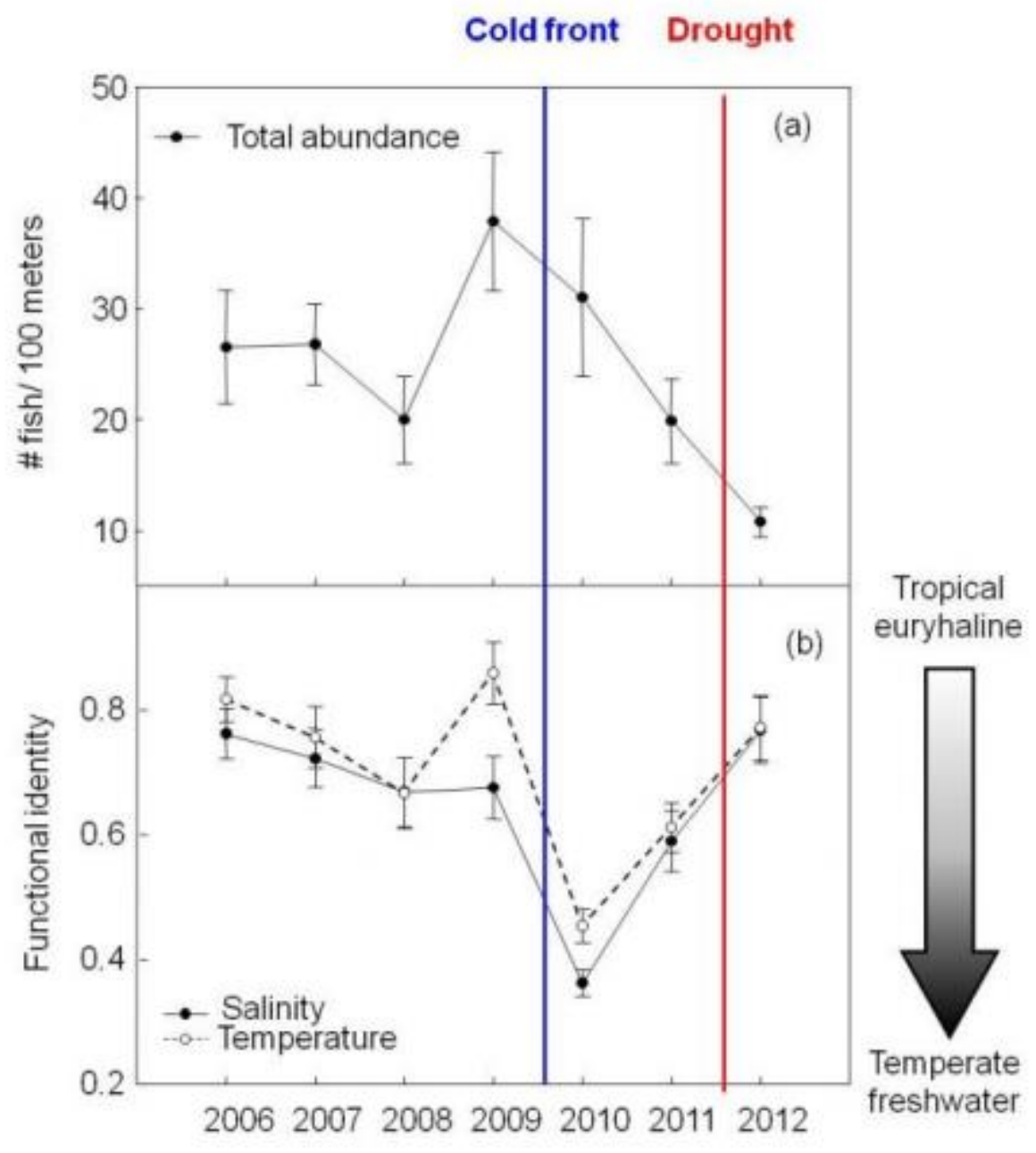


Figure 1.4 Changes in structure of our Everglades fish communities across functional trait space defined by maximum salinity and minimum temperature limits. The size of the circles corresponds to the relative abundance of each species (natural log transformed). Panels show changes in abundance across the four time periods of interest: a) predisturbance (2006-2009, green), b) pre-disturbance (green) vs. 2010 cold front (blue), c) pre-disturbance (green) vs. 2011 drought (orange), and d) pre-disturbance (green) vs. post-disturbances (red). Two letter codes identify individual species: plain codes are euryhaline species, italicized codes are freshwater species and bolded codes are nonnatives (see Table 1 for species common names). The dashed circles on figure $4 \mathrm{~d}$ highlight which species that fully recovered from the cold front.

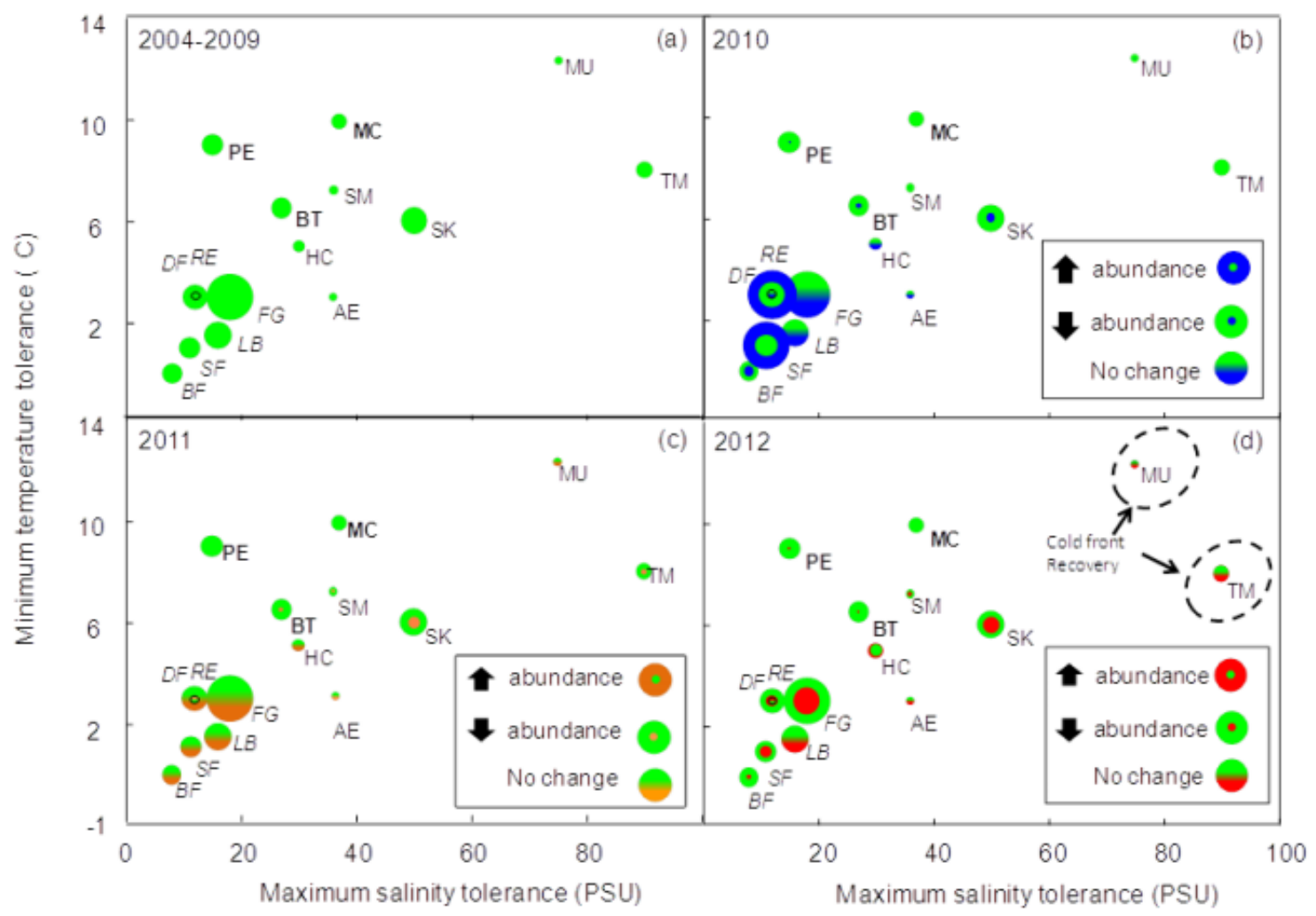


CHAPTER II

A REVIEW OF SUB-TROPICAL COMMUNITY RESISTANCE AND RESILIENCE TO EXTREME COLD SPELLS 


\begin{abstract}
Forecasted changes in global climate predict not only shifts in average conditions but also changes in the frequency and intensity of climate extremes. In the sub-tropics, the passage of extreme cold spells functions as a major structuring force for ecological communities, and can incur substantial losses to biodiversity, agriculture and infrastructure. If these events persist in the future, climate extreme effects on sub-tropical communities and ecosystems will become more pronounced, as tropical species migrate poleward. Recent extreme cold spells in subtropical China (2008) and U.S. (2010) occurred in ecosystems that are the subjects of long-term ecological study, enabling key questions about cold spell affects to be addressed. In this paper, I (1) discuss the meteorological drivers that resulted in these two extreme cold spells, and (2) use findings from case studies published in the Ecosphere special issue "Effects of extreme cold spells on the dynamics of sub-tropical communities, and on poleward expansion of tropical species" and other previously published works to identify consistencies of sub-tropical community resilience and resistance to extreme cold spells. In this review, I highlight three consistent findings related to this particularly type of extreme climate event. (1) Cold spells drive predictable community change in the subtropics by altering ratios of coexisting tropical and temperate species. (2) Certain landscape features consistently affect sub-tropical resistance and resilience to extreme cold spells. (3) Native tropical species are more resistant and resilient to extreme cold spells than tropical non-native taxa. Our review should improve forecasts of the response of sub-tropical community
\end{abstract}


dynamics in scenarios where extreme cold spells either increase or decrease in frequency and intensity.

\section{INTRODUCTION}

Forecasted changes in global climate include not only shifts in average conditions, but also changes in the frequency and intensity of climatic extremes (Easterling et al. 2000; Karl et al. 2008). Climate extremes can be defined as discrete weather events that fall within the statistical tails of some climate parameter, and create conditions exceeding the acclimation capacity of species occurring within the affected region, often causing large scale mortality events (Gutschick \& BassiriRad 2003; Smith 2011). Extreme cold spells are a form of climate extreme predicted to change in frequency, intensity, and duration in the future (Kodra et al. 2011; Field 2012; Gao et al. 2015). Changes in the future dynamics of extreme cold spells will play an important role in shaping the future distribution of species, community organization, and ecosystem function, especially in environments where species groups occur at their highest latitudinal or altitudinal distribution (Precht and Aronson 2004; Beck and Goetz 2011).

The subtropical zone $\left(25-40^{\circ}\right.$ latitude) is thermally characterized by regions where long-term average minimum monthly temperatures are greater than $13^{\circ} \mathrm{C}$, and the frequency of subfreezing minimum temperature days range from once a year to less than annual (Holdrige's life zones; Neilson 1995). Despite being a warm environment, the occurrence of cold spells are common in the sub-tropics, with ecologically meaningful events being reported in the U.S. (Boucek and Rehage 2014), China (Liu et al. 2014), Taiwan (Hsieh et al. 2008), Australia (Gilman et al. 2008), Brazil (Gallucci and Netto 
2004), and the northwest Mediterranean (Coles and Fadlallah 1991). Similar to other climate extremes, extreme cold spells affecting the sub-tropics are capable of driving wholesale changes to ecosystem structure and function (Stone 2008; Boucek and Rehage 2014; Kemp et al. 2015; Santos et al. 2015). For instance, the extreme cold spell that affected the southeastern U.S. in 2010 drove a likely stable-state shift in coral communities occurring in shallow waters off Florida's Middle and Upper Keys archipelago. The 2010 extreme climate event caused almost complete mortality of some key foundational stony coral reef building species, while causing less mortality of soft octocoral species. Since the 2010 cold spell, affected stony corals have shown little recovery, resulting in a stable, post-cold event community with an increased dominance of soft octocoral species (Colella et al. 2012; Kemp et al. 2015).

Apart from affecting ecosystem structure and function, extreme cold spells incur substantial losses to agriculture and fisheries in the subtropics (Dontown and Miller 1992; Zhou et al. 2011; Khounsy et al. 2012). For instance, a 2008 extreme cold spell that affected sub-tropical China resulted in losses of $40 \%$ of winter time crops, $30 \%$ of bee colonies, 75 million livestock, and 0.45 million tons of aquacultured fish (Zhou et al. 2011). Similar catastrophic losses to other natural resources have been observed in subtropical Florida's citrus industry (Sheridan 2003), where the passage of a series of extreme cold spells in 1980s killed approximately one third of Florida's commercial citrus trees (Downton and Miller 1993). Thus, extreme cold spells, like many climate extremes, can elicit extreme ecosystem responses, and incur substantial economic losses. If these events persist in the future, extreme cold spells will continue to be one of the dominant structuring forces of ecological communities in the subtropics. Further, as 
tropical species continue to advance poleward into the sub-tropics due to climate warming, effects of these cold events on sub-tropical communities and ecosystems will become more pronounced. Thus, in order for us to forecast ecosystem dynamics in the sub-tropics, we must understand how and what factors dictate sub-tropical community responses to these extreme disturbances.

In this introductory paper, I discuss the meteorological drivers that resulted in these two extreme cold spells in China and in the U.S., and highlight consistent findings in sub-tropical community resistance and resiliency to these extremes from the papers featured and previously-published works. Overall, I expect that the passage of extreme cold spells to function as a major force shaping sub-tropical community dynamics, changing structuring processes to those dictated by species tolerance to low temperatures, and the external features in the landscape that buffer communities from cold temperatures.

\section{CLIMATE FACTORS THAT DRIVE EXTREME COLD SPELLS}

In the subtropics, cold spells result from polar air moving into lower latitudes. Equatorial movement of polar air is often correlated with winter shifts in upper airflow from predominantly zonal (west-east) flow to meridional (north-south) flow, via changes in ocean-atmospheric teleconnections (Sheridan 2003; Chen et al. 2008; Wang et al. 2010; Na et al. 2012). For instance, in the subtropical U.S., upper air flows during the positive phase of the Pacific North American anomaly (PNA) coincide with $80 \%$ of the region's ecologically meaningful cold spells (Downton and Miller 1993; Sheridan 2003). At the onset of extreme cold spells, minimum daily air temperatures decrease to extreme low values almost overnight. These extreme low temperatures persist for usually days 
before minimum daily air temperature returns to normal variability (Zhou et al. 2011; Boucek and Rehage 2014).

In China, the 2008 cold spell brought on not only extreme low temperatures that persisted for approximately a month, but also unseasonally high precipitation (Hong and Li 2009; Zhou et al. 2011). These extreme low temperatures in sub-tropical China and Southeast Asia were a product of interactions between Siberian high (SH), intraseasonal oscillation (ISO), and El Niño Southern Oscillation (ENSO) climate anomalies. Across Asia, this 2008 extreme event started in mid-January, when the Siberian high anomaly moved into an enhanced phase, coinciding with the movement of multiple cold air outbreaks into lower latitudes in central China. These cold air outbreaks were initially blocked from the subtropics by suppressed convention over Sumatra (associated with the dry phase of the ISO). However, in February, the ISO shifted from a dry phase to a wet phase, increasing convection and pushing cold air outbreaks as far south as the South China Sea. On average, ISO wet phases and cold air advection to subtropical China persists for 10 days, but in 2008, the transition out of this wet phase was stalled by a La Niña episode, causing the ISO wet phase to persist for 30 days, resulting in continuous cold air outbreaks in sub-tropical China for the entire month of February (see Hong and Li 2009 for additional details). On top of these cold air outbreaks, an anomalous and persistent summer-monsoon-like flow pattern moved high-moisture tropical maritime air masses from the Bay of Bengal northward. The convergence of the tropical and polar air masses resulted in both extreme low minimum air temperatures in subtropical China for 24 days, and unseasonal precipitation (Zhou et al. 2011). As a result, the 2008 cold spell broke 50-year records for the maximum number of consecutive low temperature days 
throughout many regions of subtropical and temperate China (Chen et al. 2009). This extreme disturbance affected natural systems and resources and caused $\$ 22.3$ billion dollars (U.S.) in damages to infrastructure, resulting in 129 human fatalities and displacing 1.7 million people (Zhou et al. 2011).

Shifting to the 2010 extreme cold spell in subtropical United States. Across the Eastern U.S., the winter of 2009-2010 had the most snow fall and lowest temperatures since 1950 (Wang et al. 2010). The severity of the 2009-2010 winter inspired the media to report that the next 'mini ice age starts here', increasing public skepticism of climate warming (Wang et al. 2010; New York Times Feb 10, 2010; Wall Street Journal Feb 16, 2010). Like the 2008 China event, this extreme cold spell resulted from the interaction of multiple climate anomalies, namely the North Atlantic Oscillation (NAO) and the PNA. Starting on December $28^{\text {th }} 2009$, the NAO shifted into an extreme negative phase, indicating a weakening of the Icelandic low and the Azores High, and the PNA shifted into the positive phase. These phase shifts coincided with a northerly directional change in surface wind anomalies across the U.S., causing cold air outbreaks to sweep into lower latitudes and down into Florida. Extreme negative phases of the NAO usually occur during decades of longer term durations of lower phases of the NAO, therefore, it is likely that the longer the NAO remains in a negative phase the more likely an extreme negative phase event will occur, and as a consequence, an increased probability that the U.S will be affected by an extreme cold spell (Wang et al. 2010).

In Florida, cold air incursions are relatively common each winter, usually lasting one or two days, and without incurring meaningful ecological change. Once every 20 years, episodic cold spells affect sub-tropical Florida, whereby temperatures decrease to 
extreme low values ( $>3 \mathrm{SD}$ from long term temperature average), and remain at these low values for extended periods (up to seven days, Boucek and Rehage 2014). These episodic cold spells have occurred in the months of December or January in the years 1940, 1977, 1981, and 1985, all of which resulted in major ecological effects. Unlike these less severe episodic spells, the 2010 spell both drove minimum temperatures to extreme low levels (-4.16 SD from 80-year mean), but more damaging, this event kept temperatures at extreme lows for 14 days, 7 days longer the next longest cold spell (January 1940; Boucek and Rehage 2014). Effects of the 2010 cold event were severe or extreme for many taxonomic groups (e.g., corals, primary producers, and top predators; Kemp et al. 2011; Adams et al. 2012; Matich \& Heithaus 2012; Mazzotti et al. 2011; Barr et al. 2013). The Florida Citrus industry and coastal fisheries incurred substantial losses (Fantz 2010; Barbour et al. 2014; Blewett and Stevens 2015).

\section{SUB-TROPICAL EXTREME COLD SPELLS RELATIVE TO OTHER EXTREME CLIMATE EVENTS}

Despite the accepted power of climate extremes to shape natural systems, few generalizations exist to address the population, community, and ecosystem responses to such events (Jenstch et al. 2007; Smith 2011). First, few generalizations exist because climate extremes are rare, and relatively few field studies have captured ecosystem responses to such events. Second, few experimental systems are in place that can simulate extreme climate conditions over relevant spatio-temporal scales (Smith 2011). Third, ecological responses to climate extremes cannot be predicted with less severe and more frequent disturbances because climate extremes can create stressors of sufficient amplitude and duration to elicit unexpected threshold responses (Jenstch et al. 2007, 
Smith 2011, Peters et al. 2012). Finally, climate extremes often create many stressors that can interact with other local drivers to change ecosystems in complex and often contextdependent ways, limiting our ability to develop overarching generalizations of ecological responses we may expect to climate extremes (Kreyling et al. 2011, Peters et al. 2012).

The effects of extreme cold spells on subtropical ecosystems may be less complicated than effects of other climate extremes, and thus potentially easier to predict. First, subtropical cold spells are thermal events, unlike other climate disturbances such as tropical cyclones and drought that can incorporate multiple dimensions of stress (e.g., wind, fire, and precipitation in addition to temperature). Even extreme heat waves cooccur with other extreme climate drivers, including droughts, stressful UV intensity, and increased fire risk, all of which may increase context-specificity in ecological responses. For instance, during the 2011 heat wave in Australia, extreme temperatures were the dominant driver of change in coastal marine systems (Smale \& Wernberg 2013). In contrast, in the 2003 European heat wave in Northern Italy, extreme drought conditions drove a state shift in primary producer communities in Mediterranean lakes (Bertani et al. 2015). And a combination of extreme heat, extreme low precipitation, and high UV intensity drove changes in grassland communities following the same extreme 2003 European heat wave (Kreyling et al. 2011). In contrast, unlike heat waves and other extremes, the effects of cold events may be easier to link to a single driver, fostering easier comparisons across place and time, and allowing for greater predictability in their effects.

Another aspect of extreme cold spells that make their effects tractable is their relatively short duration, usually measured in days to weeks, compared to other climate 
extremes that can last for years (e.g., droughts). The consequences of such persistent extreme events can be complicated since effects can be driven by secondary influences that occur after the initial restructuring effects related to physiological stress and physical damage caused by the climate extreme. Secondary drivers might include positive feedbacks that cause persistent state changes. For instance, in arid and semi-arid grasslands, prolonged droughts combined with overgrazing can shift primary producer community dominance from perennial grasses to drought resistant woody plants that sequester nutrients and form "islands of fertility", ultimately leading to an ecosystem state change (Peters et al. 2012).

Relative to other climate extremes, ecological responses to extreme cold spells should be governed largely by thermal constraints controlled by either internal factors (e.g., physiological optima) or external factors (e.g., landscape refuges) that dictate a species' ability to tolerate relatively short durations of low temperature exposure. Though species can resist some negative deviations in temperature from less severe and more frequent cold spells, during extreme cold spells, temperatures often decrease below the physiological limits, particularly for many tropical species, resulting in abrupt, non-linear decreases in species abundances.

In the next sections, I highlight three findings consistently identified as significant in the special issue. I discuss these in the context of previous studies on subtropical community responses to extreme cold spells. Beyond improving our understanding of ecological change mediated by extreme cold spells in the sub-tropics, identifying these consistencies may help guide interpretation of short-duration thermal disturbances occurring across the globe. 


\section{CHANGES IN COMMUNITY STRUCTURE FOLLOWING EXTREME COLD SPELLS IN THE SUBTROPICS}

In the subtropics, communities are composed of tropical species at the poleward extent of their range, temperate species at their equatorial range limit, and sub-tropical species within their core range. Tropical species evolved in warm, thermally aseasonal environments (i.e., thermal specialists; Tewksbury et al. 2008), while temperate and subtropical species have adapted to relatively wide seasonal fluctuations in temperature (thermal generalists; Sunday et al. 2014). Thus, tropical species are generally limited in their physiological acclimation to extreme cold and even exhibit maladaptive behaviors during extreme cold events (see Mazzotti et al. 2016). In comparison to tropical species, temperate species have the physiological capacity to resist both relatively high and low temperature extremes (Sunday et al. 2014). Because tropical species are less resistant to extreme cold spells compared to temperate and sub-tropical species, cold spells should shift community dominance in favor of more temperate species.

The studies in this issue, along with prior work support this generalization. Starting with top predators in Florida, the 2010 event reduced abundances of tropical American crocodile (Crocodylus acutus), while having little influence on more thermally tolerant American alligators (Alligator mississippiensis; Mazzotti et al. 2016). Moving down the food web, following the same event in Florida coastal rivers, an immediate decline in tropical fishes was observed, while temperate fish abundances remained unchanged or increased (Boucek and Rehage 2014; Santos et al. 2016). Switching over to the spell in China, similar decreases in tropical species dominance were observed following the 2008 event. For instance, Wang et al. (2016) showed that the 2008 cold 
spell caused disproportionate mortalities of tropical butterflies, resulting in an increased community dominance of temperate butterflies. In coral reef communities, a switch from tropical species to broadly temperature tolerant species was observed following both the 2008 China and the 2010 U.S. event (Chen et al. 2008; Kemp et al. 2011; 2016). Outside these two extreme cold spells, other research has supports this generalization. In coastal sub-tropical zones across the globe, the passage of extreme cold spells have been shown to switch vegetation communities from tropical mangrove-dominated environments to temperate saltmarsh-dominated habitats (Stevens et al. 2006; Osland et al. 2013;

Cavanaugh et al. 2014). Sub-tropical cold spells, therefore, appear to lead to rapid shifts in community structure toward greater broadly tolerant species dominance.

\section{EFFECTS OF LANDSCAPE FEATURES ON SUBTROPICAL COMMUNITY RESISTANCE AND RESILIENCE}

Extreme cold spells affecting the sub-tropics can incur ecological change across entire regions. In both Florida and China, mortality of tropical species was observed from latitudes $19^{\circ} \mathrm{N}$, and $29^{\circ} \mathrm{N}$, to latitudes of $24^{\circ} \mathrm{N}$ and $28^{\circ} \mathrm{N}$, respectively (Chen et al. 2016; Stevens et al, 2016, Kemp et al. 2016). Despite the large footprint of the area affected by extreme cold spells, tropical species and sub-tropical community resistance and resilience vary across space.

Landscape features may either promote or reduce tropical species and sub-tropical community resistance to extreme cold events. Further, these landscape features may operate at every spatial scale. At the scale of a single forest patch, larger trees that occupy the upper canopy are more severely damaged by extreme cold spells (by both physiological damage from cold shock and physical damage from icing) than smaller 
lower understory trees in Floridian and Chinese mangrove forests and in Chinese evergreen forests (Ross et al. 2009; Chen et al. 2016; Wang et al. 2016). In these forests, temperature and humidity both decrease moving from the floor to the canopy, increasing stressful thermal conditions for taller trees (Ross et al. 2009; Chen et al. 2016). Similar differences between forest floor vs. canopy effects were also documented in small-bodied consumers inhabiting Chinese mangrove forests. Arboreal mollusks suffered higher mortalities than their benthic counterparts in Chinese mangrove forests following the 2008 cold spell, likely due to similar temperature and humidity drivers (Liu et al. 2016).

Variation in cold spell resistance across patches also exists. Landscape features that may influence cross patch resistance to extreme cold spells include, (1) proximity to water bodies that can buffer patches from extreme cold temperature, (2) features that may block wind, and (3) elevation differences (e.g., valleys) that can trap cold air. Starting with examples from citrus groves in Florida, following a series of episodic cold spells in the 1980s, Downton and Miller (1993) showed that cold resistance of citrus groves varied based on whether the grove was on a hill or in a valley, or whether the grove was close to a lake. Groves in valleys were more at risk to freeze damage due to the settling of denser cooler air in these valleys that create cold pockets. Similarly, groves on the windward north facing sides of hills suffered more damage. In mangrove forest patches in subtropical China, Liu et al. (2012) came to a similar conclusion: mangroves located on the leeward sides of hills suffered minimal damage following the 2008 cold spell relative to those on the windward side. In a similar fashion, subtle changes in elevation that may trap cool air in addition to distance to oceans that can act as a heat source and alter 
mangrove cross-patch forest resistance in both sub-tropical China and the U.S. (Liu et al. 2014; Zhang et al. 2016; Chen et al. 2010, 2016).

At the largest scales, ocean currents and ecosystem geomorphology can dictate cross-ecosystem resistance. For instance, Stevens et al. (2016) found nearly complete resistance for a tropical estuarine fish population in Florida at one estuary, and virtually no resistance in three others. These inter-estuary differences in tropical fish resistance were likely a result of multiple interacting factors, including availability and abundance of deepwater habitats (though mostly anthropogenic), abundance of freshwater springs, and proximity to warm tropical oceanic currents. Similarly, in the Florida Keys archipelago, following the 2010 cold event, shallow water coral reefs in the Middle to Upper Keys suffered community wide change while coral reefs in deeper water and closer proximity to the warm Gulfstream were less affected by the disturbance (Colella et al. 2012).

Like resistance, sub-tropical community resilience can vary across spatial scales. For instance, Rehage et al. (2016) showed that across eight non-native fish populations affected by the 2010 disturbance, population resilience varied from within one year, to populations that have exhibited no recovery five years post disturbance. Rehage et al. (2016) attribute this spatial variation in resilience to differences in distance to warm water source populations. Likewise, Stevens et al. (2016) found that following the 2010 cold spell in Florida, resistance of a tropical estuarine piscivore were similar across three of four estuaries but resilience varied, possibly an effect related to inter-estuary differences in geophysical structuring that may influence reproduction, recruitment, and 
juvenile survival. Thus, landscape features are an important consideration since they can influence both resistance and resilience.

\section{DIFFERENCES IN RESISTANCE AND RESILIENCE AMONG TROPICAL NATIVE AND NON-NATIVE TAXA}

Native and nonnative species may differ in a variety of ways, including how they are affected by extreme events. Within the context of extreme cold events, nonnative tropical species appear to be less resistant and resilient than their tropical native counterparts. This finding agrees with hypotheses proposed by Kreyling et al. (2015), when measured the thermal tolerance of 27 northern Hemisphere native and nonnative tree species. Kreyling et al. (2015) found that cold tolerance was related to the temperature conditions in the species' native range. The authors conclude that developing cold tolerance operates on relatively long timescales. Thus, the lack of cold tolerance observed in non-natives could be that tropical species native to the sub-tropics may have developed limited tolerance to extreme cold spells, while tropical non-native species with distributions in more core areas of the tropics have not yet acquired any physiological capacity or behaviors that may improve their resistance to extreme cold spells (Cook Patton et al. 2015).

Findings from previous and ongoing work support this notion. Chen et al. (2016) found that mangroves introduced to subtropical China (Sonneratia caseolaris, S. apetala) suffered higher mortalities than native species. Similarly, bamboo fields planted with non-native species suffered greater losses than fields seeded with native bamboo following the 2008 cold event (Junming et al. 2008; Zhou et al. 2011). In Florida, Boucek and Rehage (2014) and Rehage et al. (2016) found that tropical native fishes were both 
more resistant and resilient to extreme cold compared to their functionally similar nonnative counter parts. Similarly, Downing et al. (2016) found that non-native bees in subtropical Florida were less resistant to the 2010 cold spell than native bees. Many nonnative species are introduced to the subtropics from lower latitudes, because of their high ornamental value (Schofield and Loftus 2014). Thus, as the dynamics of extreme cold spells change in the future, invasion risk, and the population stability of currently established non-natives will track the changes in the frequency, intensity and duration of extreme cold spells in the sub-tropics.

\section{CONCLUSIONS: SUB-TROPICAL CONSERVATION IN A WARMING WORLD WITH EXTEME COLD SPELLS}

Whether extreme cold spells will increase or decrease in frequency, intensity, or duration is uncertain, and is likely to vary geographically (Vavrus et al. 2006, Kodra et al. 2011). Previous research shows that any change in their dynamics may have consequences for subtropical ecosystems. If these events increase in frequency, we may expect non-native population dynamics to become less stable, and the probabilities of new species invasions to be reduced. At the same time, we may see losses to many important natural resources in these latitudes, including coral reefs and mangrove forests, which provide key ecosystem services to the region, in addition to losses to agriculture and fisheries productivity. Further, increases in these events may function to slow the poleward migration of tropical species, as well as impair translocation success in conservation efforts, which could be particularly problematic since tropical species are at very high risk from climate warming (Sunday et al. 2014). 
Under scenarios where extreme cold spells remain constant or increase in frequency, we could consider developing conservation and management strategies that account for variation in resistance to these events, considering both the component species within that community (non-native, tropical, temperate), and the landscape features the community occupies. For habitats and communities that offer little resistance to these cold disturbances, we could implement strategies to provide extra protection for tropical species occurring in those areas that are at increased risk to cold spell effects (discussed in Stevens et al. 2016). This added protection may be particularly important for highly managed tropical fisheries that due to harvest are increasingly responsive to climate stressors (Britten et al. 2014; Santos et al. 2016; Stevens et al. 2016). On the other hand, habitats that have landscape features that offer high resistance to these disturbances, could be identified and set aside as refuges for endangered and or imperiled tropical species occurring in the sub-tropics such as American Crocodiles (Mazzotti et al. 2016). Similarly, these cold spell refuge habitats could serve as key introduction sites of the species being considered for assisted migration programs and translocation conservation strategies.

Last, decreases in the frequency of these events could provide long-term benefits to agriculture and aquaculture, like Florida citrus and that could add facilities at higher latitudes (Sheridan 2003). Likewise, we may expect tropical fisheries to become more stable and potentially increase in productivity (Stevens et al. 2016; Santos et al. 2016). Decreases in the frequency of these events may also increase the population stability of threatened tropical species occurring within the sub-tropics (i.e., American crocodile; Mazzotti et al. 2016), as well as increase habitat suitability in the sub-tropics for tropical 
species threatened by climate warming (Liu et al. 2012; Kemp et al. 2016). Regardless of the fate of extreme cold spells in the future, our special issue highlights key responses that we can expect subtropical systems to exhibit in light of these extreme events. 


\section{CHAPTER III}

A ONCE IN TEN YEAR DROUGHT ALTERS THE COMPOSITION AND MAGNITUDE OF A FLOODPLAIN PREY SUBSIDY TO COASTAL RIVER FISHES 


\begin{abstract}
Movement of energy, nutrients, and prey to river and stream systems from adjacent habitats can be the dominant driver of river and stream foodwebs. As such, disturbances that alter these foodweb linkages can lead to whole scale changes to receipt aquatic systems. However, how and in what ways disturbance alters cross-habitat foodweb linkages and prey subsidies is largely understudied. In coastal rivers of the Southwest Everglades (FL, U.SA.), seasonal increases in rainfall inundate adjacent floodplains, providing habitat for an abundance of floodplain fish and macroinvertebrate species. In the dry season, rainfall decreases and floodplains dry, forcing floodplain prey into these river systems. These floodplain prey provide an important prey subsidy for an estuarine predator, common snook (Centropomis undecimalis). In 2011, a once-in-tenyear drought affected the region, tripling the number of days floodplains remained dry, likely affecting this prey subsidy. In this study, I ask (1) did the 2011 drought affect the magnitude and composition of floodplain prey subsidies to snook, and (2) if species composition changed, were there energetic differences between the pre and postdisturbance prey species? Our results showed that one year following the drought, prey subsidies to snook decreased by $75 \%$. On top of that decrease in overall flux, snook diet composition switched from floodplain fishes to drought-tolerant floodplain macroinvertebrates. Last, energetic analyses showed that these post-drought macroinvertebrate prey subsidies had $43 \%$ less calories per gram than floodplain fishes. In the sub-tropics and tropics, droughts are expected to increase in frequency and intensity in the future. As droughts become more frequent and intense, these cross-habitat
\end{abstract}


foodweb linkages will likely change depending on ecosystem contexts, affecting river ecosystems.

\section{INTRODUCTION}

Over the past two decades, research has established the importance of crossecosystem resource subsidies to recipient populations, communities, and ecological processes (Polis et al. 1997; Richardson and Sato 2015: Richardson and Wipfli 2016). For instance, fluxes of prey from floodplains to rivers can provide up to $75 \%$ of the total biomass consumed by predatory fishes inhabiting riverine systems (Winemiller and Jepsen 2004; Jardine et al. 2012; Boucek and Rehage 2013). These prey subsidies can have strong direct bottom up effects, and thus sustain high predatory fish biomass (Allen and Wesner 2016). In turn, these predatory fishes not only support lucrative fisheries (Jardine et al. 2012), but through increased top-down pressure, shape riverine trophic structure and influence whole-ecosystem energy flows (Nakano et al. 1999; Kawaguchi et al. 2003). Given the scale of these effects, any alterations to these fluxes can have major ecological and economic ramifications for recipient ecosystems, and communities that rely on the fisheries provided by the river systems.

Disturbance can alter these cross-ecosystem resource subsidies in a number of ways. First, disturbance can alter the magnitude of resource fluxes. For instance, Greenwood and McIntosh (2010) showed that decreased river flows lowered aquatic insect prey abundance, which in turn reduced biomass of the recipient terrestrial consumer, a riparian fishing spider. Disturbance could also affect the species composition of trophic subsidies, with important implications for subsidy quality and incorporation 
into receipt foodwebs (Marcarelli et al. 2011). For instance, invasions by Russian olive (Elaeagnus angustifolia) in riparian corridors in the western US have resulted in a 25fold increase in allochthonous inputs to streams, but due to the low quality and chemical properties of the leaves, increased inputs did not affect stream productivity (Mineau et al. 2012). A third possibility is that disturbance could affect the ability for response by recipient consumers. In streams, flood disturbances positively affected aquatic prey abundance, but fishing spiders were unable to capitalize on this subsidy due to decreases in habitat quality in riparian areas at less flood-prone rivers (Greenwood and McIntosh 2008). Surprisingly, aside from this handful of examples, few studies have quantified how disturbance can affect upper trophic level trophic fluxes.

One of the key disturbances to consider in a future of climate change, and of relevance for secondary trophic level fluxes to many aquatic systems is drought (Lake 2011). In river floodplain systems, droughts can have persistent effects on floodplain to river energy flows (Junk et al. 1989; Magoulick and Kobza 2004; Bond et al. 2015). Drought in these river floodplain systems can be facilitated by both anthropogenic water management practices related to agricultural use, flood control and human consumption, deviations in precipitation driven by larger ocean-atmospheric teleconnections, and also by higher than normal temperatures that increase evapotranspiration (Trenberth et al. 2013). In river floodplain systems, droughts reduce the number of days that floodplains are inundated, which both increases the time that floodplain species spend in rivers, and the decreases the subsequent growing season for floodplain fishes. Similarly, freshwater flows are reduced during drought, which can create exceedingly harsh abiotic (anoxia) 
and biotic (high competitor and predator density) conditions in river habitats. These effects decrease floodplain species survival, floodplain re-colonization, and the future productivity of floodplain subsidies (Welcomme and Halls 2001; Magoulick and Kobza 2004).

In the Florida Everglades wetlands, wet-dry rainfall cycles drive prey productivity and fluxes of fish prey across ecosystem boundaries. During the wet season (JuneNovember), high rainfall results in the inundation of vast expanses of graminoid freshwater marshes that provide habitat for prey fishes (Trexler et al. 2005; Boucek and Rehage 2013). In the dry season (December-May), marsh drying forces fish prey into the deepest habitats in the landscape, including canals, sloughs, biogenic depressions, and in the southern reaches of the ecosystem, coastal rivers (Rehage and Trexler 2006; Parkos and Trexler 2011; Boucek and Rehage 2013). These prey fish concentrations are then exploited by avian, piscine, and reptilian consumers (Frederick et al. 2009). At the marshcoastal mangrove interface, concentrations of these marsh prey constitute a major subsidy for estuarine piscivores, particularly recreationally-valuable Common Snook (Centropomis undecimalis), that migrate to this river floodplain system to capitalize on this resource (Boucek and Rehage 2013).

In the greater Everglades, droughts are a common re-occurring disturbance driven by both larger ocean-atmospheric teleconnections, and anthropogenic water management practices (Gaiser et al. 2012). Like many river-floodplain systems, droughts in the Everglades both have pronounced immediate and long-term effects on prey abundances, trophic interactions and whole scale ecosystem processes (Trexler et al. 2005, Dorn and 
Cook 2015). In 2011, a once-in-10-year drought affected South Florida, providing an opportunity to examine the effects of drought of prey subsidies across the marsh-coastal mangrove interface, and more broadly learn about how disturbance can alter prey subsidies (Figure 3.2). In this study, I asked (1) how did the 2011 drought affect the magnitude and composition of floodplain prey subsidies to common snook, and (2) if drought altered species composition of subsidy, did food quality (energetic value) of prey species differ before and after the drought? I hypothesize that (1) the 2011 drought would result in a both temporary decrease in the magnitude of the subsidy, and a compositional shift in trophic subsidies from centrarchid fishes to drought tolerant macroinvertebrates (crayfish, crabs and shrimp). I also expected that (2) macroinvertebrates would be of lower energetic quality relative to centrarchid prey items. To assess the effects of the drought on subsidy quantity, composition, and quality, I tracked the abundance of common snook, biomass of centrarchid floodplain species, and snook diets for four years (2010-2014). Last, I compared the energetic value of prey species common in snook diets during the study.

Study system

\section{MATERIALS AND METHODS}

My study was conducted in a series of first and second order creeks in freshwater reaches of the upper Shark River in the southwest region of Everglades National Park (ENP; Figure 3.1). These creeks are crowned by an expansive floodplain, the Shark River Slough. The Shark River Slough and Shark River represents the largest freshwater drainage of the southern Florida Everglades and a focal point of ongoing Everglades hydrological restoration efforts (Childers et al. 2006). Long-term hydrological monitoring 
from this region shows that these floodplains generally dry every year, with the number of dry days varying from 0-210 per year (Boucek and Rehage 2014a). In the southern Everglades, the number of floodplain dry-days and drought are closely linked in the El Niño Southern Oscillation (ENSO) and Atlantic Multidecadal Oscillation (AMO) ocean atmospheric teleconnections (Gaiser et al. 2012).

On the biological side, during the dry season, three guilds of prey move into the river system (Boucek and Rehage 2013). These guilds consist of cyprinodontoid fishes, macroinvertebrates, and larger bodied sunfishes. Along with these prey, three species of freshwater floodplain top predators move off drying floodplains into the river system: Florida bass (Micropterus floridanus), bowfin (Amia Calva), and Florida gar (Lepisosteus platyrhincus). In comparison to snook, these freshwater piscivores are generally smaller in body size, and principally forage on different functional groups of prey. For instance, bass and Florida gar (Lepisosteus platyrhincus) show preference for cyprinodontoids that generally occupy the top of the water column, bowfin principally feed on floodplain macroinvertebrates, while snook primarily consume sunfishes (Boucek and Rehage 2013). Though these consumers seemingly partition resources, the abundance of freshwater floodplain piscivores can be high enough that they still consume approximately half the sunfish biomass that enters the river system (Boucek and Rehage 2013). In the wet season, high diet overlap is high among these consumers, with generally all species consuming invertebrates.

Sampling effort 
In order to examine the effects of the 2011 drought on prey fluxes between upstream marshes and the mangrove riverine areas downstream, I tracked diets of the focal consumer snook, along with changes in snook abundance, and the biomass of their dominant prey item, centrarchid fishes originating from the floodplain system. My study was conducted at five creek sites approximately each month from December to July (dry season) each year from 2010 to 2014 via electrofishing methods (Figure 1). At each creek site, three standardized electrofishing transects were conducted using a boat-mounted, generator-powered electrofisher (15 transects per month x 26 months sampled $=390$ transects). For each transect, I drove the electrofisher (two-anode, one cathode SmithRoot 9.0 unit) at idle speed in parallel to shorelines and applied power for 300 seconds, netting all immobilized snook and sunfishes. From these electrofishing samples, I report catch per unit effort (CPUE) for snook, as the number of fish caught per $100 \mathrm{~m}$ of mangrove creek shoreline (see Boucek \& Rehage, 2013; Boucek and Rehage 2015 for additional details). For sunfish prey, I report abundance as the biomass of sunfishes per $100 \mathrm{~m}$ of shoreline. Upon capturing snook, I removed stomach contents via pulsed gastric lavage, a relatively non-invasive and effective method for sampling fish stomach contents (Barbour et al. 2012, Boucek and Rehage 2013).

Stomach content samples were preserved in formalin for later processing. At the lab, consumed prey items were identified to the lowest taxonomic resolution, measured and weighed (wet weights). I then calculated the average biomass (wet weight of consumed prey) of macroinvertebrates and fishes consumed per 100 meters of shoreline by snook using the equation below. 


$$
B C_{i}=\left(\frac{\text { wet weight }(\mathrm{g}) \text { of }_{\text {prey }} \text { consumed per transect }}{\text { length sampled via electrofishing transect }(\mathrm{m})}\right) * 100
$$

Where BCi represents the prey biomass consumed per $100 \mathrm{~m}$ that was either fish (all taxa combined) or macroinvertebrate (all taxa combine). This metric provides a good measure of the overall flux of both floodplain prey that is incorporated into the foodweb, and floodplain energy and nutrients deposited in the receipt river system through trophic pathways. I then compared yearly differences in snook abundance, prey fish biomass, and the mean biomass consumed per 100 meters of all prey, macroinvertebrates, and fishes using the Friedman's test, (a nonparametric test analogous to a repeated measures ANOVA; Verbitsky 2012) with month used as the independent variable. Post hoc comparisons were done using Mann-Whitney U-tests.

\section{Energetic analyses}

Energetic values of specific prey taxa in the focal system are not available from the literature, particularly the nonnative species. However, findings from other studies show that fishes are generally higher in caloric content than invertebrates, and fish of larger body size are higher in calories than their smaller counterparts (Kushlan 1979; Adams et al. 1982). For our energetic analysis, I collected large-bodied ( $>5 \mathrm{~cm}$ total length or TL) fishes via electrofishing and small bodied fishes $(<5 \mathrm{~cm})$ and macroinvertebrate prey, using unbaited $3 \mathrm{~mm}$, metal-mesh minnow traps $(25.4 \mathrm{~mm}$ opening) set overnight. When potential prey species could not be captured from our five study sites, I augmented our collection using both electrofishing and minnow traps from canals bordering ENP (32 km away from study sites). 
I measured the caloric content of prey items that made up greater than $1 \%$ of the biomass that snook consume, or are common prey items consumed by snook in other systems (Blewett et al. 2006; Stevens et al. 2010; Blewett et al. 2013). I measured the caloric content of focal prey using bomb calorimetry (Kushlan 1979; Adams et al. 1982). This process combusts $0.5-1.0 \mathrm{~g}$ of sample, producing a change in the water temperature inside of the bomb calorimeter which is used to calculate the specific heat for the sample. Prior to combustion, all samples were dried at $75^{\circ} \mathrm{C}$ for $3-5$ days. Prey items were then homogenized, and compressed into multiple $0.5-1.0 \mathrm{~g}$ pellets. I processed 3-5 individuals per species. For the smaller prey, when the dry weight of an individual was below the minimum requirement to produce a successful run $(<0.5 \mathrm{~g})$, per previous energetic studies, I combined multiple individuals from a single species to obtain the minimum sample weight (Glover et al. 2010). I examined variation in the caloric content of prey items using a one-way ANOVA, testing for energetic differences in prey type (fish or macroinvertebrate). I analyzed a total of 17 fish prey species and 5 macroinvertebrate species. All statistical analyses were conducted in SAS 9.2.

\section{RESULTS}

\section{Drought effects on floodplain inundation}

Over the course of the four year study, the focal system experienced a drought (2011), one especially wet year where floodplains did not fully dry (2013), and two years with average conditions (Figure 3.2). Floodplains dried or reached their shallowest depth for the year in March (2011), in April (2012 and 2013), and in May (2014). In 2011, 
during the drought year, floodplains remained dry for 105 days (March $12^{\text {th }}-$ July $3^{\text {rd }}$ ), tripling the long-term average number of dry days (Boucek and Rehage 2014). In contrast, floodplains only dried for six days in 2012, and 28 days in 2014.

\section{Biomass of prey fish}

The biomass of sunfish sampled per $100 \mathrm{~m}$ via electrofishing varied across years

of study $\left(\chi^{2}=32.1, \mathrm{p}<0.01\right)$. From 2011 to 2012 , one year following the drought, average sunfish biomass per $100 \mathrm{~m}$ decreased by $90 \%$ ( $<<0.01$; Figure 3.3 upper panel). From 2012- 2013, the mean biomass of sunfish per $100 \mathrm{~m}$, showed a 12.5 fold increase $(\mathrm{p}<0.01)$. Similarly, in comparison to 2011 , mean sunfish biomass per $100 \mathrm{~m}$ in 2013 was $30 \%$ higher $(\mathrm{p}<0.01)$. Last, from 2013 to 2014 , mean sunfish biomass per $100 \mathrm{~m}$ decreased by $66 \%(p<0.01)$, and did not differ from $2011(p=0.07)$.

\section{Abundance of Common Snook}

The abundance of snook also varied across years $\left(\chi^{2}=12.9, \mathrm{p}<0.01\right.$; Figure 3.3 lower panel). From 2011 to 2012, the average number of snook per $100 \mathrm{~m}$ did not differ $(\mathrm{p}=0.14)$. But, from 2012 to 2013 , the mean number of snook per $100 \mathrm{~m}$ showed an $11 \%$ increase $(p=0.02)$. In 2014, snook abundances increased by $72 \%$ compared to 2013 . Increases in snook abundance over time are likely a result of recovery from an extreme cold spell in 2010 that resulted in $80 \%$ mortality across these study sites as well as throughout the state of Florida (Boucek and Rehage 2014; Stevens et al. 2016).

\section{Variation in Common Snook diets over time}


Through the course of the study, a total of 626 snook diets were sampled. Across the four years of the study, average biomass consumed of all prey, average consumption of macroinvertebrate biomass, and mean consumption of fish biomass per $100 \mathrm{~m}$ varied $\left(\chi^{2}>9.9, p<0.02\right.$; Figure 3.4). One year after the drought, mean biomass of all consumed prey and biomass consumed of all fishes decreased by $75 \%$ and $86 \%$ respectively in 2012 $(\mathrm{p}<0.05$; Figure 3.4 all panels). At the same time in 2012, mean consumption of macroinvertebrate biomass showed an 8.7 fold increase compared to $2011(\mathrm{p}=0.01$, Figure 3.4 middle panel). Post-drought in 2012-2013, average biomass consumed for all prey and fishes increased by 2.1 and 4.4 fold respectively. In contrast, mean consumption of macroinvertebrate biomass decreased by $94 \%$ from 2012 to 2013 . By 2014, mean biomass consumed for all prey, sunfish prey and macroinvertebrate prey, was similar to the pre drought $(2011)$ and to $2013(\mathrm{p}<0.33)$.

Prey energetic content

Energetic analyses showed that fishes were higher in calories than macroinvertebrate prey $(\mathrm{F}=76.1, \mathrm{p}<0.01)$. The mean caloric content of fish species were $18,740 \mathrm{j} \mathrm{g}^{-1}$ (joules per gram ) and $10,811 \mathrm{j} \mathrm{g}^{-1}$ for macroinvertebrates, $42 \%$ lower than fish (Figure 3.5). I found that the caloric content of fish species ranged between $23,364 \mathrm{j}$ $\mathrm{g}^{-1}$ and $14,274 \mathrm{j} \mathrm{g}^{-1}$ with dollar sunfish (Lepomis marginatus) being the most energy rich species and warmouth sunfish (Lepomis gulosus) being the lowest energetically valuable species. The caloric content of macroinvertebrates ranged from 16,143 $\mathrm{j} \mathrm{g}^{-1}$ and $6,276 \mathrm{j} \mathrm{g}^{-}$ ${ }^{1}$, with riverine grass shrimp (Palaemonetes paludosus) and blue crab (Callinectes sapidus) being the highest and the lowest energy rich species, respectively. 


\section{DISCUSSION}

Climate projections predict that precipitation will decrease in the tropics and subtropics. Overlaid on this precipitation decrease, human populations will continue to grow, and as a consequence of increased urban water demand, the frequency and intensity of droughts will likely increase as well (Obeysekera et al. 2011). Changes to drought intensity and frequency will most likely alter the dynamics of important floodplain prey resources, which, in turn, will affect river-floodplain fishery productivity and the trophic structure of these ecosystems (Trenberth et al. 2013). The results of this study indicate that droughts temporarily reduce the magnitude of prey flux from donor floodplains to receipt habitats, and change the composition of prey flux from higher calorie fish prey to lower calorie, drought-tolerant macroinvertebrate prey. We can expect such changes to increase in frequency with climate change and increased human water demands.

The South Florida disturbance regime is punctuated by three event types, cold spells, tropical cyclones, and droughts (Davis et al. 2016). In the context of coastal fishes, all three disturbances can affect fish communities. For instance, cold spells disproportionately affect tropical snook that colonized South Florida from the Caribbean, while incurring little physiological stress on temperate freshwater prey species originating from the continental U.S. (Boucek and Rehage 2014). In contrast, tropical cyclones deposit large amounts of organic matter in upstream freshwater bodies, creating anoxic conditions that trap and kill freshwater species, while having little effect on marine fishes that can flee to more oxygenated coastal waters (Stevens et al. 2006). Last, 
droughts have more pronounced effects on freshwater species in South Florida coastal environments, and have little effect on marine species. Over the last seven years, two of these disturbances affected the study site, a once-in-100-year cold spell in 2010, and the 2011 drought. The 2010 cold spell resulted in $80 \%$ decrease in snook abundance while having no negative and possibly positive effects (through top down predation releases) on sunfish abundance (discussed in Boucek and Rehage 2014). While the 2011 drought had no obvious effect on the tropical marine species. To this end, when considering the disturbance history of the study site over the last seven years, and the duration of the study, the drought likely functioned as the driver of change, at least for the abundances of forage fishes.

Consumption of macroinvertebrates might have increased following the drought for two reasons: (1) allochthonous macroinvertebrate prey availability increased while fish prey decreased, and (2) macroinvertebrate prey availability remained constant while fish prey decreased, forcing snook to consume their less-preferred food type. The second explanation is possible but the first seems more likely. Dorn and Cook (2015) simulated a drought in a 100 ha experimental Everglades wetland, and following the drought they observed a threefold increase in crayfish abundance. They attributed this increase to the drought tolerance of crayfish (Dorn and Trexler 2007) and predation release from Everglades wetland fish predators that suffered mortalities from the drought. This increase in crayfish abundance appeared to result from the higher survival of juvenile crayfish in the absence of fish predators and not from enhanced algal resources for crayfish. At larger landscape scales, Dorn and Cook (2015) also found crayfish densities 
to be positively correlated with the severity of local drying during the preceding dry season. These wetland systems are functionally similar to the focal floodplain habitats, thus the same dynamics are likely occurring (Boucek and Rehage 2014).

Similar predator-prey linkages occur in other Florida coastal river-floodplain systems. However, key differences exist between these systems and the focal Everglades system. For instance, in the Peace River of west-central Florida, floodplain inundation provisions prey subsidy for snook. Unlike the Everglades, the Peace River floodplain subsidy is dominated by crayfish (Blewett et al. 2013). Why floodplain prey subsidies in the Everglades are principally fish, and in the Peace River are primarily macroinvertebrates, is likely a function of the duration that these floodplains are inundated. In the Everglades, floodplains remain in the hydroperiod for an average of 330 days. Whereas, in the Peace River, floodplains are inundated for approximately 30-90 days (Stevens et al. 2010; Blewett and Stevens 2013). I speculate that in Florida river floodplains such as the Peace River, only drought tolerant floodplain species such as crayfish can propagate under the shorter hydroperiods. However, if floodplain inundation durations were to increase, then the subsidy may switch from energetically poor crayfish, to fish that are almost double in calories per gram. A potential exciting area of research may be developing models that explore relationships between floodplain inundation duration and floodplain prey communities, which may allow water management agencies to predict at what floodplain inundation durations are sufficient to cause compositional switch in these floodplain subsidies. 
Decreases in the magnitude of this subsidy to snook has the potential to affect snook condition, reproduction, and their population dynamics. Snook are an iteroperous, highly fecund, batch spawning species, with peak reproduction occurring in May and June (Taylor 1998; Andrade et al. 2013). This subsidy peaks in magnitude in March and April, and therefore immediately prefaces snook reproductive windows. As such, energy from this subsidy could go directly to gonadal growth. Decreases in the magnitude and quality of this subsidy facilitated by drought could affect snook spawning in a number of ways. For instance, reductions in pre-spawning prey resources could result in some individual snook forgoing reproduction or skip spawning, thus affecting future cohort size (Secor 2008; Trotter et al. 2012). Similarly, the loss of this resource may delay peak reproduction (Farmer et al. 2015). Delays in the timing of reproduction may reduce the growing season of young of the year snook, decreasing their survival during winter time and dry season stressors, such as low temperatures and increased predation risk (Houde 1998). Ongoing research aims to better understand these linkages between freshwater allocation to coastal river systems, floodplain productivity, snook reproduction, cohort strengths, and ultimately changes in catch rates of snook.

In addition to prey moving into these river systems, abundant floodplain top predators also move into these estuarine creeks. During non-drought years, dry season survival of these top predators is relatively high. However, during drought, due to increasing salinities in the estuary, increased water temperature and due to low dissolved oxygen, apparent survival of these predators decreased by $80 \%$ (Boucek \& Rehage 2015a). Similar to the fish prey, abundances of floodplain top predators returned to pre- 
disturbance in two years (Boucek and Rehage 2015b). Thus, because of the consumption of fish prey and mortalities of floodplain top predators, during drought, consumer mediated energy and nutrient flux into these creeks may be higher than normal. However, following drought, due to the absence of fish prey and absence of floodplain top predators, energy and nutrient flux may be below average.

As droughts increase in frequency and intensity in the future, year-to-year variability of fluxes to these lotic systems are likely to increase. Higher variability in the magnitude of this flux has the potential to affect processes at every ecological scale. For instance, Jardine et al. (2015) showed that ecosystem productivity, species richness, and population stability of avian top predators all decreased as the year-to-year predictability of flood pulses decreased across a gradient of neotropical rivers in Australia. Beyond river floodplain systems, increased inter-annual variance in abiotic and biotic drivers have shown to affect functional diversity and ecosystem productivity in arid desert grassland systems (Gherardi and Sala 2015). Thus, as droughts increase in these tropical and subtropical regions, and the year-to-year differences in the magnitude and composition of these fluxes increase, many processes will likely change in tandem.

Throughout aquatic ecosystems, disturbance has profound effects on the structure, function and services provided (e.g., Collins et al. 2010). The present study builds on our understanding how disturbance affects both the magnitude and composition of prey fluxes across ecosystem boundaries and particularly, on the potential energetic consequences of drought-related decreases in the quality and size of prey fluxes for socioeconomically valued recreational fisheries. With predicted intensification of 
disturbance such as droughts (Bahn et al. 2014), we must develop a more comprehensive and predictive understanding of the potential for intensified disturbance regimes to alter or sever important spatial food web connections between lotic environments and periphery habitats. 


\section{FIGURES}

Figure 3.1. Map showing the location of the five study sites in the upper Shark River Estuary in southwestern region of Everglades National Park. Study sites are shown in black circles, while black squares denote hydrological stations used to examine drought severity. Insert shows the three fixed-bout locations sampled via electrofishing at each site. Shaded area denotes Shark River Slough, located upstream of study sites and the main freshwater drainage in the southern Everglades.

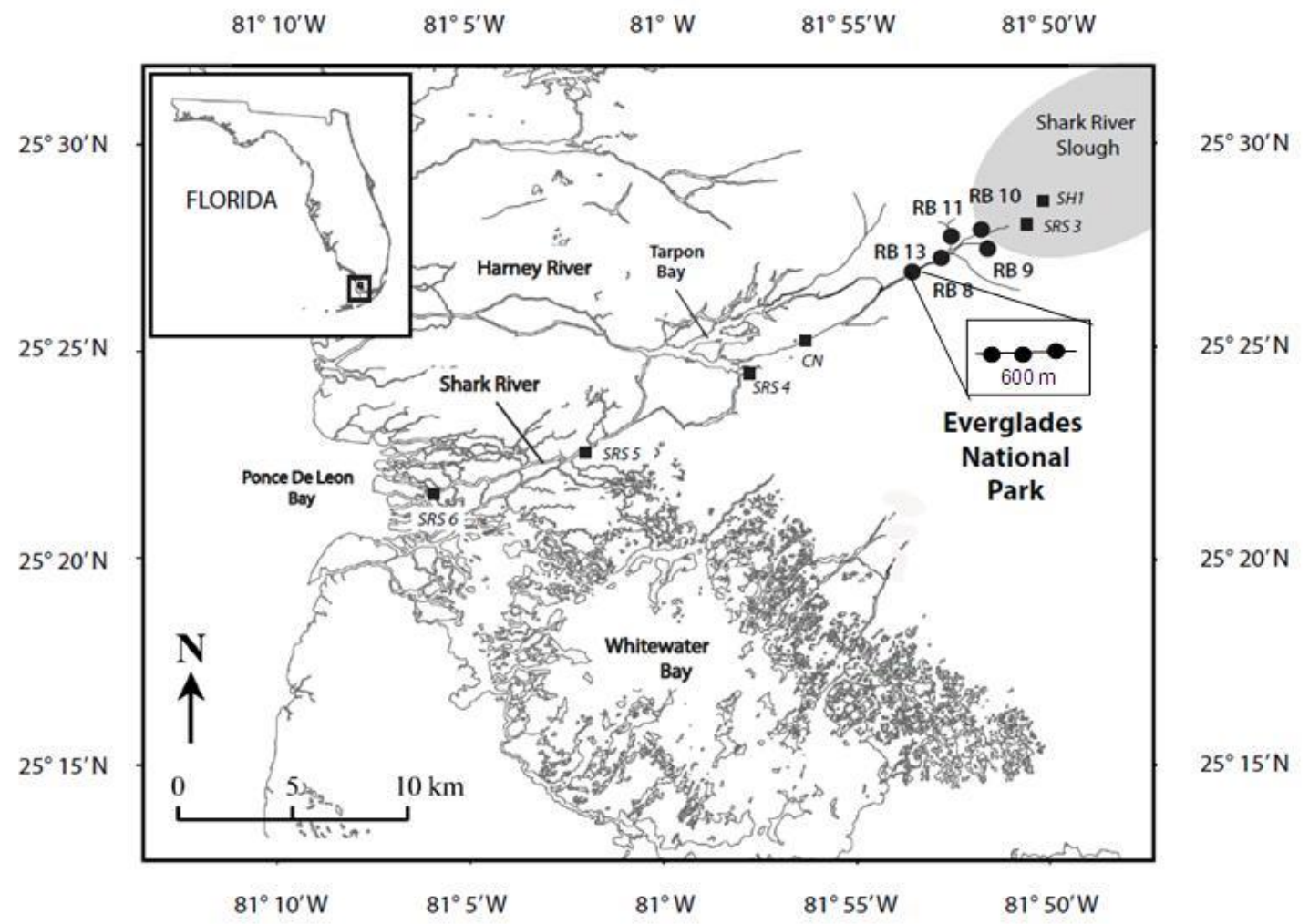


Figure 3.2. Daily floodplain stage at station SH1 (see map above) from November 2010 to September 2014 (black line), and the number of days floodplains remained dry per year (grey bars). The red line represents the water depths that floodplain habitats are effectively dry for centrarchid fishes $(10 \mathrm{~cm}$, Trexler et al. 2005).

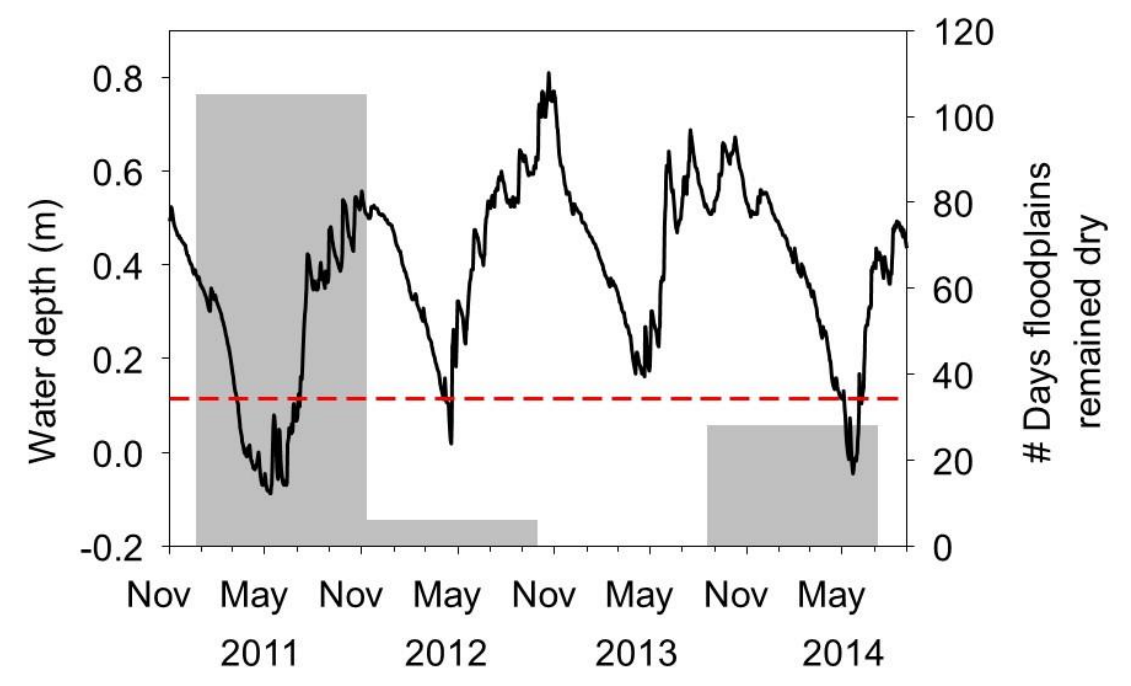


Figure 3.3 Mean kilograms of sunfishes per $100 \mathrm{~m}$ of river bank (upper panel, $\pm 1 \mathrm{SE}$ ), and the mean abundance of snook per $100 \mathrm{~m}$ (lower panel, \pm 1 SE) from 2010-2014.

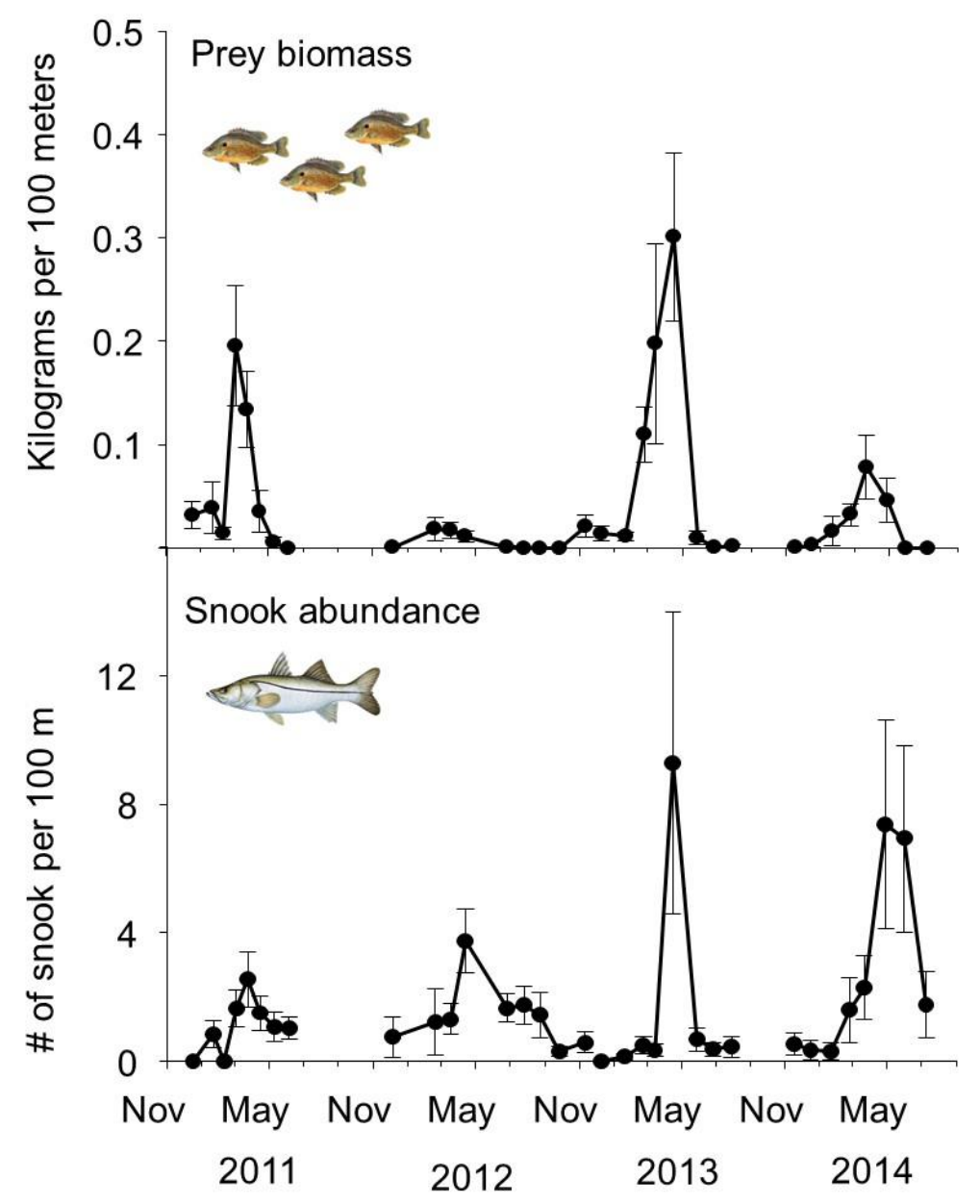


Figure 3.4 Mean biomass of all prey consumed by snook per $100 \mathrm{~m}$ of river bank (upper panel), macroinvertebrates (middle panel) and fishes $( \pm 1 \mathrm{SE})$. Note that scaling in the middle panel differs from the other panels.

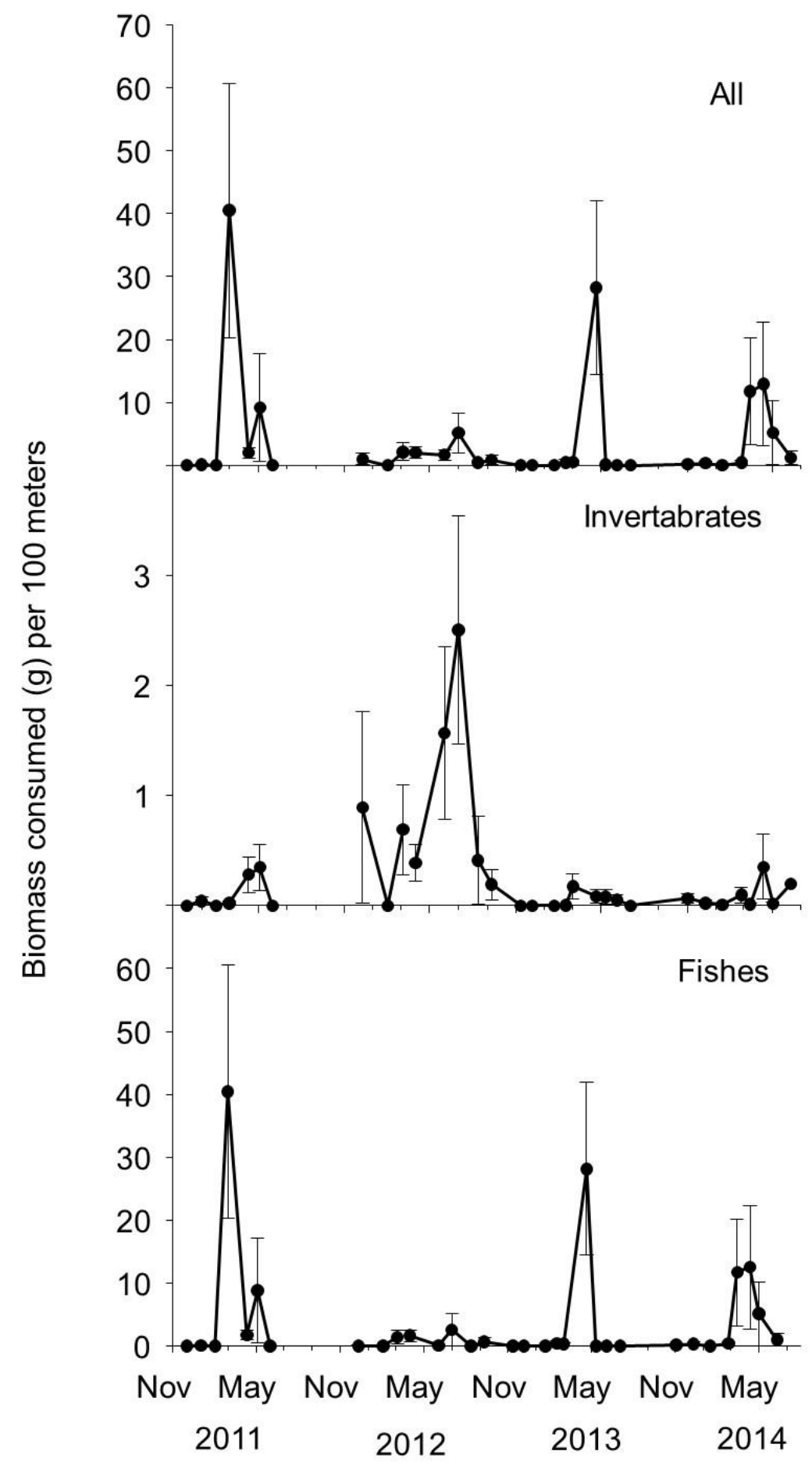


Figure 3.5 Mean caloric content of common fish (grey) and macroinvertebrates (white) species in the study region. Bars represent 1 standard error from the mean.

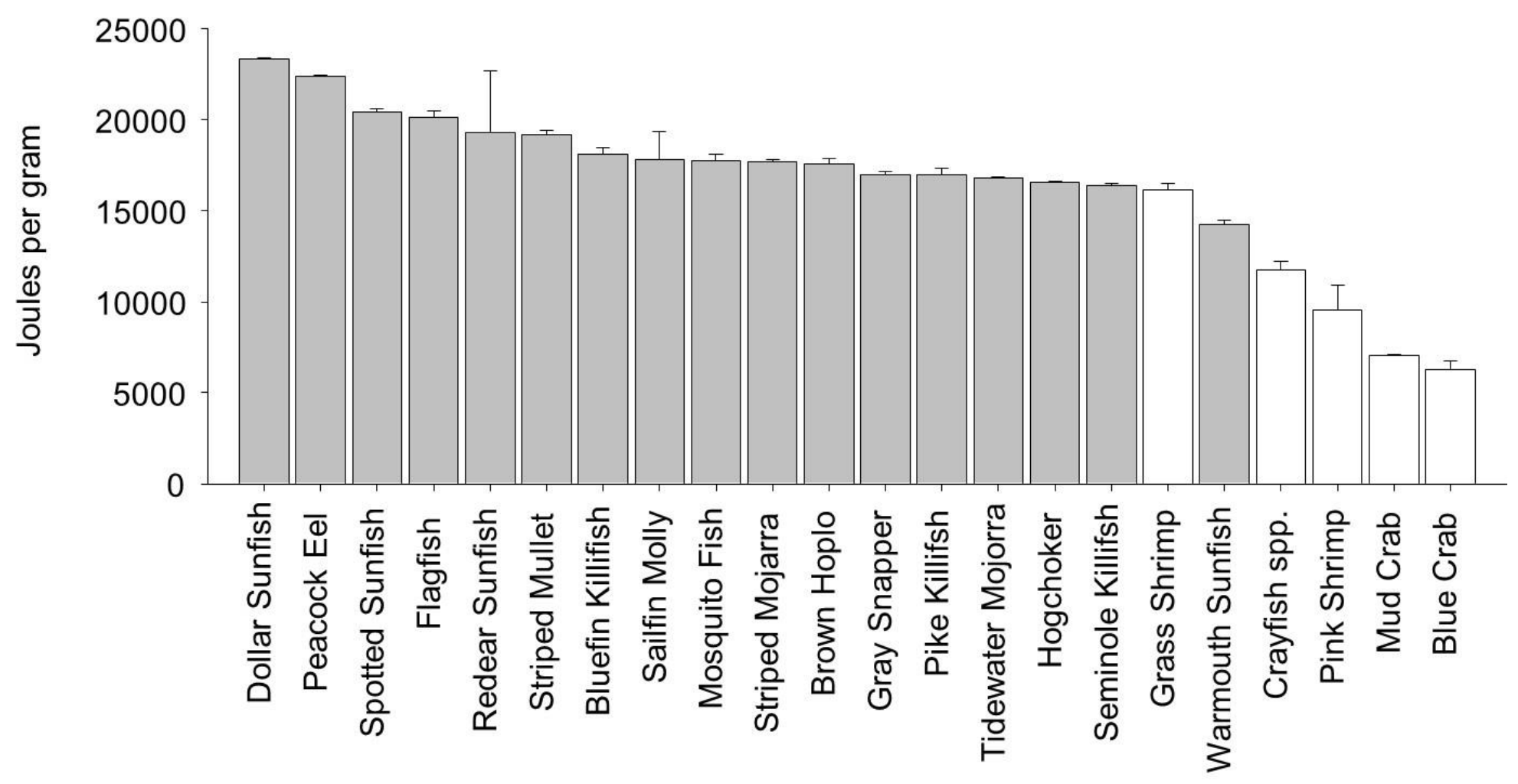




\section{CHAPTER IV}

CAN ANIMAL HABITAT USE PATTERNS INFLUENCE THEIR VOLNERABILITY TO EXTREME CLIMATE EVENTS? AN ESTUARINE SPORTFISH CASE STUDY 


\begin{abstract}
Global climate forecasts predict changes in the frequency and intensity of extreme climate events (ECEs). The capacity for specific habitat patches within a landscape to modulate stressors from extreme climate events, and animal distribution throughout habitat matrices during events could influence the degree of population change following the passage of ECEs. Here, I ask 1) does the intensity of stressors of an ECE vary across a landscape? And 2) Do habitat use patterns of a highly mobile species, potentially influence their vulnerability to ECEs? Our focal ECE are extreme cold spells, and our focal population consists of a tropical, estuarine-dependent large-bodied fish, (Centropomus undecimalis, Common Snook), occurring within Everglades National Park estuaries (FL US) which suffer catastrophic population losses following extreme cold spells. I examined temperature variation across space during cold disturbances with different degrees of severity, including an extreme cold spell occurring in January 2010. I quantified snook distribution patterns when the passage of extreme events are most likely to occur from 2012-2016 using passive acoustic tracking. Our results showed that spatial heterogeneity in the intensity of cold existed, with component habitats being $3-5{ }^{\circ} \mathrm{C}$ colder than others. Snook distribution during periods of greatest risk to experience an extreme cold event varied across years. In 2013-2014 and 2014-2015 winters, a greater proportion of snook occurred in the colder habitats. In contrast, during 2012-2013 and 2015-2016 winters, more snook were observed at the warmest habitats less likely to experience temperatures lethal to snook. This study shows that snook habitat use patterns could influence vulnerability to extreme cold events; however whether snook habitat use
\end{abstract}


increases or decrease their vulnerability to disturbance depends on the year, creating temporally dynamic vulnerability based on mechanisms that influence animal movement. Faunal global change research should address the spatially explicit nature of extreme climate events and animal habitat use patterns to identify potential mechanisms that may influence population effects following these disturbances.

\section{INTRODUCTION}

Forecasted changes in global climate predict changes in the frequency and intensity of ECEs (Dale et al. 2001; Smith 2011). ECEs can be defined as discrete weather events with climate drivers (wind speed, temperature, and precipitation) with both intensities and resultant ecosystem change that are well outside normal variability, and are statistically rare (Smith 2011). In contexts where ECEs increase in frequency or intensity, these climate disturbances will likely become a more apparent driver of ecosystem dynamics, potentially resulting in long-term and hysteretic ecological change (Jentsch et al. 2007; Smith 2011). Even in ecosystems where ECEs become less frequent or less intense, the absence of these disturbances can still have a pronounced effect on ecosystem structure. Extreme cold spells for instance, often control the poleward distribution of species (Osland et al. 2013; Kreyling et al. 2015; Osland et al. 2016). If these events decrease in frequency or intensity, then we may expect that species distributions will likely rapidly shift in accordance with that change (Osland et al. 2013; Osland et al. 2016). Given the gravity of any future changes to the ECE regime, we must develop more mechanistic understandings of how ECEs influence ecological processes, in order to predict the functioning of ecological systems in the future. 
Animal habitat use patterns, and their population distribution during the event could influence population losses and their recovery from ECEs. Animals should distribute themselves non-randomly in space and in time based of a suite of intrinsic and extrinsic drivers, thus creating dynamic spatiotemporal animal densities across habitats (Nathan et al. 2008). In conjunction with animal spatial-temporally dynamic habitat use patterns, previous research of disturbance shows that the intensity of stressors, the buffering capacity of habitat patches (i.e., ability to modulate the intensity of stressors), and the magnitude of ecological effects varies across space (White \& Jenstch 2001; Nimmo et al. 2015; Boucek et al. 2016a). Thus, by combining information on the spatial pattern of disturbance and on animal habitat use, we can potentially identify mechanisms responsible for faunal population change from ECEs. For example, if animal density is high in habitat patches that do not mitigate or even exacerbate the intensity of stressors from an extreme climate event, then following the event, population losses would be greater than predicted if individuals were uniformly distributed across all patches (Figure 4.1). Conversely, if animal density were higher in a habitat patch that modulates stressful conditions from disturbance, then population change would be less than predicted if the population was uniformly distributed in space (Figure 4.1). Thus, understanding the spatially explicit nature of ECEs, and spatio-temporal dynamics of animal habitat use could improve predictions of the degree of effects expected from ECEs.

In sub-tropical Florida, the passage of winter time cold events are a common phenomenon, but do not induce ecological changes. However, higher intensity cold events, and or cold spells (i.e. multiple consecutive cold events) that result in isolated effects to 
natural systems occur once every 10 years. And, importantly, extreme cold spells that cause catastrophic losses to natural resources, and non-linear ecosystem change occur once every 20-30 years (Boucek et al. 2016a). These extreme disturbances are abrupt, decreasing temperatures to lethal levels for vulnerable species within days, resulting in punctuated and mass mortality events that are highly visible to the public, and as a consequence, effects of these disturbances are well publicized. Of particular importance, these extreme cold spells drive population crashes of many of Florida's economically important tropical sportfishes, including bonefish, juvenile goliath groupers, and common snook (Santos et al. 2016). The effects of these disturbances on sportfishes result in substantial economic losses for those who rely on those resources (Boucek et al. 2016a; Stevens et al. 2016).

In 2010, the most severe cold spell to occur in the last 80 years affected sub-tropical Florida (Boucek and Rehage 2014). This ECE was particularly detrimental in the estuaries of Everglades National Park (F.L., U.S.), where water temperatures rapidly dropped to lethal levels for tropical species within 3 days, remained at lethal temperatures in some areas for 4 days, and kept temperatures at sub-lethal levels for 12 days. The spell was the third coldest and the longest spell on record (Boucek and Rehage 2014). The abundance of adult snook, the most sought after gamefish in the area, decreased by over $94 \%$ following the passage of this event (Santos et al. 2016; Stevens et al. 2016). The occurrence of this event in South Florida, coupled with comprehensive long-term biological and abiotic monitoring networks occurring in Everglades National Park, provide a model to study how animal habitat use patterns and subsequent population distributions can influence population vulnerability to these events. Using snook in Everglades Nation Park as our model, our research questions were: 
1) Does the degree of coldness during cold spells vary across habitats in the Everglades estuaries?

2) When are extreme cold events most likely to occur in South Florida?

3) Does snook habitat use patterns during the coldest winter windows (i.e. when extreme cold spells are most likely to occur), place their populations at lower or greater vulnerability to ECEs than what would be predicted in they were uniformly distributed throughout the system?

Snook are a good candidate species to assess how landscape patterns of disturbance and animal movement could influence vulnerability to disturbance for 3 reasons. 1) Snook are highly mobile, and use the entire estuary during the course of the year (Trotter et al. 2012; Barbieri et al. 2015). 2) Due to the economic importance of the fishery, general biology and ecology of the species are well understood (Muller and Taylor 2006), 3) population crashes from previous extreme cold spells are well studied, and previous research has anecdotally attributed their habitat use patterns and distribution during cold events to be a mechanism that regulates population effects and recovery (Stevens et al. 2016).

To answer these questions, I compared landscape differences in cold temperatures during a series of cold disturbances that affected the Everglades over the last 12 years, including the extreme event in 2010. To assess snook spatial temporal habitat use patterns, I tracked the movements of 79 snook throughout the estuary using acoustic telemetry from 2012-2016. Our research approach follows the flow chart in Figure 4.2. I hypothesized that downstream coastal habitats that mix with the Gulf of Mexico, which, 
due to the size of the water body, would take longer to cool and stay warmer during cold disturbances. In contrast, upstream habitats fed by to vast expanses of shallow freshwater marshes that cools rather quickly, would be colder during cold events. Second, I hypothesize that a greater proportion of snook would occur in upstream habitats when cold spells are most frequently occurring, due to the coincidental occurrence of a prey subsidy available within that habitat around that window in time (Boucek and Rehage 2014; Boucek et al. 2016b).

\section{MATERIALS AND METHODS}

Study system: Shark River estuary in the Everglades National Park

This study took place in the Shark River of the Everglades National Park FL, U.S. (Figure 4.3). South Florida and the Everglades National Park are within a subtropical climate zone, experiencing a pronounced hydrologic seasonality, with $80 \%$ of annual rainfall occurring in the summer and fall (July - November; Price et al. 2008). Within the estuarine habitats of the greater Everglades, freshwater inputs function as one of the major drivers of ecological processes, affecting spatial patterns in productivities, biogeochemical processes, community structuring, animal movements, and possibly water temperatures (Childers 2006; Rosenblatt \& Heithaus 2011, Boucek and Rehage 2013). In this estuary, oligotrophic freshwater inputs create an upstream-downstream gradient of productivity, with phosphorus limited conditions upstream and more productive conditions downstream, fueled by marine derived phosphorous subsidies (Childers 2006). Though the upstream environment is generally the least productive, due to its connectivity to upstream floodplains, this region receives a seasonal pulse of prey in 
the winter and spring that many piscivores including snook migrate upstream to consume (Boucek and Rehage 2013; Boucek et al. 2016b). I can partition the focal study system, the Shark River, into three ecologically distinct zones that snook may utilize at different times of the year. Not only are these zones ecologically distinct, but the zones may vary in their capacity to mitigate extreme cold temperatures. The three zones are the freshwater upstream zone, mesohaline bay zone, and the more marine coastal zone (Matich et al. 2016; Figure 4.3). Previous research has shown that in the winter, snook move upriver to freshwater and oligohaline areas to capitalize on highly abundant freshwater prey flushing off of upstream floodplains, then migrate to the coastal zone in the spring and summer to spawn (Taylor et al. 1998; Blewett and Stevens 2013; Boucek \& Rehage 2013, Boucek et al. 2016b).

Temperature Analysis: Assessing cross-habitat differences during cold spells

To assess whether habitat differences in water temperatures during cold events exist, and if those habitat differences were consistent across multiple cold disturbances, I used two approaches. I first used a long-term, albeit coarse spatial resolution approach, to capture temperature variation across the three zones during every cold disturbance that affected the region from 2003-2012 (window based off of data availability, \# of cold disturbances $=22$ ). Second, I examined temperature changes at higher spatial resolutions (3-7 sensors per zone, 19 sensors total), during the extreme 2010 spell, one moderate event (January 2008) and another moderate spell (December 2010) that resulted in negative effects on tropical species (Rehage et al. 2016; Zhang et al. 2016).

For the long-term, low spatial resolution approach, I compared both the absolute lowest daily minimum water temperature $\left(\mathrm{T}_{\mathrm{min}}\right)$, and the absolute lowest daily average 
water temperature recorded during a cold event $\left(\mathrm{T}_{\mathrm{ave}}\right)$, within each of the three ecological zones across 22 cold events that occurred from 2003-2012. Water temperature observations used here were from bottle creek (upstream), SH2 (Bay) and Gunboat Island (coastal) hydrostations (http://sofia.usgs.gov/; Figure 4.3). I identified these 22 events as cold disturbances using long term (1927-2012) minimum daily air temperature observations from Everglades City (FL; approximately $66 \mathrm{KM}$ from focal study sites). I defined a cold event as single or consecutive days when the minimum daily air temperature dropped to or below two standard deviations from the mean minimum daily winter temperature of the entire 85-year time series (See Boucek and Rehage 2014 for a more detailed description). From these 22 events, $I$ then identified $\mathrm{T}_{\min }$ and $\mathrm{T}_{\mathrm{ave}}$ at each monitoring station during each event. To determine if landscape differences in the degree of coldness existed, I calculated the habitat paired differences in both $\mathrm{T}_{\min }$ and $\mathrm{T}_{\text {ave }}$ (i.e., Bay vs Upstream, Bay vs Coastal, etc) during each of the 22 events. I then calculated the average paired difference of $\mathrm{T}_{\min }$ and $\mathrm{T}_{\text {ave }}$ for each habitat pairing (i.e. upstream versus bay) and used those for comparisons.

I acknowledge that temperature observations can vary depending on location of sensors in relation to water depth, and fine scale landscape contexts such as exposure to winds (Blewett and Stevens 2014). Thus, as a supplement to our longer-term analysis, and to potentially account for finer scale spatial patterns in temperatures, I conducted a higher spatial resolution analysis of water temperatures. These disturbances occurred in January of 2008, January 2010 (ECE), and December 2010, and all resulted in some negative impact to tropical species (Rehage et al. 2016; Blewett and Stevens 2014; Zhang et al. 2016). Though these events incurred ecological change, they differed in both their 
intensity (degree of coldness) and duration (number of days temperatures remained at stressful levels for tropical species). For instance, the 2008 event drove minimum daily air temperatures at the Everglades City to $-1.7^{\circ} \mathrm{C}$, however, those temperatures only remained at levels stressful for tropical species for 1 night. The January 2010 spell, drove air temperatures to a minimum of $-3.3{ }^{\circ} \mathrm{C}$, and kept temperatures at stressful levels for over 12 days. In contrast, the December 2010 spell reached a minimum of $1{ }^{\circ} \mathrm{C}$, leaving temperatures at stressful levels for 4 days.

For this higher spatial resolution analysis, I only used $\mathrm{T}_{\text {ave }}$ (based off of availability) from a total of sixteen $\mathrm{HOBO}$ temperature loggers that were active for at least one of the 3 focal events, provided through the Florida Coastal Everglades Long Term Ecological Research Network (http://fce.lternet.edu/data). Most temperature loggers were attached to VR2W acoustic monitoring station housings in the focal system (Figure 4.3). I also incorporated the three USGS data loggers from long term analysis, thus totaling 19 temperature stations that were available for at least 1 of the three events. From these temperature stations, I identified $\mathrm{T}_{\text {ave }}$ at each station during each of the three focal severe cold events.

Our goal was to assess whether 1) zone specific differences in temperature existed, and 2) if those spatial differences were consistent across the three events. Prior to analyses I first applied a standardization to each station to account for differences in the overall magnitude and degree of coldness across disturbances. For my standardization, I first calculated the mean $T_{\text {ave }}$ across all active stations during each event. I then calculated the difference between $\mathrm{T}_{\text {ave }}$ at each station and the mean $\mathrm{T}_{\text {ave }}$ across all stations for that event, providing us with a standardized temperature change at each station that I could 
now compare. Last, I calculated the mean standardized $\mathrm{T}_{\text {ave, }}$, for all stations occurring within each zone, and used those averages for comparisons.

\section{Identifying risk in time to experience an extreme cold event or spell}

Following the flow chart, I identified when cold spells and events were most frequent, and when extreme events occurred over the last 80 years. This analysis provides a temporal window when snook are most vulnerable to cold disturbances. I identified the calendar day that every cold disturbance between 1927-2012 began (first day the disturbance decreased minimum daily air temperatures $<2$ SD of the winter time average). Once events were identified from the temperature time series, I calculated the number of calendar days before or after January $1^{\text {st }}$ that each cold event began, and built a frequency distribution from those values. I also identified the days before or after January first that extreme cold events over the last 80 years occurred. I considered the temporal window in which the focal system is most likely to be affected by a cold event or spell as the range of calendar days that are within one standard deviation from the mean day of the year in which cold spells and events occur. I validated this window by identifying if the extreme events fell within this timeframe.

\section{Tracking snook habitat use patterns during temporal windows of highest risk of extreme} cold

I tracked the movements of individual fish using acoustic telemetry. With acoustic telemetry, researchers fit transmitters to individuals, and once a transmitter is deployed, the transmitter sends ultrasonic sound pulses that can be interpreted by specialized listening acoustic receivers (Hussey et al. 2015). To track habitat use patterns of snook, I 
used the Florida Coastal Everglades Long Term Ecological Research acoustic telemetry array in place in the Shark River (Figure 4.3, Matich et al. 2011; Rosenblatt and Heithaus 2011). The array consists of 37 autonomous VR2W listening receivers, spaced approximately $1 \mathrm{KM}$ apart, extending from the upper reaches of the Shark River down to the coastal regions of the Shark and Harney River systems (Figure 4.3). If a tagged snook passes a listening station, the autonomous device records the tag ID, along with a date and time stamp. Snook were captured using a boat-mounted, generator-powered electrofisher (two-anode, one cathode Smith-Root 9.0 unit; Boucek et al. 2016b). Electrofishing effort was roughly split between the bay zone and the upstream zone. Upon capture, snook were measured, weighed, and internally marked with a Passive Integrated Transponder (PIT) tag to identify recaptures.

To quantify habitat use patterns, 79 snook caught in good condition (based on swimming performance and visual inspection) from February 2012 to April 2015 were anesthetized in an ambient water and Alka-Seltzer solution (1 to 1.5 tablets per four liters of water) prior to surgery. Once a fish was anesthetized, a $30 \mathrm{~mm}$ incision was cut in the lower abdomen of each snook, and each individual was surgically fitted with either a Vemco V16 or V13 transmitter (interpulse delay, 120 seconds) and wounds were closed with 1-3 stitches (Adams et al. 2009). Approximately seventy percent of tags were deployed in the spring and 30\% in the fall. Body length of tagged fish ranged from 45-86 cm standard length.

Using these detections by acoustic receivers, I calculated the daily proportion of tracked snook that occupied each of the three habitat zones, from May 2012 to May 2016. 
Since tagging effort varied across habitats, I standardized these daily proportions by habitat type using the equation below.

standardized daily proportion $_{i}=\frac{\left(\text { Daily proportion }_{i}-\text { Average daily proportion }_{i}\right)}{\text { Average daily proportion }_{i}}$

Where the standardized daily proportion of snook within the ith habitat is a function of the difference between daily observed proportion in habitat $i$ and the average daily proportion for that habitat during the entire time series, divided by the daily proportion for that habitat during the entire time series. Standardized daily proportions within each zone were then smoothed prior to analysis using an 11 day running average. The 11 day binning was chosen based on previous estuarine fish habitat use studies that showed the 11 day temporal window as effective measure to reduce auto-correlation between observations with a minimal loss of information (Walsh et al. 2013).

Using the results from the previous sections, I assessed the potential for snook habitat use patterns to contribute to their population vulnerability to extreme cold events. I calculated the mean standardized 11 day average proportion of snook per year occurring within each habitat zone during the windows in time when cold spells are most frequent and used these averages were used for comparisons.

\section{Statistical analyses}

For each average I derived for temperature and movement data, I calculated the $95 \%$ confidence interval around those means. Confidence intervals were built from a bootstrapped distribution using 1,000 simulations (Program R, mosaic package). For statistical comparisons, I determined if effects existed depending on if these $95 \%$ confidence intervals overlapped with zero or the confidence intervals of other treatments. 


\section{RESULTS}

Habitat specific temperature differences during cold spells

Over the 11 years and 22 cold events, I found consistent differences in $\mathrm{T}_{\min }$ and $\mathrm{T}_{\text {ave }}$ experienced across habitat types during a cold event. As expected, I found that in the coastal zone $\mathrm{T}_{\min }$ and $\mathrm{T}_{\text {ave }}$ daily temperatures stayed on average 4.5 and $2.8^{\circ} \mathrm{C}$ warmer than the upstream zone, and 4.8 and $3.2{ }^{\circ} \mathrm{C}$ warmer than the bay habitat (Figure 4.4). The mean habitat differences in temperatures were similar for $\mathrm{T}_{\min }$ and $\mathrm{T}_{\text {ave, }}$, for upstream versus bay comparisons, and bay versus coastal comparisons, indicating that patterns in minimum daily temperatures and average temperatures track each other between those zones. In contrast, for upstream versus coastal comparisons, differences in $\mathrm{T}_{\text {ave }}$ and $\mathrm{T}_{\min }$ existed, with average differences in $\mathrm{T}_{\min }$ between those zones being $1.7^{\circ} \mathrm{C}$ colder than $\mathrm{T}_{\mathrm{ave}}$, indicating a greater separation in the degree of coldness for minimums than average temperatures.

The fine scale spatial analysis during the three disturbances (e.g., January 2008, January 2010, December 2010) showed variation in their degree of coldness both within and between the habitat zones. For instance, the 2008 event decreased average daily temperatures to a minimum of $12.8^{\circ} \mathrm{C}$ in the upstream zone, $17.9{ }^{\circ} \mathrm{C}$ in the bay and 16.9 ${ }^{\circ} \mathrm{C}$ at the coastal station (Figure 4.5a). The January 2010 spell average daily temperatures reached below the $10{ }^{\circ} \mathrm{C}$ lethal limit of snook in the upstream zone $\left(\mathrm{T}_{\mathrm{ave}}=8.3{ }^{\circ} \mathrm{C}\right)$ and in bay zone $\left(\mathrm{T}_{\mathrm{ave}},=9.9^{\circ} \mathrm{C}\right)$, while remaining above the lethal limit in coastal zone $\left(\mathrm{T}_{\mathrm{ave}}, 11.9\right.$ $\left.{ }^{\circ} \mathrm{C}\right)$. Importantly, average daily temperature in the upstream zone stayed at or below the lethal limit for 4 days during the January 2010 event (Figure 4.5b). The December 2010 spell created one day of average temperatures at the lethal limit for snook in the upstream 
zone $\left(\mathrm{T}_{\mathrm{ave}}, 10.5^{\circ} \mathrm{C}\right), 2$ days below the lethal limit in the bay zone $\left(\mathrm{T}_{\mathrm{ave}}, 9.5^{\circ} \mathrm{C}\right)$, and temperatures well above the snook lethal limit in the coastal zone $\left(\mathrm{T}_{\mathrm{ave}}, 14.3{ }^{\circ} \mathrm{C}\right.$; Figure $4.5 \mathrm{c})$.

When examining the finer scale examining spatial patterns in coldness across the specific disturbances, I found variation in $\mathrm{T}_{\text {ave }}$ across stations (Figure $4.5 \mathrm{~d}, \mathrm{e}, \mathrm{f}$ ). Consistently across all three disturbances, $\mathrm{T}_{\mathrm{ave}}$ at the two upstream most stations remained 2 to $4{ }^{\circ} \mathrm{C}$ cooler than the mean $\mathrm{T}_{\text {ave. }}$. In contrast, the coastal stations' $\mathrm{T}_{\text {ave }}$ did not decrease below the average during any event, with most coastal stations $\mathrm{T}_{\text {ave }}$ being $1-2{ }^{\circ} \mathrm{C}$ warmer than the average. The bay zone stations seemed to vary more across events, and showed the most within zone variation. For instance, during the 2008 event, all bay stations were near, or above average, however during the extreme January 2010 spell, and December 2010 spell, bay stations recorded $\mathrm{T}_{\text {ave }}$ that were both above and below the all station averages.

Our finer scale analysis for two of the three disturbances (January 2010 \& December 2010), showed that during cold spells, the coastal habitat stays warmer than the upstream habitat (Figure $4.5 \mathrm{~g}, \mathrm{~h}, \mathrm{i}$ ). For instance, during the extreme January 2010 spell, mean $\mathrm{T}_{\text {ave }}$ for the upstream habitat was $3.3^{\circ} \mathrm{C}$ colder than the coastal habitat. Likewise, during the December 2010 spell, the upstream habitat remained $4.0^{\circ} \mathrm{C}$ colder than the coastal habitat.

Habitat use analysis: Identifying temporal windows when cold disturbances are most likely to occur

Boucek and Rehage (2014) identified 319 cold disturbances from 1927 to 2012. Cold disturbances identified in that analysis were most likely to occur from December 
$23^{\text {rd }}$ to Feburary $17^{\text {th. }}$ The average day of the year that a cold event began was January $20^{\text {th }}$, with a standard deviation of 29 days (Figure 4.6). In agreement with our distribution, all of the extreme events over the last 90 years identified by Boucek and Rehage (2014) fell within this \pm 1SD window. These other extreme cold spells started on January $25^{\text {th }}, 1940$ and January $11^{\text {th }}, 1981$, with the 1940 spell being more severe than the 1981 spell, but less severe than the 2010 spell.

Snook habitat use patterns when cold events are most frequent

The average number of days I detected a snook out of the 79 tagged was 344 days (+- 33 days SE, range $=15-912$ days). On average, I tracked 26 snook per day $(+-1$ snook SE, range $=18-35)$. Over the entire time series, snook habitat use and distribution patterns showed both inter- and intra-annual variation (Figure 4.7). As expected from previous work, in the upstream and bay zone, snook distribution showed seasonal temporal patterns, increasing in the winter and spring and decreasing in the summer and fall. In contrast, the proportion of snook in the coastal areas showed more interannaual variation, with the years of 2012 and 2016 having generally higher numbers of snook at the coastal areas. During the windows in time of highest risk (December $23^{\text {rd }}$ to February $17^{\text {th }}$ ), I found that the distribution of snook varied across years (Figure 4.8). During the winter of 2013-2014 and 2014-2015, more snook occupied the upstream zone whereas during 2015-2016, more snook occupied the coastal zone during the temporal window of highest risk.

\section{DISCUSSION}

Forecast changes in global climate predict changes to extreme climate disturbance regimes. Spatially explicit approaches that both quantify landscape variation in 
disturbance intensity and spatial-temporal habitat use patterns of mobile individuals could help identify mechanisms that influence population change from ECEs. Our results showed that during cold spells, temperature differences across the estuary existed (by up to $4-5^{\circ} \mathrm{C}$ ), with the upstream habitats being the coldest and the coastal being the warmest. I also found that snook distribution throughout the estuary during windows when cold disturbances are most frequent (December $23^{\text {rd }}$-February $17^{\text {th }}$ ) varies across years, potentially creating temporally dynamic scenarios of risk. If a severe or extreme cold event spell were to occur in 2013-2014, when a greater proportion of snook were upstream, I postulate that the disturbance would result in greater snook mortality than an event occurring in 2015-16 when fewer fish were upstream. Future work should focus on identifying drivers that influence interannual variation in snook habitat use, and as such, those drivers could be used to improve predictions of population change from extreme cold spells and ultimately management actions. At the more general scale, our results highlight the importance of considering both spatial patterns of disturbance and animal habitat use when developing mechanistic models to predict population level effects from extreme climate events at least for mobile species.

I was not surprised to find habitat-specific differences in cold temperatures across the cold events. In the sub-tropics and across a suite of ecosystem types, the degree of coldness experienced by habitat patches from extreme cold spells varies depending on landscape contexts (Reviewed in Boucek et al. 2016a). For instance, in coastal aquatic systems of South Florida, coral community resistance was largely a function of their distance to warm water ocean currents. Coral patches occurring in shallow waters away from tropical ocean currents experienced almost complete loss of habitat-forming hard 
corals, while reefs occurring in deeper waters adjacent to ocean currents experienced minimal change (Kemp et al. 2016). In the Shark River estuary, the upstreamdownstream gradient in absolute low temperatures during these events was likely a function of the hydrology of the estuary. First, freshwater flowing into the upstream habitat prior to reaching the estuary travels across a shallow expansive floodplain (McVoy et al. 2011). Water on these shallow, exposed floodplains during cold nights rapidly cools before it enters the estuary, creating a colder environment in the upstream zone. Similar thermal gradients occurred in other Florida rivers, where water temperatures far inland were colder than the lower river (Blewett and Stevens 2014). At the downstream coastal zone, extreme low temperatures are buffered to some degree by tidal mixing from the Gulf of Mexico, that takes longer to cool, and possibly groundwater seepage in the deeper sections of the rivers (Saha et al. 2011). Last, in the bay zone, temperatures recorded across sensors were more variable during cold events. This between sensor variability was likely a function of finer scale spatial processes such as exposure to wind and U.V., that would have more of an effect in that open water environment relative to the other riverine habitats.

Spatial variation in disturbance intensity of are not specific to cold events (White and Jentsch 2001). For instance, during tropical cyclones that affect Caribbean islands, the dimensions and intensity of stress imposed on ecological systems vary considerably in space, depending on ecosystem distance to the coast, whether the system occurs on a windward or leeward side of the island, and their proximity and orientation to geologic features such as mountains that may block winds (Borkaw and Gutreuter 2012). Heatwaves also show spatial patterning; for instance, the extreme heatwave that affected 
most of Europe in 2003 showed that mortalities of rocky benthic macro-invertebrate species varied across a gradient in space, with populations occurring in deeper waters showing lesser change, while populations in shallow waters decreased by $80 \%$ (Garrabou et al. 2009). Similar relationships between habitat patch depth and survival of stream fish have been observed following extreme drought (White et al. 2016). To conclude, spatial variation in the intensity and dimensions of stressors caused by ECEs is likely a consistent property across most, if not all, extreme climate events and should be considered in conceptual models.

An important generalization of ECEs is that the events are rare enough to not promote local adaptions and propagation of phenotypes that would be more resistant to those disturbances (Smith 2011, Lytle and Poff 2004). Tropical species in Everglades National Park and in the sub-tropics, both are unable to physiologically tolerate extreme cold temperatures (thermal specialists Tweksbery 2010), and utilize behaviors that hinder their survival during extreme cold spells (Boucek et al. 2016a). For instance, tropical American Crocodiles show maladaptive behaviors during extreme cold spells compared to more temperate American Alligators (Mazzotti et al. 2016). During these events, American Crocodiles will attempt to bask out of the water to warm themselves, despite that basking in the cold windy days during events have deleterious cooling effects. In contrast, American Alligators, adapted to coping with cold, will actively seek warm water refugia during these events (Mazzotti et al. 2016). Like American Crocodiles, snook exhibit somewhat mal-adaptive movement behaviors with respect to risk from cold disturbances. Stevens et al. (2016) showed that in other estuaries on the east coast of Florida, during the extreme cold spell in 2010, most snook did not make broad- 
scale movements from their position at the time of the cold spell to the suitable refugia for extreme cold spells. Instead, snook likely made shorter movements to habitats that would function as appropriate refuge during less severe but more frequent cold disturbances. In contrast to the limited movement behaviors of snook during the 2010 event, and similar to more temperate alligators, sub-tropical bullsharks that were tracked in the Everglades estuary during the 2010 extreme cold event, underwent whole population movements, leaving the bay habitat and migrating to the warmer coastal habitat (Matich and Heithaus 2012). Thus, during extreme cold spells in the Everglades, snook likely do not actively migrate to the most appropriate refuge habitat, but instead move to the closest habitat they perceive to be a refuge, which is possibly an ineffective strategy unless those individuals are already in the coastal environment.

A trait of extreme cold spells, relative to other types of ECEs, that may emphasize the interaction between animal habitat use and the spatially explicit dimensions of stress from ECEs, are the abrupt nature of extreme cold spells. For instance, during extreme cold spells, air and water temperatures decrease to stressful and lethal levels of tropical estuarine species within one to three days (Boucek et al. 2016a). In comparison, droughts and heatwaves can take weeks or months to reach stressful and lethal levels (Peters et al. 2012). Under more gradual ECEs, animals may have the time to explore and relocate to refugia, exemplified by the hyper abundance of faunal species at or near remaining water sources during drought (Wato et al. 2016). I speculate with pulsed disturbances such as extreme cold spells, individuals likely do not have the time to find refugia prior to the onset of lethal stressors, resulting in a more static distribution during the event than you would expect for more gradual disturbances such as drought . Further, for ectothermic 
species like snook, as temperature begins to decrease at the onset of cold disturbances, animal metabolism will decrease, and as a consequence, mobility and activity of fishes is reduced (Portner and Kunst 2007). This physiological constraint on activity imposed by temperature, will act as another impediment for individuals to seek out distant refuge habitats, and further function to freeze population distributions during events.

I hypothesize that two drivers influence the habitat use of snook within the coastal and upstream habitats: 1) annual variation in freshwater flow, and 2) spawning and lifehistory patterns. In the Everglades, freshwater flows decrease to the lowest levels during March or April, drying floodplains that crown the upstream habitat, forcing an abundance of prey there (Boucek and Rehage 2013; Boucek et al. 2016b). Around the same time, snook catch per unit effort (CPUE) in upstream electrofishing samples triples (Boucek et al. 2016b) as the snook move upstream from the coast and bays to capitalize on the increased prey densities (movement upstream is also apparent from telemetry, this study). However, the timing of decreasing flows and this prey subsidy varies somewhat across years (Boucek et al. 2016b), potentially causing snook to migrate to the upstream environment earlier or later in the year, affecting their vulnerability to extreme cold. The interaction between freshwater inputs and snook vulnerability to extreme cold events is exemplified in another Florida estuary. Snook in the Charlotte Harbor estuary (FL), were one of the most resilient populations following the 2010 spell. Like the Everglades, Charlotte Harbor experiences cross-habitat differences in low temperatures during cold spells (Blewett and Stevens 2014). The warmest habitats during a cold disturbance there are in the lower river, where deep bends and canal systems are thought to moderate water temperatures. The proportion of the snook population that is present in the lower rivers 
during winter varies by year, and is strongly correlated with mean annual freshwater inflow (Blewett et al. 2016). The 2010 cold event occurred during a wet year, and so snook use of deep, wind-protected river habitat was maximized. If the cold event had occurred a year later (a dry year), there would have been half as many snook in the rivers. Snook typically move upstream during the latter half of the winter cold period or just after. Thus, an early snook migration to upstream habitats puts snook at greater risk of mortality. Such early migrations could occur with greater frequency if overall conditions in the Everglades become drier and with sea level rise, which is expected under climate change scenarios and without restoration (Obeysekera et al. 2011). Both sea-level rise and predicted decreases in precipitation could be offset to a degree by Everglades restoration actions.

Another possible mechanism that could explain interannual variation in habitat use observed during the cold spell months are snook spawning and life-history patterns. Snook are iteroperous marine-obligate batch-spawners that spawn in coastal habitats between April and November (Trotter et al. 2012). Like many iteroperous species, snook exhibit skip spawning, where a segment of the sexually mature population does not reproduce in a given season (Trotter et al. 2012). For snook, skip-spawning fish will remain in upstream freshwater and brackish water environments throughout the spawning season. During 2012 and 2015, spawning effort seemed to be high and the number of skip spawning fish was relatively low (Boucek unpublished data), which may explain the increased proportion of snook that were observed in coastal habitats in the subsequent winters (2012-2013 and 2015-2016) of this study. Alternatively, greater use of coastal habitats may have been influenced by other drivers including storm events (a tropical 
storm in 2012) or growth of tagged fish into larger sizes that use habitat differently than when they were smaller (last year of the study 2015-2016). Regardless, a variety of life history traits and environmental cues may influence the distribution of snook across the landscape, which in turn affects resistance to disturbances such as cold events. Snook vulnerability to other disturbances is not considered here (e.g., red tide, hurricanes), but are likely predicated on the distribution of snook across the landscape at a given time. Unraveling the factors that contribute to differential use of habitat between seasons and years can lead to predictive models that incorporate scenarios of climate change, anthropogenic stress, and restoration.

To conclude, the evolution of ECE research must progress from documenting effects of these disturbances, to identifying mechanisms that drive observed ecological change. By identifying these mechanisms that cause ecological change from ECEs, we will improve our capacity to, at the least, predict and adapt to that ecological change. And, more optimistically, manage ecosystems in ways that improves resistance and resilience. For snook, resource managers should continue to develop risk assessments for extreme cold spells in Florida, incorporating animal movement and landscape contexts into conceptual models. Incorporating these processes could potentially optimize management interventions aimed at protecting both the species and angler fishing rights. Beyond snook, research focusing on animal population change and disturbance should aim to incorporate space into their conceptual models and study design. As animal movement tracking technologies become more sophisticated, affordable, and pervasive across many systems and species, spatially explicit models will only improve. These 
models will likely not only improve stock assessment and fisheries management but conservation management strategies in the future, and our resilience to global change. 


\section{FIGURES}

Figure 4.1 Conceptualization of the interaction between animal habitat use and spatially explicit nature of ECEs. Consider a population that moves freely between habitat patches (shaded shapes) that differ in their capacity to mitigate stressors from ECEs, represented by the color of the shape. In the high vulnerability scenario, animal density is high in habitats that cannot modulate stressors from the disturbance (blue circle), and population losses are high. In the low vulnerability scenario, population densities are higher in a habitat that mitigates stressors of climate disturbance (green symbol), and population losses are lessened.

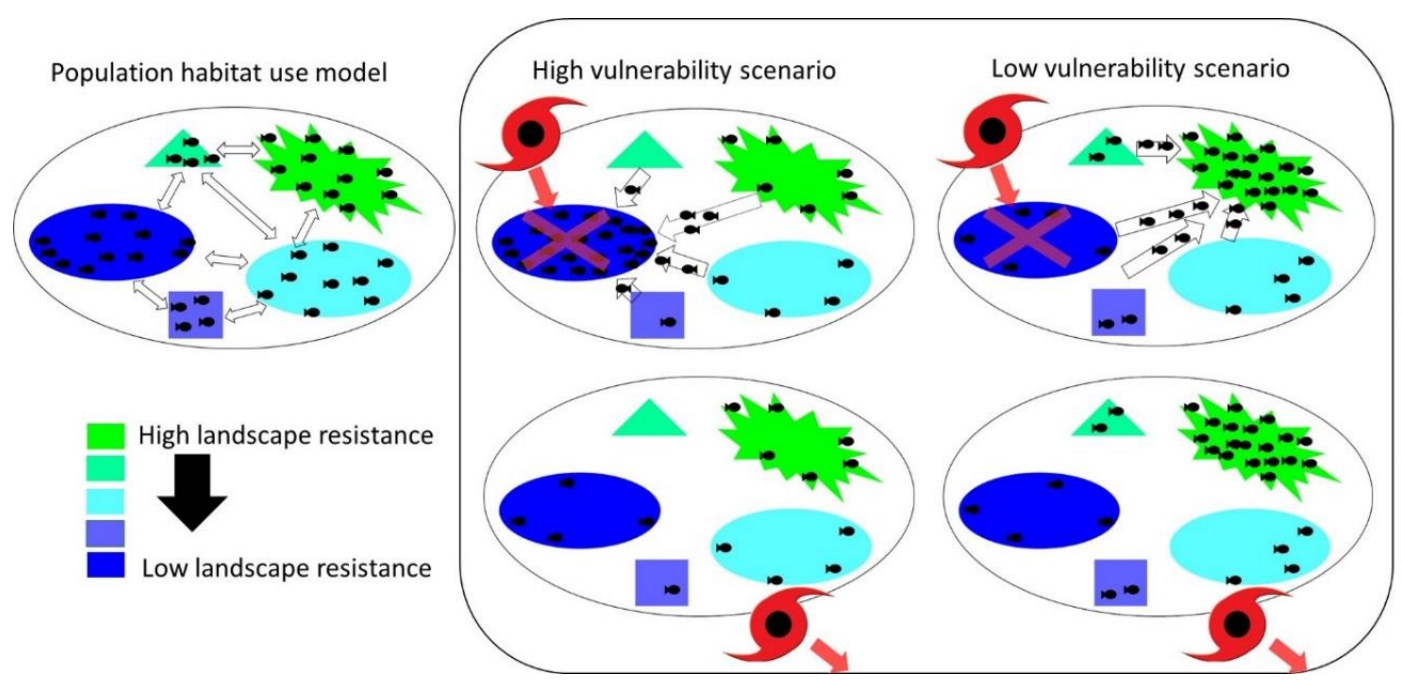


Figure 4.2 Flow diagram of our research approach

\begin{tabular}{|c|c|c|c|}
\hline $\begin{array}{l}\text { Is cold intensity } \\
\text { heterogeneous in } \\
\text { space? }\end{array}$ & $\begin{array}{l}\text { When are extreme } \\
\text { cold events most } \\
\text { likely to occur? }\end{array}$ & $\begin{array}{l}\text { How are snook } \\
\text { distributed throughout } \\
\text { the estuary when ECES } \\
\text { are most likely to occur? }\end{array}$ & $\begin{array}{l}\text { Does the landscape of cold } \\
\text { and snook distribution } \\
\text { patterns affect their } \\
\text { vulnerability to ECEs? }\end{array}$ \\
\hline
\end{tabular}


Figure 4.3 Map of study system, polygons represent habitat zones, consisting of the downstream coastal zone (black dashed line), meso-haline bay habitat (grey dashed line), and the upstream habitat (solid black line). Black dots represent passive acoustic monitoring stations used to track snook movements. Red dots and red halos on acoustic monitoring stations represents temperature loggers that were active for a least a portion of the study, and grey squares represent USGS temperature loggers.

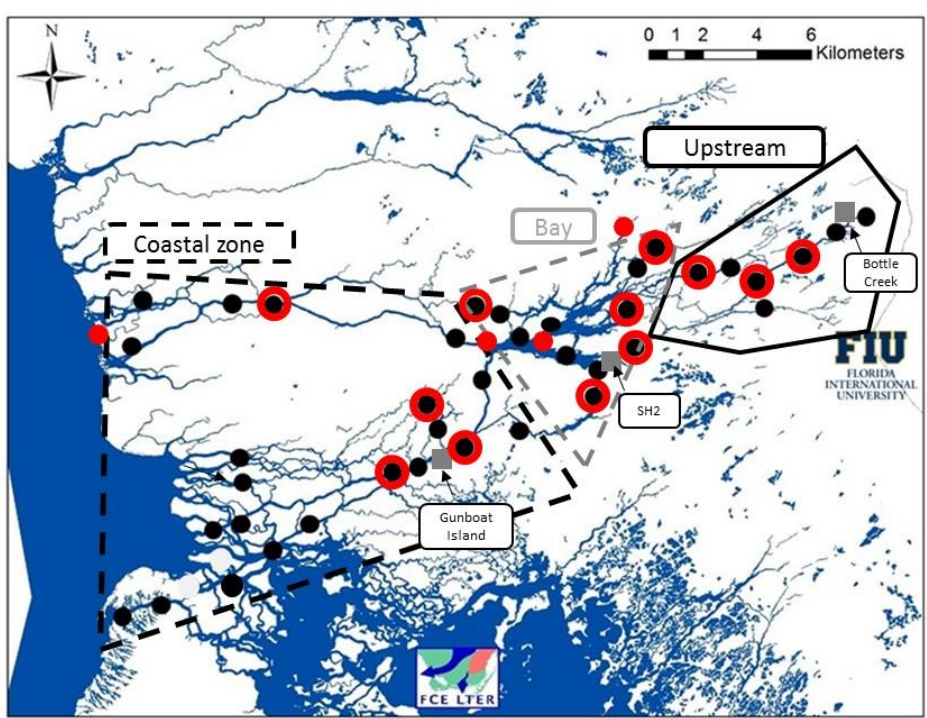


Figure 4.4 Average paired difference in $\mathrm{T}_{\text {ave }}$ (open circles) and $\mathrm{T}_{\min }$ (black circles) during the 22 cold events that occurred from 2003-2012. The error bars represent $95 \%$ confidence intervals.

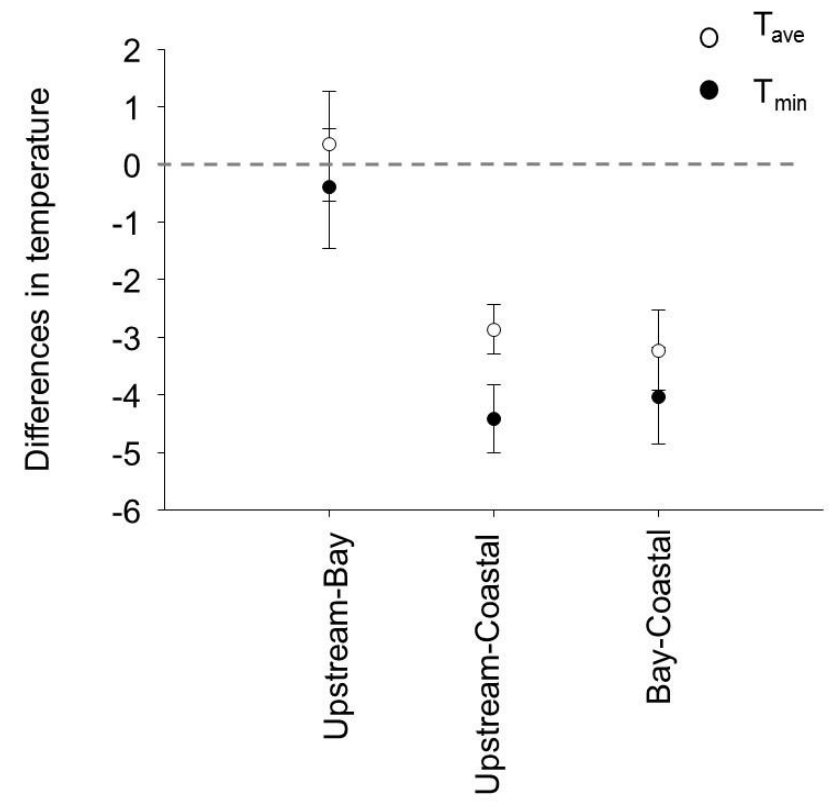


Figure 4.5 Left: Average daily temperatures across the three USGS stations during the January 2008 (A), the January 2010 (B), and the December 2010 (C) event, grey shaded areas mark the lethal limit for snook. Center: Spatial variation in $\mathrm{T}_{\text {ave }}$ across the January 2008 (D), January 2010 (E), and December 2010 (F) events, each bubble represents a temperature logger active during the event, the size and color of the bubble represents the difference in $\mathrm{T}_{\mathrm{ave}}$ at that station relative to the mean $\mathrm{T}_{\text {ave }}$ across all stations active during the event. For visual aid, those bubbles that recorded $\mathrm{T}_{\mathrm{ave}}$, similar to the mean are outlined in red. Bubbles with the dashed border are the USGS hydrostations used in for the long term analysis. Polygons correspond to the zones used in analyses. Mean $T_{\text {ave }}$ per zone for the January 2008 (G), January 2010 ( H), December 2010(I) disturbances. Error bars represent 95\% confidence intervals.

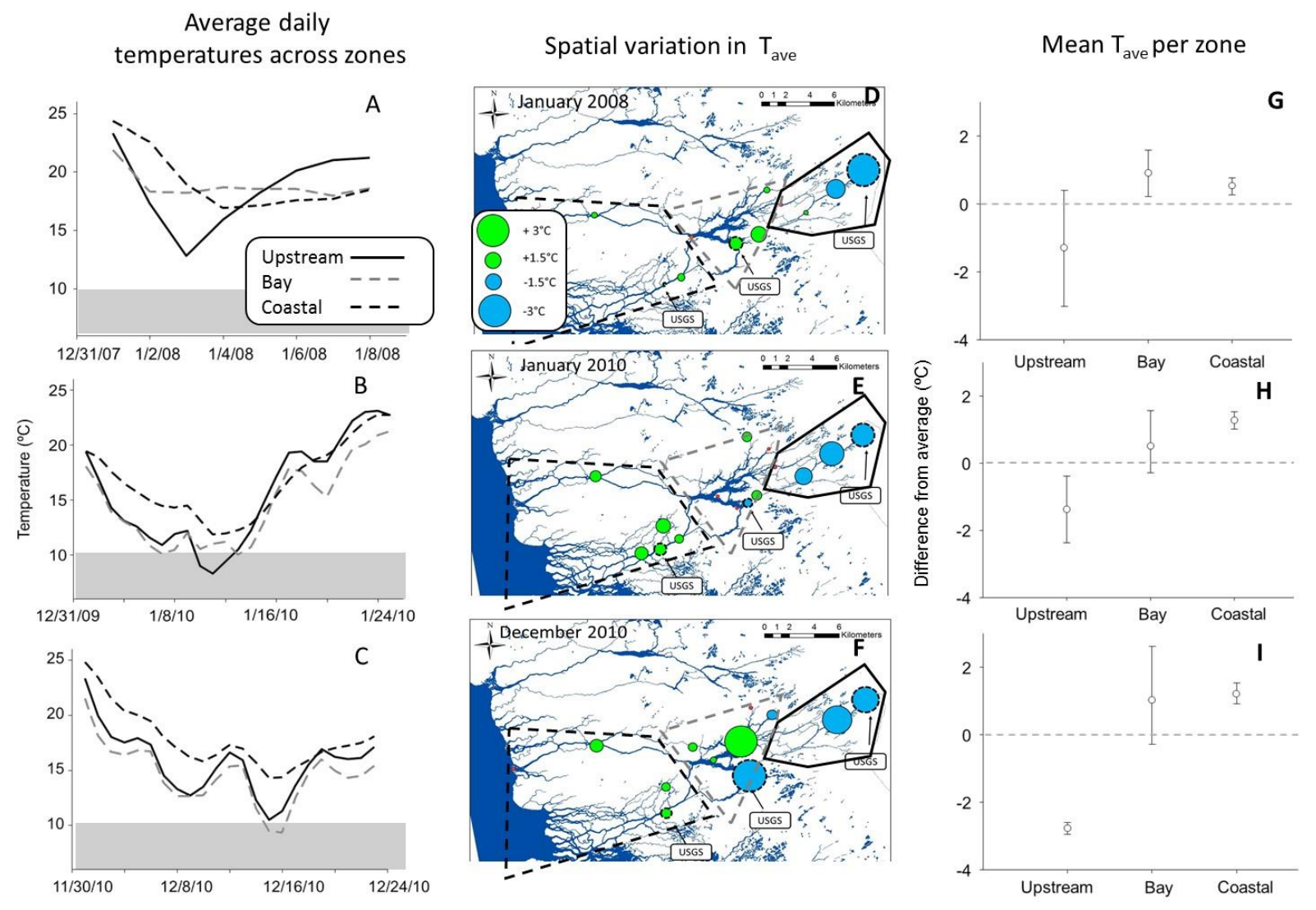


Figure 4.6 Frequency distribution of the calendar day of the year that each of the 319 cold events occurring in Everglades National Park. The Black dashed lines represent +-1 standard deviation around the mean (January $20^{\text {th }}$ ). The blue lines indicate when each of the three extreme events occurred over the last 90 years. The height of the lines represents their relative severity from Boucek and Rehage (2014).

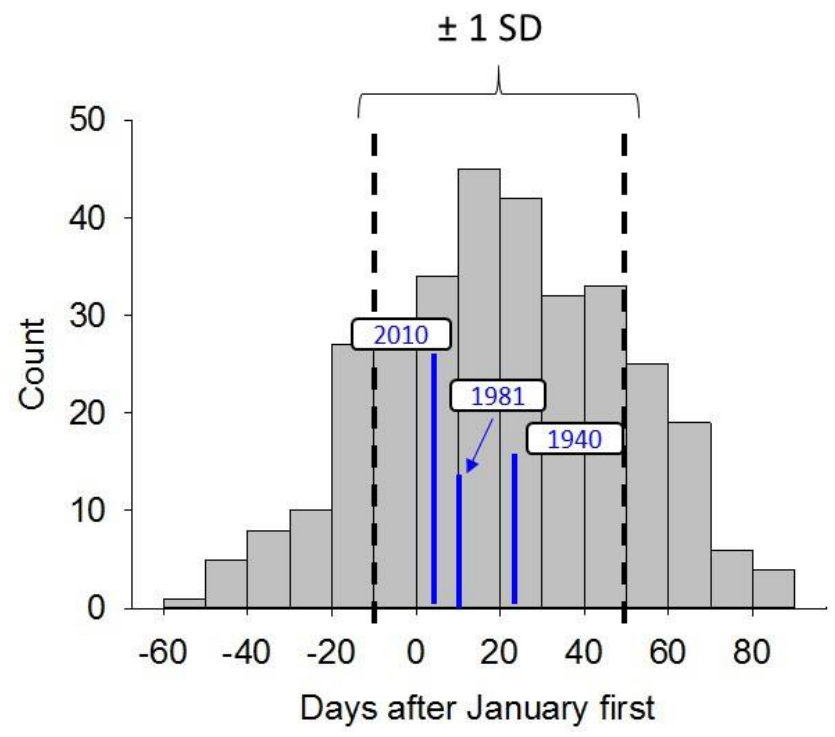


Figure 4.7 The daily standardized proportion of snook occurring within the upstream zone (upper panel), bay zone (mid panel) and the coastal zone (lower panel). Error bars represent $+-1 \mathrm{SE}$ from the mean. The grey dashed line represents the average proportion of snook occurring within each zone for the entire time series. The grey shading indicates the windows in time when cold spells are most frequently occurring (Dec 23-Feb 17).

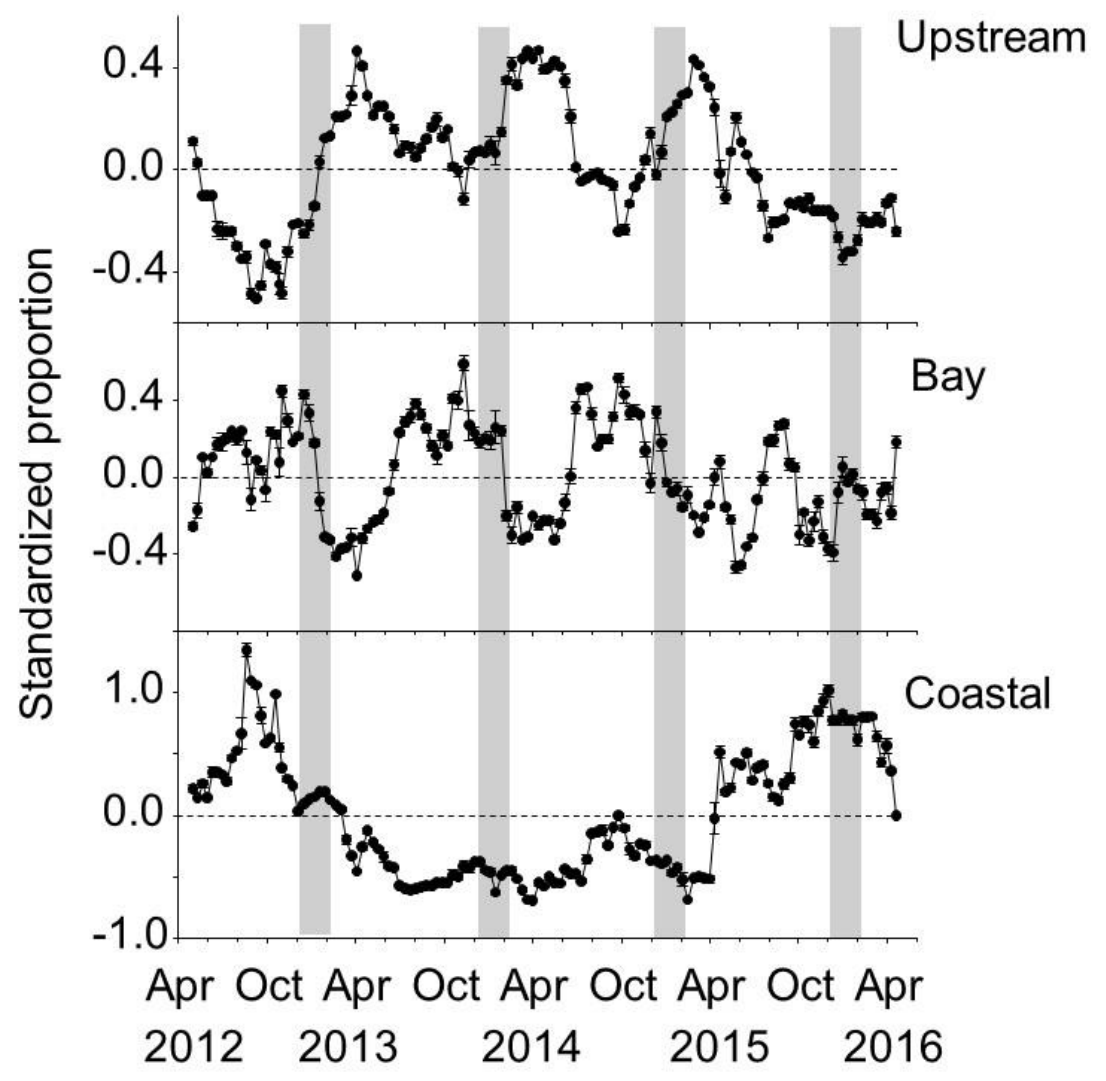


Figure 4.8 The average proportion of snook occurring within the a) upstream zone), bay zone (b) and the coastal zone (c) during the Dec $23^{\text {rd }}-$ Feb $17^{\text {th }}$ window in time when cold spells are most frequent. The error bars represent 95\% confidence intervals.

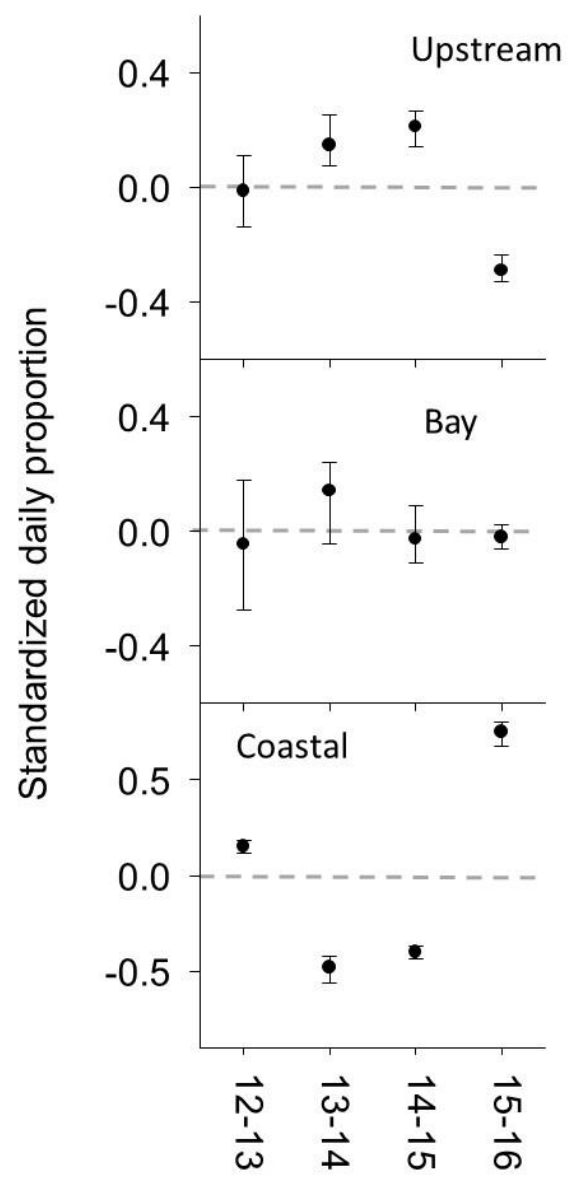




\section{CONCLUSIONS AND DISCUSSION}

Forecasts of global climate predict changes in the climate disturbance regime that ecosystems are currently experiencing. In many instances, this change in the climate disturbance regime is associated with increases in frequency and intensity of events, as well as potential shifts in the timing in which these events occur. In contexts where climate disturbance increases in frequent, disturbance may become a more apparent driver of community dynamics, potentially overwhelming and replacing other current drivers that shape communities (Smith 2011). Even in ecosystems where climate disturbance becomes less frequent or less intense, the absence of these disturbances can still have pronounced effects on ecosystem structure. Cold spells for instance, often control the poleward distribution of species (Kreyling et al. 2015). If these events decrease in frequency or intensity, then we may expect that the distribution of species will likely rapidly shift in accordance with that change (Cavanaugh et al. 2014). Given the gravity of changes to future disturbance regimes, we must develop a more mechanistic understanding of the role that climate disturbance plays on influencing communities. With this information, we will improve our predictive capacity of community structure and function under future scenarios of climate variability.

In chapter I, I provide evidence that community change from a once-in-80-year cold spell is predictable based off component species lower lethal limits to temperature. In contrast, community change following a once-in-10-year drought was not well explained by the thermal and osmotic trait structure of the community. We speculate the 
differences in predictability between these two climate disturbances may be due to differences in the durations of the event. For instance, the cold spell, though extreme, only lasted for 12 days. In contrast, the drought persisted for nearly 100 days. During the 100 days of drought, species less resistant to those stressors from the disturbance (i.e., increases salinity) were forced to into small refugia, with likely limited food, high conspecific densities, and gradually decreasing water quality, creating extra dimensions of stress that was not accounted for in our two-trait analysis. Thus, as we develop predictions and generalities for community change from climate disturbance, we should consider not only the classification of the climate disturbance (cold spell, drought etc.) but also the functional traits of disturbance, such as the amplitude, duration, and timing of the event.

Chapter II builds off of my cold spell findings in Chapter I, providing a review of community effects of cold spells that affect the sub-tropics. In particular, I contrast community change from extreme cold spells that affected sub-tropical China in 2008, and sub-tropical U.S. in 2010. In this review, I identify three consistencies across the two extreme events, and other extreme events that have affected other regions in the subtropics. The first consistency is that extreme cold events alter the ratios of co-existing tropical and temperate species, namely by causing mortalities to those species of tropical origin. The second consistency is that the effect of these climate disturbances vary in space, and that some landscape features can consistently promote community resistance to extreme cold spells. The last consistency I found is that tropical non-natives are less resistant to extreme cold spells than tropical natives. 
With these consistencies in mind, I propose general predictions about sub-tropical communities in scenarios where extreme cold spells increase in frequency and decrease in frequency. For instance, if extreme cold spells decrease in frequency, we may expect community dominance to shift towards more tropical species, spatial differences in community structure to decrease, and increased presence and abundance of non-native tropical species. In contrast, if these climate disturbances increase in frequency, we may expect increases temperate species community dominance, increases in the spatial structuring of communities, and a decreased presence of non-native species.

In chapter III, I show that droughts can temporarily alter the trophic dynamics of an estuarine fish population. In particular, I show that droughts reduce the overall magnitude of a seasonal freshwater prey subsidy. Droughts also affect species composition of prey from fish that are relatively high in calories, to invertebrates that are approximately half the calories per gram. This study shows that not only can climate disturbance such as drought affect community structuring, but that these changes can then have consequences on trophic interactions, and the potential performance of species not directly affected by disturbance (i.e., estuarine piscivore).

Last in chapter IV, I demonstrate the potential value of incorporating spatial ecology into understanding population resistance to extreme climate events. As these disturbances become a more prominent driver of ecological change, research needs to emphasize spatial processes and adapt more spatial approaches to predicting and managing for resistance. 
In conclusion, climate disturbance can function as an important driver of community dynamics. And, as climate disturbance regimes change in the future, their role in influencing communities will change with it. Changes to communities from climate disturbance can have important consequences for services provided by natural systems, such as the provisioning of fish and wildlife (Stevens et al. 2016), agriculture (Downton \& Miller 1993), coastal storm protection (Zhang et al. 2016), and many others. These studies improve our mechanistic understandings of how two types of climate disturbances can affect sub-tropical communities, and provides a framework of research to build on, especially related to those indirect consequences of these community changes, such as changes to predator prey interactions that could be studied in the future. 


\section{LIST OF REFERENCES}

Adams, A., Wolfe, R.K., Barkowski, N. and Overcash, D., (2009) Fidelity to spawning grounds by a catadromous fish, Centropomus undecimalis. Marine Ecology Progress Series, 389: 213-222.

Adams, A.J., Hill, J.E., Kurth, B.N., Barbour, A.B. (2012) Effects of a severe cold event on the subtropical, estuarine dependent common snook, Centropomus undecimalis. Gulf and Caribbean Research, 24: 13-21.

Adams, S.M., McLean, R.B., \& Parrotta, J.A. (1982) Energy partitioning in Largemouth Bass under conditions of seasonally fluctuating prey availability. Transactions of the American Fisheries Society, 111(5): 549-558.

Adger, W. N., Hughes, T. P., Folke, C., Carpenter, S. R., \& Rockström, J. (2005) Social-ecological resilience to coastal disasters. Science, 309(5737): 10361039.

Allen, D.C., \& Wesner, J.S. (2016). Synthesis: comparing effects of resource and consumer fluxes into recipient food webs. Ecology, 97(3): 594-604.

Anderson, M.J., Ellingsen, K.E., \& McArdle, B.H. (2006) Multivariate dispersion as a measure of beta diversity. Ecology Letters, 9: 683-693

Andrade, H., Santos, J., \& Taylor, R. (2013) Life-history traits of the Common Snook Centropomus undecimalis in a Caribbean estuary and large-scale biogeographic patterns relevant to management. Journal of Fish Biology, 82(6): 1951-1974.

Bahn, M., Reichstein, M., Dukes, J.S., Smith, M.D., \& McDowell, N.G. (2014) Climate-biosphere interactions in a more extreme world. New Phytoligist, 202(2): 356-359.

Barbour, A. B., Adams, A. J., \& Lorenzen, K. (2014) Emigration-corrected seasonal survival of a size-structured fish population in a nursery habitat. Marine Ecology Progress Series, 514: 191-205.

Barr, J.G., Engel, V., Fuentes, J.D., Fuller, D.O., \& Kwon H (2013) Modeling light use efficiency in a subtropical mangrove forest equipped with $\mathrm{CO}_{2}$ eddy covariance. Biogeosciences, 10, 2145-2158.

Baskerville, G.L., \& Emin, P. (1969) Rapid estimation of heat accumulation from maximum and minimum temperatures Ecology, 50: 514-517

Basset, A., et al., (2013) A unifying approach to understanding transitional waters: Fundamental properties emerging from ecotone ecosystems Estuarine and Coastal Shelf Science, 132: 5-16 
Beck, P.S., \& Goetz, S.J. (2011) Satellite observations of high northern latitude vegetation productivity changes between 1982 and 2008: ecological variability and regional differences. Environmental Research Letters, 6(4): 045501 .

Beckage, B., Platt, W. J., Slocum, M. G., \& Panko, B. (2003) Influence of the El Nino Southern Oscillation on fire regimes in the Florida Everglades. Ecology, 84(12): 3124-3130.

Bender, M.A., Knutson, T.R., Tuleya, R.E. et al., (2010) Modeled impact of anthropogenic warming on the frequency and of intense Atlantic hurricanes. Science, 327: 454-458.

Berry, L. et al., (2011) Florida water management and adaptation in the face of climate change, Florida Climate change task force http://Floridaclimate.org/whitepapers

Blewett, D.A., Hensley, R.A., \& Stevens, P.W. (2006) Feeding habits of common snook, Centropomus undecimalis, in Charlotte Harbor, Florida. Gulf and Caribbean Research, 18(1): 1-14.

Blewett, D.A., \& Stevens, P.W. (2013) The effects of environmental disturbance on the abundance of two recreationally-important fishes in a subtropical floodplain river. Florida Scientist, 76: 191-197

Blewett, D.A., Stevens, P.A., \& Call, M.E. (2013) Comparative ecology of euryhaline and freshwater predators in a subtropical floodplain river. Florida Scientist 76(2): 166-190.

Blewett, D.A., \& Stevens, P.W. (2014) Temperature variability in a subtropical estuary implications for Common Snook Centropomus undecimalis, a coldsensitive fish. Gulf of Mexico Science, 32:44-54.

Bertani, I., Primicerio, R., \& Giampaolo, R. (2016) Extreme climate events trigger regime shifts in lakes that propagate across multiple trophic levels. Ecosystems 19:16-31.

Boeuf, G., \& Payan, P. (2001) How should salinity influence fish growth? Comparative Biochemistry and Physiology Part C: Toxicology \& Pharmacology 130: 411-423

Bond, N.R., Balcombe, S.R., Crook, D.A., Marshall, J.C., Menke, N., \& Lobegeiger, J.S. (2015) Fish population persistence in hydrologically variable landscapes. Ecological. Applications 25(4): 901-913. 
Bonnington, C., Gaston, K.J., Evans, K.L. (2013) Fearing the feline: domestic cats reduce avian fecundity through trait-mediated indirect effects that increase nest predation by other species. Journal of Applied Ecology, 50: 1524.

Boucek, R,E., \& Rehage, J.S. (2013) No free lunch: Displaced marsh consumers regulate a prey subsidy to an estuarine consumer. Oikos, 122: 1453-1464.

Boucek, R. E., \& Rehage, J.S. 2014. Climate extremes drive changes in functional community structure. Global Change Biology, 20(6): 1821-1831.

Boucek, R.E., \& Rehage, J.S. (2015) A tale of two fishes: using recreational angler records to examine the link between fish catches and floodplain connections in a subtropical mangrove estuary. Estuaries and Coasts, 128:124135

Boucek, R.E., Gaiser, E.E., Liu, H. and Rehage, J.S. (2016a) A review of subtropical community resistance and resilience to extreme cold spells. Ecosphere, 7(10).

Boucek, R.E., Soula, M., Tamayo, F. and Rehage, J.S., (2016b) A once in 10 year drought alters the magnitude and quality of a floodplain prey subsidy to coastal river fishes. Canadian Journal of Fisheries and Aquatic Sciences,73(11): 1672-1678.

Britten, G. L., Dowd, M., Minto, C., Ferretti, F., Boero, F., \& Lotze, H.K. 2014. Predator decline leads to decreased stability in a coastal fish community. Ecology letters, 17(12): 1518-1525.

Brokaw, N. ed., (2012) A Caribbean forest tapestry: the multidimensional nature of disturbance and response. Oxford University Press.

Burkhardt, R.W., \& Gutreuter, S. (1995) Improving electrofishing catch consistency by standardizing power North American Journal of Fisheries Management, 15: 375-381

Castillo, D.M., et al., (2013) Specialist pollinating seed predator exhibits oviposition strategy consistent with optimal oviposition theory. Ecological Entromology, 38: 164-172.

Cavanaugh, K. C., Kellner, J.R., Forde, A.J., Gruner, D.S., Parker, J.D., Rodriguez, W., \& Feller, I.C (2014) Poleward expansion of mangroves is a threshold response to decreased frequency of extreme cold events. Proceedings of the National Academy of Sciences, 111(2): 723-727. 
Chen, Y. G., \& Nong, M.S. (2008) Causality Analysis on a severe chilling icy rain and snow freezing disaster weather event in early 2008 in Guangxi [J]. Journal of Meteorological Research and Application, 2: 004.

Chen, T., Yu, K., Shi, Q., Li, S., Price, G.J., Wang, R. \& Zhao. J. (2008) Twentyfive years of change in scleractinian coral communities of Daya Bay (northern South China Sea) and its response to the 2008 AD extreme cold climate event. Chinese Science Bulletin, 54(12): 2107-2117.

Chen, L., WenQing, W., YiHui, Z., Li, H., ChunLei, Z., ShengChang, Y., \& Chang, J. 2010. Damage to mangroves from extreme cold in early 2008 in southern China. Journal of Plant Ecology (Chinese Version), 34(2): 186-194.

Chezik, K.A., Nigel, P.L., \& Wenturelli, P.A. (2014) Fish growth and degree-days I: selecting a base temperature for a within-population study Canadian Journal of Fish and Aquatic Sciences, 71: 47 -55.

Childers, D. L. (2006) A synthesis of long-term research by the Florida Coastal Everglades LTER Program. Hydrobiologia 569(1): 531-544.

Childers, D.L., Boyer, J.N., Davis, S.E., Madden, C.J., Rudnick, D.T., \& Sklar, F.H. (2006) Relating precipitation and water management to nutrient concentrations in the oligotrophic "upside-down" estuaries of the Florida Everglades. Limnology and Oceanography. 51(1 Pt 2): 602-616.

Coles, S.L., \& Fadlallah, Y.H. (1991) Reef coral survival and mortality at low temperatures in the Arabian Gulf: new species-specific lower temperature limits. Coral Reefs, 9:231-237.

Colella, M.A., Ruzicka, R.R., Kidney, J.A., Morrison, J.M., Brinkhuis V.B. (2012) Coldwater event of January 2010 results in catastrophic benthic mortality on patch reefs in the Florida Keys. Coral Reefs, 31: 621-631.

Collins, M.R. (1985) Species profiles: life histories and environmental requirements of coastal fishes and invertebrates (South Florida) striped mullet . U.S. Fish Wild life Service Biological Report 82(11.34). U.S. Army Corps of Engineers, TR EL-82-4. 11 pp.

Collins, S.L., Carpenter, S.R., Swinton, S.M., Orenstein, D.E., Childers, D.L., Gragson, T.L., Grimm, N.B., Grove, J.M., Harlan, S.L., Kaye, J.P., Knapp, A.K., Kofinas, G.P., Magnuson, J.J., McDowell, W.H., Melack, J.M., Ogden, L.A., Robertson, G.P., Smith, M.D., \& Whitmer, A.C. (2011) An integrated conceptual framework for long-term social-ecological research. Frontiers in Ecology an Environment 9(6): 351-357. 
Cook-Patton, S. C., Lehmann, M., \& Parker, J.D. (2015) Convergence of three mangrove species towards freeze-tolerant phenotypes at an expanding range edge. Functional Ecology, 29: 1332-1340.

Dale, V.H., Joyce, L.A., McNulty, S., Neilson, R.P., Ayres, M.P., Flannigan, M.D., Hanson, P.J., Irland, L.C., Lugo, A.E., Peterson, C.J. and Simberloff, D. (2001) Climate change and forest disturbances: climate change can affect forests by altering the frequency, intensity, duration, and timing of fire, drought, introduced species, insect and pathogen outbreaks, hurricanes, windstorms, ice storms, or landslides. BioScience, 51(9): 723-734.

Davis, M.A., Grime, J.P., \& Thompson, K. (2001) Fluctuating resources in plant communities: a general theory of invisibility Journal of Ecology, 88: 528-534.

Deutsch, C. A., Tewksbury, J.J., Huey, R.B., Sheldon, K.S., Ghalambor, C.K., Haak, D.C., \& Martin, P.R. (2008) Impacts of climate warming on terrestrial ectotherms across latitude. Proceedings of the National Academy of Sciences, 105(18): 6668-6672.

Diez, J.M., et al., (2012) Will extreme climatic events facilitate biological invasions? Frontiers in Ecology and Environment, 10: 249-257.

Dorn, N.J., \& Trexler, J.C. (2007) Crayfish assemblage shifts in a large droughtprone wetland: the roles of hydrology and competition. Freshwater Biology, 52(12): 2399-2411.

Dorn, N.J., \& Cook, M.I. (2015) Hydrological disturbance diminishes predator control in wetlands. Ecology, 96(11): 2984-2993.

Downing J.L., Borrero, H., \& Liu, H. (2016) Differential impacts from an extreme cold spell on subtropical vs. tropical specialist bees in southern Florida. 7(5).

Downton, M. W., \& Miller, K. A. (1993) The freeze risk to Florida citrus. Part II: Temperature variability and circulation patterns. Journal of Climate 6: 364372.

Easterling D.R., Meehl, G.A., Parmesan, C., Changnon, S.A., Karl, T.R., \& Mearns, L.O. (2000). Climate extremes: observations, modeling, and impacts. Science, 289: 2068-2074.

Elliott, M., Whitfield, K., Potter, I.C., Blaber, S.J.M., Cyrus DP, Nordlie FG, Harrison TD (2007) The guild approach to categorizing estuarine assemblages: a global review. Fish and Fisheries, 8: 241-268.

Elliot, M., Whitfield, A.K. (2011) Challenging paradigms in estuarine ecology and management Estuarine, Coastal and Shelf Science, 94: 306-314. 
Facey, D.E., Van Den Avyle, M.J. (1987) Species profiles: Life histories and environmental requirements of coastal fishes and invertebrates. U.S. fish and wildlife Service Biological Report 82(11.74). U.S. Army Corps of Engineers, TR EL-82-4. 28 pp

Fantz, A. (2010) Pythons and citrus and iguanas, oh my! Frigid Florida copes. CNN US [Internet]. http://www.cnn.com/2010/US/weather/01/10/us.cold. weather/index.html. Accessed 12 Feb 2010

Field C. B., ed. 2012. Managing the risks of extreme events and disasters to advance climate change adaptation: special report of the intergovernmental panel on climate change. Cambridge University Press,

Frederick, P., Gawlik, D.E., Ogden, J.C., Cook, M.I., \& Lusk, M. (2009) The White Ibis and Wood Stork as indicators for restoration of the Everglades ecosystem. Ecological. Indicators. 9(6): S83-S95.

Gallucci, F. \& Netto, S. (2004). Effects of the passage of cold fronts over a coastal site: an ecosystem approach. Marine Ecology Progress Series. 281: 79-92

Gaiser, E.E., Trexler, J.C., \& Wetzel, P.R. (2012) The Florida Everglades. Wetland habitats of North America: ecology and conservation concerns. University of California Press, Berkeley, Calif. pp. 231-252.

Gao, Y., Leung, L. R., Lu, J., \& Masato, G. (2015) Persistent cold air outbreaks over North America in a warming climate. Environmental Research Letters, 10(4): 044001.

Garrabou, J., Coma, R., Bensoussan, N., Bally, M., Chevaldonné, P., Cigliano, M., Díaz, D., Harmelin, J.G., Gambi, M.C., Kersting, D.K. and Ledoux, J.B. (2009) Mass mortality in Northwestern Mediterranean rocky benthic communities: effects of the 2003 heat wave. Global change biology,15(5), pp.1090-1103.

Gilman, E. L., Ellison, J., Duke, N.C., Field, C. (2008) Threats to mangroves from climate change and adaptation options: a review. Aquatic Botany 89(2): 237250 .

Gherardi, L.A., \& Sala, O.E. (2015) Enhanced interannual precipitation variability increases plant functional diversity that in turn ameliorates negative impact on productivity. Ecology. Letters. 18(12): 1293-1300.

Gilmore, R.G., Bullock, L.H., Berry, F.H. (1978) Hypothermal mortality in marine fishes of South-Central Florida January 1977. Northeast Gulf Science. 2:77-97 
Glover, D.C., DeVries, D.R., Wright, R.A., and Davis, D.A. (2010) Sample preparation techniques for determination of fish energy density via bomb calorimetry: an evaluation using Largemouth Bass. Transactions of the American. Fisheries. Society. 139: 671-675.

Greenwood, M.J., \& McIntosh, A.R. (2008) Flooding impacts on responses of a riparian consumer to cross-ecosystem subsidies. Ecology, 89(6): 1489-1496.

Greenwood, M.J., \& McIntosh, A.R. (2010) Low river flow alters the biomass and population structure of a riparian predatory invertebrate. Freshwater. Biology. 55: 2062-2076.

Gutschick, V.P., \& BassiriRad, H. (2003) Extreme events as shaping physiology, ecology, and evolution of plants: toward a unified definition and evaluation of their consequences. New Phytologist, 160: 21-42.

Haddad, N.M., Tilman, D., Knops, J.M.H. (2002) Long-term oscillations in grassland productivity induced by drought. Ecology Letters, 5: 110-120.

Hanson, R.C., Duff, D., Brehe, J., Fleming, W.R. (1976) The effect of various salinities, hypophysectomy, and hormone treatments on the survival and sodium and potassium content of juvenile bowfin, Amia calva. Physiological Zoology 49: 376-385.

Hong, C. \& Li, T. (2009) The Extreme Cold Anomaly over Southeast Asia in February 2008: Roles of ISO and ENSO. Journal of Climate: 22: 3786-3801

Hsieh, H. J., Hsien, Y. L., Jeng, M.S., Tsai, W.S., Su, W.C., \& Chen, C. A. (2008) Tropical fishes killed by the cold. Coral reefs, 27(3): 599-599.

Hussey, N.E., Kessel, S.T., Aarestrup, K., Cooke, S.J., Cowley, P.D., Fisk, A.T., Harcourt, R.G., Holland, K.N., Iverson, S.J., Kocik, J.F. and Flemming, J.E.M. (2015) Aquatic animal telemetry: a panoramic window into the underwater world. Science: 348(6240) 1255642.

Jardine, T.D., Pusey, B.J., Hamilton, S.K., Pettit, N.E., Davies, P.M., Douglas, M.M., Sinnamon, V., Halliday, I.A., and Bunn, S.E. (2012) Fish mediate high food web connectivity in the lower reaches of a tropical floodplain river. Oecologia, 168(3): 829-838.

Jardine, T.D., Bond, N.R., Burford, M.A., Kennard, M.J., Ward, D.P., Bayliss, P., Davies, P.M., Douglas, M.M., Hamilton, S.K., Melack, J.M., Naiman, R.J., Pettit, N.E., Pusey, B.J., Warfe, D.M., and Bunn, S.E. (2015) Does flood rhythm drive ecosystem responses in tropical riverscapes? Ecology, 96(3): 684-692. 
Jentsch. A., Kreyling, J., Beierkuhnlein. C. (2007) A new generation of climatechange experiments: events, not trends. Frontiers in Ecology and Environment 5: 365-374.

Jiménez, M.A., Jaksic, F.M., Armesto, J.J., Gaxiola, A., Meserya, P.L., Kelt, D.A., Gutiérrez, J.R. (2011) Extreme climatic events change the dynamics and invisibility of a semi-arid annual plant communities. Ecology Letters, 14: 1227-1235

Junk, W.J., Bayley, P.B., and Sparks, R.E. (1989) The flood pulse concept in river-floodplain systems. In Proceedings of the International Large River Symposium. Edited by D.P. Dodge. Can. Spec. Publ. J. Fish. Aquat. Sci. 106: $110-127$.

Junming, J. I., Benxiang, A.N.G., Nanqing, L. I., WeiShuang, A.N.G., Ying, Z., \& XiuMing, C. (2008) Impact of the snow disaster occurred in 2008 in South China to the clump bamboo in South Sichuan. Scientia Silvae Sinicae,44(11): $141-144$

Karl T.R., Meehl, G.A., Miller, C.D. et al. (eds.). (2008) Weather and Climate Extremes in a Changing Climate. NOAA National Climatic Data Center, Washington, DC.

Kawaguchi, Y., Taniguchi, Y., \& Nakano, S. (2003) Terrestrial invertebrate inputs determine the local abundance of stream fishes in a forested stream. Ecology, 84(3): 701-708.

Kearney, M., Shine, R., Porter, W.P. (2009) The potential for behavioral thermoregulation to buffer "cold blooded" animals against climate warming Proceedings of the National Academy of Sciences 106: 3835 -3840

Kemp, D.W., Oakley, C.A., Thornhill, D.J., Newcomb, L.A., Schmidt, G.W., Fitt, W.K. (2011) Catastrophic mortality on inshore coral reefs of the Florida Keys due to severe low-temperature stress. Global Change Biology, 17: 3468-3477.

Kemp, D. W., Colella, M. A., Bartlett, L. A., Ruzicka, R. R., Porter, J. W., \& Fitt, W. K. (2016) Life after cold death: reef coral and coral reef responses to the 2010 cold water anomaly in the Florida Keys. Ecosphere, 7:e01373.

Kline, J.L., Loftus, W.F., Kotun, K., Trexler, J.C., Rehage, J.S., Lorenze, J.J., Robinson, M (2014) Recent fish introductions into Everglades National Park: An unforeseen consequence of water management? Wetlands, 34:174-187

Koch, J.D. et al. (2009) Population dynamics and potential management of bowfin (Amia calva) in the upper Mississippi River. Journal of Applied Ichthyology 25: 545-550. 
Kodra, E., Steinhaesuer, K., Ganguly, A.P. (2011) Persisting cold extremes under 21 st century warming scenarios. Geophysical research letters, 38: DOI, 10.1029/2011GL047103

Koehn, J.D., Hobday, A.J., Pratchett, M.S., Gillanders, B.M. (2011) Climate change and Australian marine and freshwater environments, fishes and fisheries: synthesis and options for adaptation Marine and Freshwater Research, 62: 1148-1164.

Kreyling, J., Beierkuhnlein, C., Ellis, L., Jentsch, A. (2008) Invasibility of grassland and heath communities exposed to extreme weather events additive effects of diversity resistance and fluctuating physical environment, Oikos, 117: 1542-1554

Kreyling, J., Jentsch, A., Beierkuhnlein, C. (2011) Stochastic trajectories of succession initiated by extreme climatic events. Ecology Letters, 1414(8): $758-764$.

Kreyling, J., Schmid, S., \& Aas, G. (2015) Cold tolerance of tree species is related to the climate of their native ranges. Journal of Biogeography 42:156166.

Kushlan, J.A. (1979) Feeding ecology and prey selection in the White Ibis. Condor, 81: $376-389$.

Jardine, T.D., et al., (2012) Fish mediate high foodweb connectivity in the lower reaches of a tropical floodplain river. Oecologia, 168: 829-838.

Lake, P.S. (2003) Ecological effects of perturbation by drought in flowing waters. Freshwater. Biology. 48(7): 1161-1172.

Liu, H., Feng, C. L., Chen, B. S., Wang, Z. S., Xie, X. Q., Deng, Z. H., \& Luo, Y. B. (2012) Overcoming extreme weather challenges: successful but variable assisted colonization of wild orchids in southwestern China. Biological Conservation, 150:68-75.

Liu, H., Feng, C. L., Xie, X. Q., Lin, W., Deng, Z. H., Wei, X. L., \& Luo, Y. B. (2014a) Impacts of Extreme Weather Spells on Flowering Phenology of Wild Orchids in Guangxi, Southwestern China. Darwin's Orchids: Then and Now.

Liu, K., Liu, L., Liu, H., Li, X., \& Wang, S. (2014b) Exploring the effects of biophysical parameters on the spatial pattern of rare cold damage to mangrove forests. Remote Sensing of Environment, 150:20-33.

Liu, Y., Wang, M., Wang, W., Fu, H., Lu, C. (2016) Chilling damage to mangrove mollusk species by the 2008 cold event in southern China. Ecosphere, 7:e01312. 
Lodge, T.E. (2005) Everglades handbook: understanding the ecosystem. $2^{\text {nd }}$ ed. CRC Press, Boca Raton, U.S.

Lowerre-Barbieri, S., Villegas-Ríos, D., Walters, S., Bickford, J., Cooper, W., Muller, R. and Trotter, A. (2014) Spawning site selection and contingent behavior in Common Snook, Centropomus undecimalis. PloS one, 9(7), p.e101809.

Lytle, D.A. and Poff, N.L. (2004) Adaptation to natural flow regimes. Trends in ecology \& evolution, 19(2), pp.94-100.

Magoulick, D.D., \& Kobza (2003) The role of refugia for fishes during drought: a review and synthesis. Freshwater Biology. 48(7): 1186-1198.

Matich, P., Heithaus, M.R. (2012) Effects of an extreme temperature event on the behavior and age structure of an estuarine top predator, Carcharhinus leucas. Marine Ecology Progress Series, 447: 165-178.

Marcarelli, A.M., Baxter, C.V., Mineau, M.M., and Hall, R.O., Jr. (2011) Quantity and quality: unifying food web and ecosystem perspectives on the role of resource subsidies. Ecology, 92:1215-1225.

Marchand, F.L., Kockelbergh, F., van de Vijver, B., Beyens, L., Nijs, I. (2006) Are heat and cold resistance of arctic species affected by successive extreme temperature events? New Phytologist, 170: 291-300.

Mazzotti, F.J., Cherkiss, M.S., Hart, K.M., Snow, R.W., Rochford, M.R., Dorcas, M.E., Reed, R.N. (2011) Cold-induced mortality of invasive Burmese pythons in south Florida. Biological Invasions, 13: 143-151.

Mazzotti, F. J., Cherkiss, M. S., Parry, M., Beauchamp, J., Rochford, M., Smith, B., Hart, K., \& Brandt, L. (2016) Large reptiles and cold temperatures: Do extreme cold spells set distributional limits for tropical reptiles in Florida? Ecosphere, 7:e01439.

McGill, B.J., Enquist, B., Weiher, E., Westoby, M. (2006) Rebuilding ecology from functional traits. Trends in Ecology and Evolution, 21: 178-185.

McVoy, C.W., Said, W.P., OBeysekera, J., Van Arman, J., Dreschel, T. (2011) Landscapes and hydrology of the Predrainage Everglades. University Press of Fl. Gainesville Florida U.S.A.

Milbau, A., Scheerlincka, L., Reheulb, D., De Cauwerb, B., Nijs, I. (2005) Ecophysiological and morphological parameters related to survival in grass species exposed to an extreme climatic event. Journal of Plant Physiology, 125: $500-512$. 
Mineau, M.M., Baxter, C.V., Marcarelli, A.M., and Minshall, G.W. (2012) An invasive riparian tree reduces stream ecosystem efficiency via a recalcitrant organic matter subsidy. Ecology, 93(7): 1501-1508.

Mouillot, D., Graham, N.A.J., Villéger, S., Mason, N.W.H., Bellwood, D.R. (2013) A functional approach reveals community responses to disturbances. Trends in Ecology and Evolution, 28: 167-177

Mueller, R.C., Scudder, C.M., Porter, M.E., Trotter, R. III, Gehring, C.A., Whitham, T.G. (2005) Differential tree mortality in response to severe drought: evidence for long-term vegetation shifts. Journal of Ecology, 93: 1085-1093.

Muller, R.G., Taylor, R.G. (2006) The 2005 stock assessment update of common snook, Centropomus undecimalis, Fish and Wildlife Research Institute Tampa Florida

Na, L., Jiping, L., Zhanhai, Z., Hongxia, C., \& Mirong, S. (2012) Is extreme Arctic sea ice anomaly in 2007 a key contributor to severe January 2008 snowstorm in China? International Journal of Climatology, 32:2081-2087.

Nakano, S., Miyasaka, H., \& Kuhara, N. (1999) Terrestrial-aquatic linkages: riparian arthropod inputs alter trophic cascades in a stream food web. Ecology, 80(7): 2435-2441.

Nathan, R., Getz, W.M., Revilla, E., Holyoak, M., Kadmon, R., Saltz, D. and Smouse, P.E. (2008) A movement ecology paradigm for unifying organismal movement research. Proceedings of the National Academy of Sciences, 105(49):19052-19059.

Neilson, R. P. (1995) A model for predicting continental scale vegetation distribution and water balance. Ecological Applications, 5:362-385.

Nimmo, D.G., Mac Nally, R., Cunningham, S.C., Haslem, A. and Bennett, A.F. (2015) Vive la résistance: reviving resistance for 21st century conservation. Trends in ecology \& evolution, 30(9):516-523.

Obeysekera, J., Irizarry, M., Park, J., Barnes, J. and Dessalegne, T. (2011). Climate change and its implications for water resources management in south Florida. Stochastic Environmental Research and Risk Assessment,25(4), pp.495-516.

Osland, M. J., Enwright, N., Day, R. H., \& Doyle, T. (2013) Winter climate change and coastal wetland foundation species: salt marshes vs. mangrove forests in the southeastern United States. Global Change Biology, 19:14821494. 
Osland, M.J., Day, R.H., Hall, C.T., Brumfield, M.D., Dugas, J.L. and Jones, W.R. (2016) Mangrove expansion and contraction at a poleward range limit: climate extremes and land-ocean temperature gradients. Ecology, doi: $10.1002 /$ ecy. 1625

Page, L.M., \& Burr, B.M. (1991) A field guide to freshwater fishes of North America north of Mexico. Houghton Mifflin Company, Boston. $432 \mathrm{p}$

Parkos, J.J., Ruetz, C.R., and Trexler, J.C. (2011) Disturbance regime and limits on benefits of refuge use for fishes in a fluctuating hydroscape. Oikos, 120(10): $1519-1530$.

Peralta-Meixueiro, M.A., \& Vega-Cendejas, M.E. (2011) Spatial and temporal structure of fish assemblages in a hyperhaline coastal system: Ría Lagartos, Mexico. Neotropical Ichthyology, 9.3: 673-682.

Peters, D., Yao, J., Sala, O. E., \& Anderson, J. P. (2012) Directional climate change and potential reversal of desertification in arid and semiarid ecosystems. Global Change Biology, 18: 151-163.

Peterson, M.S. \& Meador, M.R. (1994) Effects of salinity on freshwater fishes in coastal plain drainages in the southeastern U.S. Reviews in Fish Biology and Fisheries, 2:95-121 737

Pinho, P. F., Marengo, J. A., \& Smith, M. S. (2015) Complex socio-ecological dynamics driven by extreme events in the Amazon. Regional Environmental Change, 15(4): 643-655.

Polis, G.A., Anderson, W.B., and Holt, R.D. (1997) Toward an integration of landscape and food web ecology: the dynamics of spatially subsidized food webs. Annual Reviews in Ecology and Systematics, 28: 289-316..

Pörtner, H.O. and Knust, R. (2007) Climate change affects marine fishes through the oxygen limitation of thermal tolerance. Science, 315(5808): 95-97.

Precht, W. F., \& Aronson, R. B. (2004) Climate flickers and range shifts of reef corals. Frontiers in Ecology and the Environment, 2:307-314.

Price, R.M., Swart, P.K. and Willoughby, H.E., 2008. Seasonal and spatial variation in the stable isotopic composition $(\delta 18 \mathrm{O}$ and $\delta \mathrm{D})$ of precipitation in south Florida. Journal of Hydrology, 358(3): 193-205.

Rehage, J.S., \& Loftus, W.T. (2007) Season fish community variation in headwater mangrove creeks in the Southwestern Everglades. An examination of their role as dry-down refuges. Bulletin of Marine Science, 80: 625 -646 
Rehage, J. S., Blanchard, J. R., Boucek, R. E., Lorenz, J. J., \& Robinson, M. (2016) Knocking back invasions: variable resistance and resilience to multiple cold spells in native vs. nonnative fishes. Ecosphere, 7:e01268.

Richardson, J.S., \& Sato, T. (2015) Resource subsidy flows across freshwaterterrestrial boundaries and influence on processes linking adjacent ecosystems. Ecohydrology, 8(3): 406-415.

Richardson, J.S., \& Wipfli, M.S. (2016) Getting quantitative about consequences of cross-ecosystem resource subsidies on recipient consumers. Canadian Journal of Fisheries and Aquatic Sciences 73. doi:10.1139/cjfas-2016-0242.

Robins, C.R. \& Ray, G.C. (1986) A field guide to Atlantic coast fishes of North America. Houghton Mifflin Company, Boston, U.S.A. $354 \mathrm{p}$

Robins, C.R., et al. (1991) Common and scientific names of fishes from the United States and Canada. American Fisheries Society Special Publication, 20:183

Rosenblatt, A.E. and Heithaus, M.R., (2011) Does variation in movement tactics and trophic interactions among American alligators create habitat linkages? Journal of Animal Ecology, 80(4): 786-798.

Ross, M. S., Ruiz, P. L., Sah, J. P., Hanan, E. J. (2009) Chilling damage in a changing climate in coastal landscapes of the subtropical zone: a case study from south Florida. Global Change Biology, 15:1817-1832.

Saha, A.K., Saha, S., Sadle, J., Jiang, J., Ross, M.S., Price, R.M., Sternberg, L.S. and Wendelberger, K.S., (2011) Sea level rise and South Florida coastal forests. Climatic Change, 107(1-2), 81-108.

Santos, R. O., Rehage, J. S., Boucek, R. E., Osborne, J. (2016) Shift in recreational fishing catches as a function of an extreme cold event. Ecosphere, 7:e01335.

Schofield, P.J., Loftus, W.F., Brown, M.E. (2007) Hypoxia tolerance of two centrarchid sunfishes and an introduced cichlid from karstic Everglades wetlands of southern Florida, U. S. A. Journal of Fish Biology, 71: 87-99.

Schofield, P.J., Loftus, W.F., Kobza, R.M., Cook, M.I., Slone, D.H. (2010) Tolerance of nonindigenous cichlid fishes (Cichlasoma urophthalmus, Hemichromis letourneuxi) to low temperature: laboratory and field experiments in south Florida. Biological Invasions, 128: 2441-2457

Schofield, P. J., \& Loftus, W. F. (2015) Non-native fishes in Florida freshwaters: a literature review and synthesis. Reviews in Fish Biology and Fisheries, 25:117-145. 
Secor, D.H. (2008) Influence of skipped spawning and misspecified reproductive schedules on biological reference points in sustainable fisheries. Transactions of the American Fisheries Society. 137(3): 782-789.

Shafland, P.L., \& Pestrak, J.M. (1982) Lower lethal temperatures for fourteen non-native fishes in Florida. Environmental Biology of Fishes, 7(2):149-156.

Shea, K., \& Chesson, P. (2002) Community ecology theory as a framework for biological invasions. Trends in Ecology and Evolution, 17: 170-176

Sheridan, S. C. (2003) North American weather-type frequency and teleconnection indices. International Journal of Climatology, 23:27-45.

Sklar FH, et al., (2005) The ecological-societal underpinnings of Everglades restoration Frontiers in Ecology and Environment, 3: 161-169.

Smale, D. A., \& Wernberg, T. (2013) Extreme climatic event drives range contraction of a habitat-forming species. Proceedings of the Royal Society, 280:20122829.

Smith, M.D. (2011) An ecological perspective on extreme climatic events: a synthetic definition and framework to guide future research. Journal of Ecology, 99: 656-663.

Sponseller R. A., Grimm N. B., Boulton A. J., \& Sabo, J. L. (2010) Responses of macroinvertebrate communities to long-term flow variability in a Sonoran Desert Stream. Global Change Biology, 16: 2891- 2900

Sousa, W. P. (1984) The role of disturbance in natural communities. Annual Review of Ecology and Systematics, 15: 353-391.

Stevens, P. W., Fox, S. L., \& Montague, C. L. (2006) The interplay between mangroves and saltmarshes at the transition between temperate and subtropical climate in Florida. Wetlands Ecology and Management, 14:435-444

Stevens, P.W., Blewett, D.A., Champeau, T.R., \& Stafford, C.J. (2010) Posthurricane recovery of riverine fauna reflected in the diet of an apex predator. Estuaries and Coasts, 33(1): 59-66.

Stevens, P. W., Blewett, D. A., Boucek, R. E., Rehage, J. S., Winner, B. L., Young, J. M., Whittington, J. A., \& Paperno, R. (2016) Resilience of a tropical sport fish population to a severe cold event varies across five estuaries in southern Florida. Ecosphere, 7:e01400.

Stone, R. (2008) Ecologists report huge storm losses in China's forests. Science, 319:1318-1319. 
Suding, K.N., Lavorel, S., Chaplin, F.S., et al., (2008) Scaling environmental change through the community-level: a trait-based response and- effect framework for plants. Global Change Biology, 14: 1125- 1140.

Sunday, J. M., Bates, A. E., Kearney, M. R., Colwell, R. K., Dulvy, N. K., Longino, J. T., \& Huey, R. B. (2014) Thermal-safety margins and the necessity of thermoregulatory behavior across latitude and elevation. Proceedings of the National Academy of Sciences, 111:5610-5615.

Susanto, G.N., \& Peterson, M.S. (1996) Survival, osmoregulation and oxygen consumption of YOY coastal largemouth bass, Micropterus salmoides (Lacepede) exposed to saline media. Hydrobiologia, 119-127. 744

Taylor, C.J.L. (1993) The zooplankton of the Fourth Estuary. Aquatic Ecology, 27: 87-99

Taylor, R.G., Grier, H.J., \& Whittington, J.A. (1998) Spawning rhythms of common snook in Florida. Journal of Fish Biology. 53(3): 502-520.

Tewksbury, J. J., R. B. Huey, and C. A. Deutsch. 2008. Putting the heat on tropical animals. Science, 320:1296-1297.

Trenberth, K.E., Dai, A., van der Schrier, G., Jones, P.D., Barichivich, J., Briffa, K.R., and Sheffield, J. (2014) Global warming and changes in drought. National Proceedings of Climate Change, 4(1): 17-22.

Trexler, J.C., Loftus, W.F., \& Perry, S. (2005) Disturbance frequency and community structure in a twenty-five year intervention study, Oecologia, 145, $140-152$.

Trotter, A.A., Blewett, D.A., Taylor, R.G., \& Stevens, P.W. (2012) Migrations of common snook from a tidal river with implications for skipped spawning. Transactions of the American Fisheries Society. 141(4): 1016-1025.

Thibault, K.M., \& Brown, J.H. (2008) Impact of an extreme climatic event on community assembly. Proceedings of the National Academy of Sciences, 105: 3410-3415.

Vavrus, S., Walsh, J. E., Chapman, W. L., \& Portis, D. (2006) The behavior of extreme cold air outbreaks under greenhouse warming. International Journal of Climatology, 26:1133-1147.

Verbitsky, O. (2012) Repeated measurements and pseudo-replication in captive studies. Marine Mammal Science, 28: 220-223 
Walsh, C.T., Reinfelds, I.V., Ives, M.C., Gray, C.A., West, R.J. and van der Meulen, D.E. (2013) Environmental influences on the spatial ecology and spawning behaviour of an estuarine-resident fish, Macquaria colonorum. Estuarine, Coastal and Shelf Science, 118: 60-71.

Wang, C. Liu, H, Lee S. (2010) The record-breaking cold temperatures during the winter of 2009/2010 in the Northern Hemisphere. Atmospheric Science Letters, 11: 161-168

Wang, X., Huang, S., Li, J., Zhou, G., \& Shi, L. (2016) Sprouting response of an evergreen broad-leaved forest to a 2008 winter storm in Nanling Mountains, southern China. Ecosphere, 7:e01395.

Wang, X., Liu, H., Gu, M., Boucek, R. E., Wu, Z., \& Zhou, G. (2016) Greater impacts from an extreme cold spell on tropical than temperate butterflies in southern China. Ecosphere, 7:e01315.

Wato, Y.A., Heitkönig, I.M., van Wieren, S.E., Wahungu, G., Prins, H.H. and van Langevelde, F., (2016) Prolonged drought results in starvation of African elephant (Loxodonta africana). Biological Conservation, 203:89-96.

Webb, C.T. Hoeting, J.A., Ames, G.M., Pyne, M.I., Poff, N.L. (2010) A structured and dynamic framework to advance traits-based theory and prediction in ecology. Ecology Letters, 13: 267-283.

Welcomme, R.L., and Halls, A.S. (2001) Some considerations of the effects of differences in flood patterns on fish populations. Ecohydrology and Hydrobiology, 1: $313-321$

Welcomme, R.L. \& Halls, A.S. (2003) Dependence of tropical river fisheries on flow. Proceedings of the Second International Symposium on the Management of Large Rivers for Fisheries: Volume 2 (eds. R.L.Welcomme \& T. Petr), pp 267-283. Food and Agriculture Organization of the United Nations \& Mekong River Commission. FAO Regional Office for Asia and the Pacific, Bangkok.

White, P. S., \& Jentsch, A. (2001) The search for generality in studies of disturbance and ecosystem dynamics. In Progress in botany (pp. 399-450). Springer Berlin Heidelberg.

White, R.S., McHugh, P.A. and McIntosh, A.R., 2016. Drought-survival is a threshold function of habitat size and population density in a fish metapopulation. Global change biology.

Whitfield, A.K., Elliot, M., Basset, A., Blaber, S.J.M., West, R.J. (2012) Paradigms in estuarine ecology- A review of the Remane diagram with a 
suggested revised model for estuaries Estuarine Coastal and Shelf Science, 97: $78-90 /$

Wilhite, D. A., \& Glantz, M. H. (1985). Understanding: the drought phenomenon: the role of definitions. Water International, 10(3): 111-120.

Winemiller, K.O., and Jepsen, D.B. (2004) Migratory neotropical fish subsidize food webs of oligotrophic blackwater rivers. Food webs at the landscape level. University of Chicago Press, Chicago, Illinois. 115-132.

Wootton, T.J., Emmerson, M. (2005) Measurement of interaction strength in nature. Annual Reviews of Ecology Evolution and Systematics, 36: 419-444.

Zhang, K., B. Thapa, M. Ross, and D. Gann. 2016. Remote sensing of seasonal changes and disturbances in mangrove forest: a case study from South Florida. Ecosphere, 7:e01366.

Zhou, B., Gu, L., Ding, Y., Shao, L., Wu, Z., Yang, X. \& Zeng, B. (2011). The great 2008 Chinese ice storm: its socioeconomic-ecological impact and sustainability lessons learned. Bulletin of the American Meteorological Society, 92(1): 47-60. 
VITA

\section{ROSS BOUCEK}

2009

2011

$2013-2016$

$2013-2016$
B.S., Fisheries Science

Virginia Tech

Blacksburg, Virginia

M.S., Environmental Sciences

Florida International University

Miami, Florida

Graduate student co-chair

Long Term Ecological Research Network

Graduate student co-chair

Long Term Ecological Research Education Committee

Student President

American Fisheries Society education sub-section

Ph.D., Biology

Florida International University

Miami, Florida

\section{PUBLICATIONS AND PRESENTATIONS}

Lead Editor: Boucek R. E., Gaiser E. E., Liu H., Rehage J. S. (2015) Impacts of extreme cold spells on dynamics of tropical species and implications on poleward expansion. Special issue published in the Journal Ecosphere

Boucek R. E., Gaiser E. E., Liu H., Rehage J. S. (In press) A review of sub-tropical community resistance and resiliency to extreme cold spells. Ecosphere. Submitted 8.27.2015

Wang X., Liu H., Gu M. B., Boucek R. E. (in press) Knocking back invasions: the effect of extreme cold events on nonnative Everglades fishes. Ecosphere. Submitted 7.23.2015

Rehage J. S., Blanchard J. A., Boucek R. E. (In press) Knocking back invasions: the effect of extreme cold events on nonnative Everglades fishes. Ecosphere. Submitted 7.2.2015

Boucek R. E., Rehage J. S. (2014) Climate extremes drive changes to functional community structure. Global Change Biology 20(6), 1821-1831 
Santos R. A., Boucek R. E., Rehage J. S. (In press) Shift in recreational fishing catches as a function of extreme cold event. Ecosphere. Submitted 7.22.2015

Boucek R. E. Rehage J. S. (2015) Effects of an episodic drought on a floodplain subsity in a mangrove river. Mangroves as Fish Habitat. Eds. Murchie K. \& Daneshager P.

Rehage J. S., Boucek R.E., Gandy D. Lee J. (2015) Mangrove habitat use by a displaced freshwater species in the coastal Everglades. Mangroves as Fish Habitat. Eds. Murchie K. \& Daneshager P.

Boucek R. E., Rehage J. S. (2015) A tale of two fishes: using recreational angler records to examine the link between fish catches and freshwater inflows in a subtropical mangrove estuary. Estuaries and Coasts 38, 124-135

Boucek R. E., Rehage J. S. (2014) Examining the effectiveness of consumer diet sampling as a non-native detection tool in a subtropical estuary. Transactions of the American Fisheries Society. 143, 489-494

Boucek R. E., Rehage J. S. (2013) No free lunch: displaced marsh consumers regulate prey subsidies to estuarine consumers. Oikos 122, 1453-1464

Rehage J. S., Boucek R. E., Cline E.A., Cook M.I., Gallagher M.B., Kobza M., Saha A.K. (2013) Turning passive detection systems into field experiments: an application using wetland fishes and enclosures to track fine-scale movement and habitat choice. Acta Ecologia 17, 53-61

Barbour A. B., Boucek R. E., Adams A. (2012) Effect of pulsed gastric lavage on apparent survival of a juvenile fish in a natural system. Journal of Marine Experimental Biology and Ecology 422-423: 107-113.

Layman C., Araujo M., Boucek R. E., Hammerschlag-Peyer C., Harrison E., Jud Z., Matich P., Rosenblatt A., Vaudo J., Yeager L., Post D., Bearhop S. (2012) Applying stable isotopes to examine food web structure: an overview of analytical tools. Biological Reviews: $87,545-562$

Boucek R. E., Adams A. (2011) Comparison of retention success for multiple tag types in common snook. North American Journal of Fisheries Management. 31: 693-699

Carlson A., Dunmall K., Boucek R. E., et al. (2015) How to navigate fisheries education and employment. Fisheries 40, 196-198 (contributor) 